

\section{INFORMATION TO USERS}

This reproduction was made from a copy of a manuscript sent to us for publication and microfilming. While the most advanced technology has been used to photograph and reproduce this manuscript, the quality of the reproduction is heavily dependent upon the quality of the material submitted. Pages in any manuscript may have indistinct print. In all cases the best available copy has been filmed.

The following explanation of techniques is provided to help clarify notations which may appear on this reproduction.

1. Manuscripts may not always be complete. When it is not possible to obtain missing pages. a note appears to indicate this.

2. When copyrighted materials are removed from the manuscript, a note appears to indicate this.

3. Oversize materlals (maps, drawings, and charts) are photographed by sectioning the original, beginning at the upper left hand corner and continuing from left to right in equal sections with small overlaps. Each oversize page is also filmed as one exposure and is avallable, for an additional charge, as a standard $35 \mathrm{~mm}$ slide or in black and white paper format.*

4. Most photographs reproduce acceptably on positive microfilm or microfiche but lack clarity on xerographic copies made from the microfilm. For an additional charge, all photographs are avallable in black and white standard $35 \mathrm{~mm}$ slide format.*

*For more information about black and white slides or enlarged paper reproductions, please contact the Dissertations Customer Services Department.

\section{U.M.I $\begin{aligned} & \text { Dissertation } \\ & \text { Information Service }\end{aligned}$}

University Microfilms International A Bell \& Howell Information Company

$300 \mathrm{~N}$ Zeeb Road, Ann Arbor, Michigan 48106 
Howard, Daniel James

QUESTION EFFECTS ON INFORMATION PROCESSING IN ADVERTISING

\section{University \\ Microfilms \\ International 300 N. Zeeb Road, Ann Arbor, MI 48106}

\section{Copyright 1986 \\ by}

Howard, Daniel James

All Rights Reserved 


\section{PLEASE NOTE:}

In all cases this material has been filmed in the best possible way from the available copy. Problems encountered with this document have been identified here with a check mark

1. Glossy photographs or pages

2. Colored illustrations, paper or print

3. Photographs with dark background

4. Illustrations are poor copy

5. Pages with black marks, not original copy

6. Print shows through as there is text on both sides of page

7. Indistinct, broken or small print on several pages

8. Print exceeds margin requirements

9. Tightly bound copy with print lost in spine

10. Computer printout pages with indistinct print

11. Page(s) lacking when material received, and not available from school or author.

12. Page(s) seem to be missing in numbering only as text follows.

13. Two pages numbered - Text follows.

14. Curling and wrinkled pages

15. Dissertation contains pages with print at a slant, filmed as received

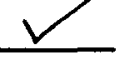

16. Other

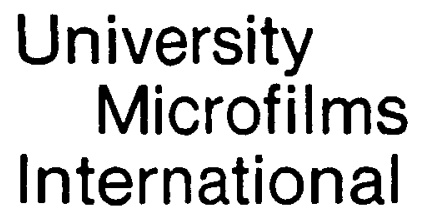




\title{
QUESTION EFFECTS ON INFORMATION \\ PROCESSING IN ADVERTISING
}

\begin{abstract}
DISSERTATION
Presented in Partial Fulfillment of the Requirements for the Degree Doctor of Philosophy in the Graduate Program in Business Administration at The Ohio State University
\end{abstract}

By

Daniel James Howard, B.A., M.A., M.S.S.A.

$\star \star \star \star \star ~$

The Ohio State University

1986

Dissertation Comittee:

Approved by

R.E. Burnkrant

P.R. Dickson

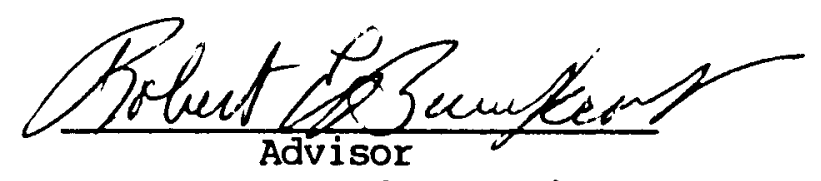

P.W. Miniard

Department of Marketing 
Copyright by

Daniel James Howard

1986 
To my parents

and

To my wife Renee

11 


\section{ACKNOWLEDGMENTS}

Any project of this size inevitably involves the efforts of many individuals. I wish to primarily thank the members of my committee, Robert Burnkrant, Peter Dickson and Paul Miniard, all of whom contributed to the final product. However, I wish to especially acknowledge the guidance and involvement of Robert Burnkrant, my Chairman, who provided many critical suggestions throughout this investigation.

Gratitude is also expressed to the W.O.S.U. Broadcasting Stations for developing the radio show used in this study. In particular, I wish to thank Dave WeIbell, Boyce Lancaster and Herb Howenstine for use of their "voices." The technical assistance of David Jones and the staff at the 0.S.U. Recording studios is much appreciated. I offer sincere thanks to The Oh1o State University Graduate Alumn Research Council for an award which funded the development of this investigation.

This manuscript was typed by Nadine Hill, who deserves many thanks. Last, but not least, I wish to extend my warmest appreciation to Renee Howard for assisting in the collection of question advertisements and for marrying me in spite of it all. 
VITA

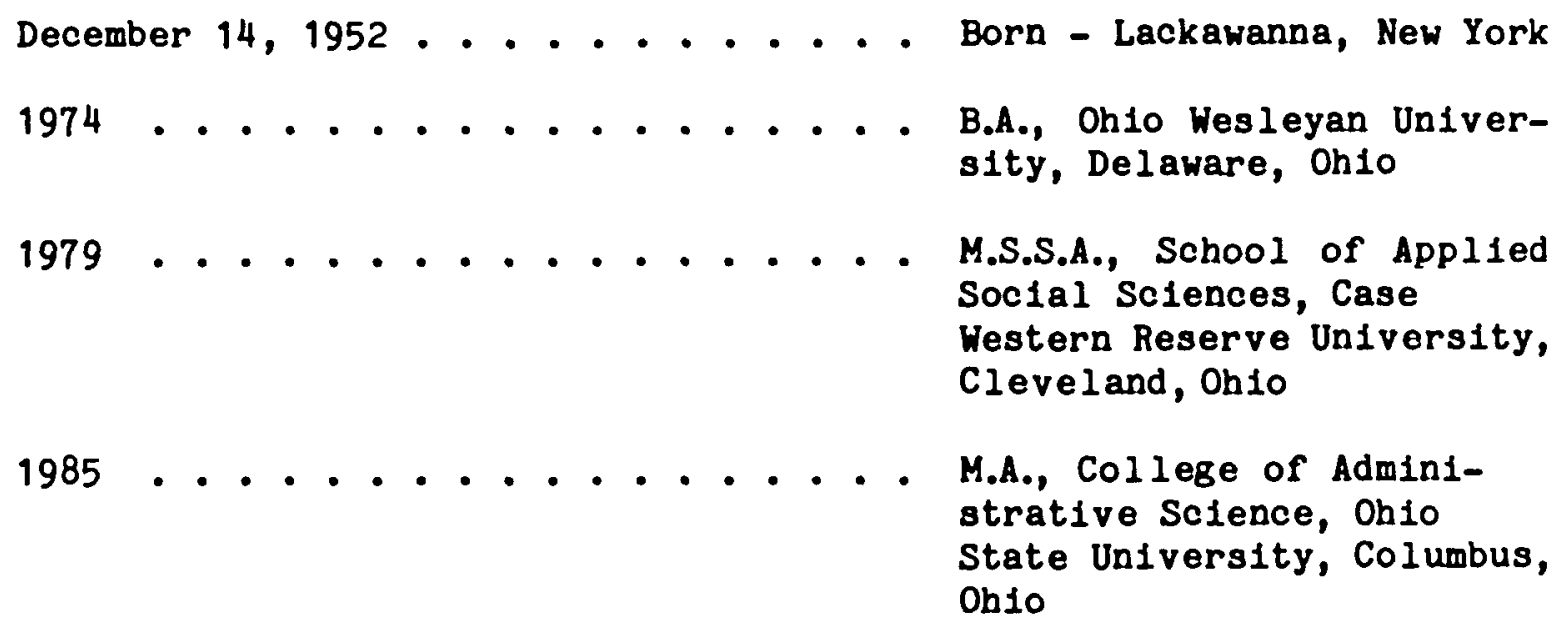

August, 1985-Present .. . . . Assistant Professor of Marketing, Edwin L. Cox School of Business, Southern Methodist University, Dallas, Texas

REFEREED PUBLICATIONS

Howard, Daniel J. and Alan G. Sawyer (1985), Mecall, Recognition and the Dimensionality of Memory for Print Advertisements: A Reappraisal," Marketing Science, (accepted for publication).

Burnkrant, Robert E. and Daniel J. Howard (1984), "Effects of the Use of Introductory Rhetorical Questions Versus Statements on Information Processing," Journal of Personality and Social Psychology, Vol. $47,6,1218-1230$.

Howard, Daniel J. (1984), "Drug Related Deaths in a Major Metropolitan Area: A Sixteen Year Review," Journal of Applied Soclal Sclences, Vol. 8, No. 2, 235-248. 
Brooks, Charles H. and Daniel J. Howard (1983), "The Response of Special Education Students to an Activity-Centered Health Curriculum," Journal of School Health, Vol. 53, No. 9, 527-530.

Brooks, Charles H. and Daniel J. Howard (1982), "Evaluation of an Activity-Centered Health Curriculum: Assessment of Cognitive Knowledge," Journal of School Health, Vol. 52, No. 9, 549552 .

Brooks, Charles H. and Daniel J. Howard (1981), nEvaluation of an Activity-Centered Health Curriculum Using the Health Belief Model," Journal of School Health, Vol. 51, No. 8, 565-569.

FIELDS OF STUDY

Major Field: Marketing

Minor Field: Consumer Behavior 
TABLE OF CONTENTS

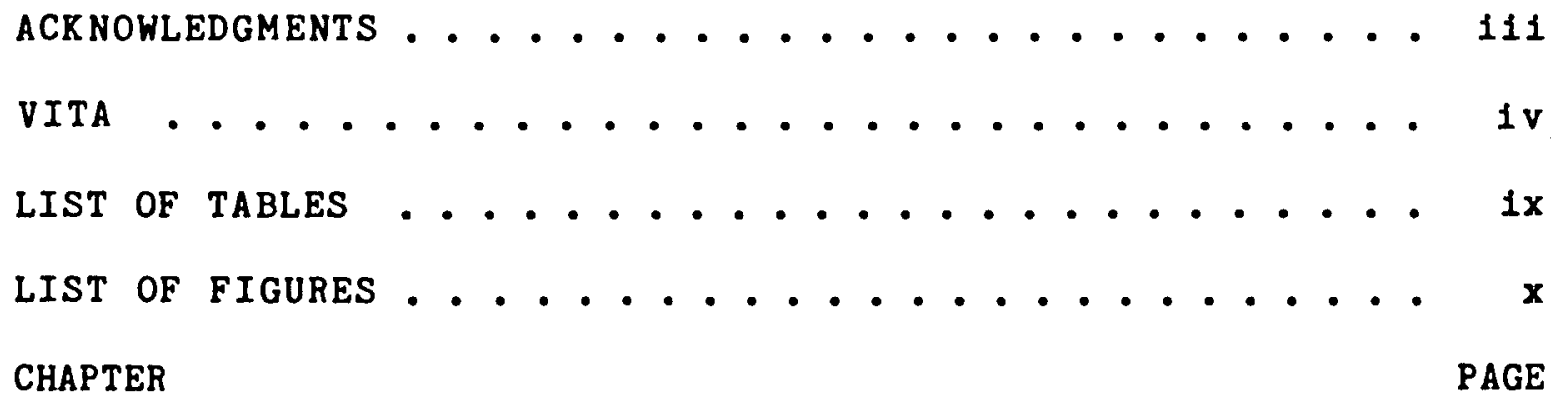

I. INTRODUCTION AND PROBLEM STATEMENT . . . . . . . . 1

Introduction ................ 1

Problem Overview ................ 7

Study Overview ................. 9

II. LITERATURE REVIEW . . . . . . . . . . . . 11

Literature Overview .............. 11

Question Versus Statement Advertising Headilnes . . 11

Factual Adjunct Question Effects on Learning . . . 12

Factual Adjunct Question Effects on

Learning: Discussion and Critique ....... 24

Higher-Level Adjunct Question Effects on Learning - 26

Higher-Level Adjunct Question Effects on

Learning: Discussion and Critique ....... 32

The Arousal of Curiosity Through Questioning . . 33

Question Effects on Attitude and Bellef Formation - 37

Question Effects on Attitude and Belief Formation:

Discussion and Critique ........... 47

Communicative Silence .............. 50

A Cognitive Effort Perspective on

Question Effects .............. 52

Research Implications ............. 56

III. RESEARCH HYPOTHESES . . . . . . . . . . . . 59

Overview of Expectations .......... 59 
HYPOTHESES .................. 64

Hypothesis I ................ 64

Hypothes1s II ................. 64

Hypothes1s III ............... 65

Hypothes1s IV ................. 66

Summary of Expectations............ 67

IV. PRETESTS, METHOD AND MEASUREMENTS . . . . . . . 68

PRETESTS .................... 68

Argument Quality Pretest .......... 68

Question Versus Statement Discrimination

Pretest ............... 70

TIme Delay Pretest ............ 71

METHOD ..................... 76

Des18n .......................... 76

Independent Varlable Manipulations ....... 76

Study Context ................... 77

Radio Show Programing ............. 77

The Supplemental Vitamin Advertisement . . . . 81

Sampling Procedure ............... 84

Testing Procedure .............. 85

DEPENDENT VARIABLE MEASUREMENTS . . . . . . 85

Measures of Product Evaluation .......... 87

Measures of Bellef Reappraisal: the

Arousal of Doubt ............. 88

Measures of Message Learning ........... 89

Measures of Message Topic Thinking . . . . . . . 92

Additional Measures . . . . . . . . . . 93

v. RESULTS . . . . . . . . . . . . . . 94

Review of Expectations . . . . . . . . 94

Hypotheses Testing ............... 95

Effects Observed: A Cautionary Note . . . . . 97

Effects Observed: Analyt1c Approach ...... 97

HYPOTHESIZED MEASURES . . . . . . . . . . 99

Measures of Product Evaluation . . . . . . . 99

Measures of Bellef Reappraisal: the

Arousal of Doubt ............ 101

Measures of Message Topic Thinking . . . . . 103

Measures of Message Learning . . . . . . . . 105

ADDITIONAL ANALYSES . . . . . . . . 105

Measures of Advertisement Evaluation . . . . . 105

Speaker Ratings . . . . . . . . . . . . 110 
Perceptions of Advertisement Length . . . . . 110

Four Factor Design . . . . . . . . . 112

The Effect of Product Usage . . . . . . . . 120

Determinants of outcomes .......... 125

VI. DISCUSSION AND INTEGRATION . . . . . . . . . 130

Summary of Expectations ........... 130

Summary of Principal Results . . . . . . . . 130

Uninterpretable Effects ........... 132

Failure of the Time Delay Manipulation . . . . 132

Questions and Memory .. . . . . . . . 136

Question Versus Statement Discrimination

Pretest: A Re-examination ......... 137

Outcomes By Question Position.......... 141

Alternative Models ........... 145

Further Note on Question Response . . . . . 148

Processing Mode ............... 153

Theoretical Restrictions .......... 155

Future Research ............... 156

Summary Conclusion . . . . . . . . . . 158

APPENDICES

A. Argument Quality Pretest Instrument. ......... 160

B. Question Versus Statement

Discrimination Pretest Instrument . . . . . . 166

C. Time Delay Pretest Instrument . . . . . . . . 177

D. Remarks Made by the Disc Jockey Wh1le on the Radio Show . . . . . . . . . 184

E. Music Interest and Attention Test Instrument . . . . 189

F. Instrument Used to Collect Formal Study Measures . . 193

G. Question Versus Statement Discrimination
Pretest Re-Examination Instrument . . . . . . 209

H. Question Comparison Instrument . . . . . . . . 214

LIST OF REFERENCES . . . . . . . . . . . . . . . . . 221 


\section{LIST OF TABLES}

TABLE

PAGE

1. Prevalence of Question Advertisements in

Ten National Consumer Magazines: 1983-1985 . . . . 3

2. Radio Program Time Segments . . . . . . . . 78

3. Cell Sizes for Experimental Conditions . . . . . 86

4. Analysis of Varlance Summary Table for Hypothesized

Dependent Variables ............ 96

5. Analysis of Varlance Summary Table for Ad

Stimulation and Interest Measures . . . . . . 106

6. Four-Factor Analysis of Variance Summary

Table for Attitude, Purchase Intention and

Ad Bellevab1lity Measures ............ 114

7. Mean Scores on Outcome Measures Demonstrating a

Grammatical Form by Position Interaction . . . . . 121

8. Grammatical Form by Position Interaction: Summary of Selected Cell Comparisons . . . . . . . . 122

9. Within Cell Correlation Between Product Thinking and the Arousal of Doubt . . . . . . . 127 
LIST OF FIGURES

FIGURES

PAGE

1. Hypothesized Interaction Between Grammatical Form,

Position and Time Delay: Overview ......... 61

2. Hypothesized Interaction Between Grammatical Form, Position and Time Delay: Positional Question Effects as : Function of Time Delay ........... 62

3. Gramatical Form by Position Interaction for Production

of Positive Message Topic Thoughts . . . . . . 100

4. Grammatical Form by Position Interaction for Arousal

of Doubt Concerning Vitamin Related Needs . . . . 102

5. Grammat1cal Form by Position Interaction for

Extent of Product Related Thinking . . . . . . 104

6. Grammatical Form by Position Interaction for

Ratings of Advertisement Interest . . . . . . 107

7. Grammatical Form by Position Interaction for

Ratings of Advertisement Stimulation . . . . . . 109

8. Grammatical Form by Position Interaction for

Attitude Towards Taking Supplemental V1tamins . . . 115

9. Grammatical Form by Position Interaction for

Intentions to Purchase Supplemental Vitamins . . . . 117

10. Grammatical Form by Position Interaction for

Ratings of Advertisement Bellevability . . . . . . 119 


\section{CHAPTER I}

INTRODUCTION AND PROBLEM STATEMENT

\section{Introduction}

The problem to be addressed in this study concerns the effects of asking questions on the learning and acceptance of an advertising message. The art, or science, of judicious questioning has long been an area of interest to many disciplines. D11 Ion (1982a) observes that the recent literatures of philosophy, logic, grammar, linguistics, personal interviewing, psychotherapy and education indicate an expanding interest in the area of questioning. Interestingly, Dillon's multidisciplinary review of flelds with a basic or applied interest in questioning does not include marketing, although marketers have recommended the use of questions in advertisements at least since the turn of the century (see Starch, 1914).

A review of advertising textbooks reveals that the recommended use of questions has been almost exclusively presented as a technique for developing effective headlines. As early as 1914, Starch observed In one tabulation, that approximately 2-48 of advertising headilnes in a consumer magazine were presented in question form. Starch suggested that the logic of the strategy is based on the premise that na question naturaliy stimulates a response as a matter of habit" (Starch, 1914, p. 194). However, based on Starch's tabulation, one 
would suspect that question use in advertising occurs relatively infrequently. If questions are thought by practitioners to be effective in facilitating desired outcomes, a more accurate reflection of usage patterns would extend beyond ooncern only with headlines. However, no data could be located presenting such information. As part of a larger study, this author has complied provalence figures for question use in advertising across a variety of national consumer magazines. Table 1 presents those figures for 1983 through 1985 for Time, Newsweek, Smithsonian, Reader's Digest, National Geographic, Sports Illustrated, McCall's, Good Housekeeping, Parents and Parade magazines. For that three-year period of time, all fullpage or larger advertisements were examined $(N=33,023)$ of which 6,689 , or 20.25\%, were advertisements which contained a question in either the headline, sub-headlines, picture captions, corporate/brand slogans or body copy. ${ }^{1}$ This information is presented here only with descriptive intent, the point being that the extent of question use in advertising may be greater than is generaldy reoognized.

What is unfortunate, however, is that since the days of Starch discussions of question advertisenents do not seem to have significantly progressed in a conceptual and theoretical understanding of effective question use. Textbooks have been and remain quite

${ }^{1}$ An ad was defined as a "question ad" if it contained a sentence, phrase or word followed by a question mark in either the headline, subheadlines, picture captions, corporate/brand slogans or body copy, while excluding consideration of text presented in footnotes, tables, graphs, coupons, order forms, and similar arrangements. 
TABLE 1

Prevalence of Question Advertisements in Ten National Consumer Magazines: 1983-1985

\begin{tabular}{|c|c|c|c|c|}
\hline TIME & $\begin{array}{c}\frac{1983}{481 / 2240} \\
(21.478)\end{array}$ & $\begin{array}{c}\frac{1984}{495 / 2389} \\
(20.728)\end{array}$ & 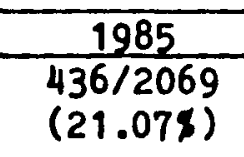 & $\begin{array}{c}3 \text { YR. TOTAL } \\
1412 / 6698 \\
(21.088)\end{array}$ \\
\hline NEWSWEER & $\begin{array}{l}437 / 2023 \\
(21.608)\end{array}$ & $\begin{array}{l}474 / 2224 \\
(21.318)\end{array}$ & $\begin{array}{l}431 / 1919 \\
(22.456)\end{array}$ & $\begin{array}{r}1342 / 6166 \\
(21.768)\end{array}$ \\
\hline SMITHSONIAN & $\begin{array}{l}113 / 492 \\
(22.978)\end{array}$ & $\begin{array}{l}159 / 598 \\
(26.598)\end{array}$ & $\begin{array}{l}120 / 618 \\
(19.428)\end{array}$ & $\begin{array}{l}392 / 1708 \\
(22.95 \%)\end{array}$ \\
\hline READER'S DIGEST & $\begin{array}{l}139 / 630 \\
(22.068)\end{array}$ & $\begin{array}{l}162 / 688 \\
(23.55 \%)\end{array}$ & $\begin{array}{l}179 / 695 \\
(25.758)\end{array}$ & $\begin{array}{l}480 / 2013 \\
(23.848)\end{array}$ \\
\hline $\begin{array}{l}\text { NATIONAL } \\
\text { GEOGRAPHIC }\end{array}$ & $\begin{array}{c}69 / 236 \\
(29.24 x)\end{array}$ & $\begin{array}{c}88 / 279 \\
(31.548)\end{array}$ & $\begin{array}{c}51 / 251 \\
(20.318)\end{array}$ & $\begin{array}{l}208 / 766 \\
(27.158)\end{array}$ \\
\hline $\begin{array}{l}\text { SPORTS } \\
\text { ILLUSTRATED }\end{array}$ & $\begin{array}{l}371 / 2108 \\
(17.598)\end{array}$ & $\begin{array}{l}416 / 2264 \\
(18.37 x)\end{array}$ & $\begin{array}{l}306 / 1949 \\
(15.70 \%)\end{array}$ & $\begin{array}{r}1093 / 6321 \\
(17.298)\end{array}$ \\
\hline MCCALL'S & $\begin{array}{l}107 / 736 \\
(14.548)\end{array}$ & $\begin{array}{l}127 / 775 \\
(16.398)\end{array}$ & $\begin{array}{l}102 / 727 \\
(14.03 \%)\end{array}$ & $\begin{array}{l}336 / 2238 \\
(15.018)\end{array}$ \\
\hline $\begin{array}{l}\text { GOOD BOUSE- } \\
\text { IEEPING }\end{array}$ & $\begin{array}{l}240 / 1245 \\
(19.278)\end{array}$ & $\begin{array}{l}254 / 1323 \\
(19.208)\end{array}$ & $\begin{array}{l}244 / 1268 \\
(19.248)\end{array}$ & $\begin{array}{l}738 / 3836 \\
(19.23 \%)\end{array}$ \\
\hline PARENTS & $\begin{array}{l}150 / 664 \\
(22.598)\end{array}$ & $\begin{array}{l}178 / 721 \\
(24.689)\end{array}$ & $\begin{array}{l}170 / 741 \\
(22.948)\end{array}$ & $\begin{array}{l}498 / 2126 \\
(23.428)\end{array}$ \\
\hline PARADE & $\begin{array}{c}71 / 458 \\
(15.508)\end{array}$ & $\begin{array}{c}61 / 373 \\
(16.358)\end{array}$ & $\begin{array}{l}583 / 320 \\
(18.124)\end{array}$ & $\begin{array}{l}190 / 1151 \\
(16.50 \%)\end{array}$ \\
\hline TOTALS & $\begin{array}{c}2178 / 10832 \\
(20.114)\end{array}$ & $\begin{array}{c}2414 / 11634 \\
(20.748)\end{array}$ & $\begin{array}{c}2097 / 10557 \\
(19.865)\end{array}$ & $\begin{array}{c}6689 / 33023 \\
(20.258)\end{array}$ \\
\hline
\end{tabular}

$a_{A l l}$ entries are the number of question advertisements/number of full page or larger advertisements, with the percentage of total ads being question ads in parentbeses. 
consistent in the reasons why the use of a question is recommended in an advertisement: 1) a question can serve as an nattention-gettern; 2) a question can arouse curiosity; 3) a question can draw an individual Into the body copy of an advertisement (Starch, 1914; Brewster, Palmer and Ingram, 1947; Burton, Kreer and Gray, 1949; Barton, 1950; Dav1s, 1955; Burton and Kreer, 1962; Mande11, 1974; Dunn and Barban, 1974; Runyon, 1979; Sandage, Fryburger and Rotzol1, 1979; Kleppner, 1979; Gibson and Berkman, 1980; Faison, 1980; Bovee and Arens, 1982; Bolen, 1984). In the textbooks reviewed here, elaboration on reasons for and conditions underlying effective question use do not signifioantiy extend beyond these three basic assumptions, nor does discussion extend beyond the use of questions in headines. It also remains unclear and unstated what benefits in terms of outcomes should be expected from utilizing questions in advertisements. No discussion has been offered suggesting that partioular outcomes have a higher likelihood of beling obtained through the use of questions in advertisements.

One probable reason for the attenuated range of discussion on the use of questions in advertising textbooks is the absence of any empirical support for the position that questions are indeed more effective than a content equivalent alternative in stimulating desired outcomes. It appears that the recommended use of questions in ads has been made solely on the basis of intuitive judgment. Only one published study could be looated examining the effects of questions in advertising. Myers and Haug (1967) suggested that since question 
headlines were relatively "unusual," they should be more readily remembered than non-question headlines. These authors found, however, that question headilnes were not more memorable than equivalent declarative statement headlines. This study will be discussed in more detail in the next chapter.

An information processing perspective on anticipated question effects will be developed in the present investigation. An Information processing view would suggest that it is not the static occurrence of a question in itself which should be evaluated for outcomes associated with asking the question (e.g., whether the question itself is remembered). Rather, questions can be conceptualized as dynamic in nature, where interrogation facilitates the cognitive effort that Individuals expend when processing associated message information. Such activity may be reflected in measures of learning and evaluation of message material. Thus, potential benefits derlved from presenting questions in confunction with an advertising message may include not only greater retention of the message arguments, but also an inoreased probability of message acceptance if the accompanying arguments are percelved as strong and compelling (see Burnkrant and Sawyer, 1983; Burnkrant and Howard, 1984). Given the apparent frequency of question use in advertising, a further exploration of its effectiveness appears indicated. An examination of outcomes based on information processing theory would likely bave ut1lity for both advertising research and practice. These issues will be the focus of this research. 
Given the long recommended use of questions in advertising, as well as the prevalence of question ads in practioe, it is quite surprising to find a lack of empirical support for the technique. However, even disciplines that have empiricaliy examined question efrects on outoomes rairly extensively seem to have experienced frustration with unambiguously specifying the loous and nature of those effects. As summarized by D1lion (1982b):

$$
\begin{aligned}
& \text { Asking and answering questions are } \\
& \text { among the most common human activities, } \\
& \text { yet it is remarkable how little is } \\
& \text { know, in a systematic way, about the } \\
& \text { effect of questions on a respondent (p. 127). }
\end{aligned}
$$

Th1s statement seems true despite a falrly long history of empirically examining question effects on learning in the field of education. Anderson and Blddle (1975) report fac1litative effects of questions on learning in 77 of 110 studies reviewed. One major problem, however, 1s the apparent accepted practice in educational experimentation of explicitly 1nstructing subjects to attempt to answer all questions they encounter in the text, or warning them of an impending test on the material. The demonstrated effects of questions on learning, therefore, may not generalize to situations where recipients have no previous warnings or instructions to answer the questions presented to them--as with advertising messages. Clearly, advertisers face the more difficult task of developing questions that facilitate the analysis and evaluation of a message without the aid of external motivating supports. 
Problem Qverview

Two of the factors whioh may influence effective question use in advertising are the position of a question in message relative to the argument to which it refers, and the opportunity to respond to the question posed. Consider the case of a broadcast advertisement. When a prequestion is utilized (a question presented before the argument to whiob the question refers) opportunity is avaliable to analyze, evaluate and respond to the question as its supporting argument is being transmitted. When a postquestion is utilized (a question presented after the argument to which the question refers), however, the opportunity to respond may be lacking when the transmitted question is immediately followed by subsequent arguments or comments. Wright (1974) notes that arousal to process and opportunity to process information must be considered theoretioally separate variables. Thus, even if a question is thought, to be effective at motivating information processing, anticipated outcomes may not be obtained if adequate opportunity to respond to the question is not provided.

One way around the potential postquestion difficulty is to explicitly provide a brief interval of silence after a postquestion to provide recipients with the opportunity to process the interrogative request. Advertisers may already be aware of this option. Chrysler has recently alred a television commercial promoting their five-year 50,000-m1le warranty on all Chrysler cars and trucks. The commercial ends with Lee Iacocca asking: We at Chrysler don't want to be the biggest, just the best. What else is there?" That question is then 
followed by four seconds of silence with the television screen reading: "Chrysler--We don't want to be the biggest, just the best." Ken Dusk1n, developer of the Chrysler ad, has stated that the purpose of the interval of silence after the concluding question was to give oonsumers "time to think about what was asked," while simultaneously highlighting the corporate slogan. ${ }^{2}$ The use of an interval of sllence in conjunction with advertising questions to facilitate learning and persuasion is an intriguing notion that has yet to be examined emplrically. However, it should be noted that effects of postquestions on message persuasion have been obtained using a broadcast message without explicitly providing added time to oonsider the quest1ons posed (e.B., 2111man, 1972; Petty, Cac1oppo and Heesacker, 1981). What needs to be examined, therefore, is whether added time may maximize the potential effectiveness of postquestion use. Onder the assumption that information processing of language is temporal and sequential and not an instantaneous event, increased time to consider the implications of a question before additional information 18 provided may plausibly influence outcomes associated with processing the request. If the use of silence after questioning is found not to significantly influence outcomes, the 1ssue of whether question use varies in effectiveness across different message positions can still be addressed.

${ }^{2}$ Personal Communication. Ben Duskin, Executive Creative Director, Kenyon and Eckhardt, Inc., New York, New York. September 4, 1985. 
An empirical examination of these 18sues should have applied value. For example, Webster (1981) reports that a major concern of corporate management for marketing in the $1980^{\prime} \mathrm{s}$ is the declining productivity of marketing in the face of minoreased media costs, partioularly the costs of broadcast median (p. 12). If the use of sllence after questioning can be shown to inorease ad effectiveness, then its use is certainly warranted; if not, then it would suggest that the time might be more productively used, for example, by providing additional product related information. In addition, if the effectiveness of question usage is seen to vary by position within a message, this might al low the development of initial guidelines on where and how to use certain types of questions in advertising where no guidelines currently exist. Finaliy, questions may be more effective in stimulating certain outcomes, as opposed to others. A specification of which outcomes appear to respond mest" would assist advertising researchers in refining ruture measurements.

\section{Study Overview}

The present study should represent the first comprebensive examination of question effects on learning and persuasion conducted In broadcast in the fleld of advertising. The format of this Investigation will be advertisements inserted in the context of a radio show professionally arranged to help reduce the artificiality of the typical laboratory experiment. Any differential benefits derived from asking questions will be determined by comparisons with content equivalent declarative statements. Question/statement position 
relative to the message argument to whioh it refers will also be manipulated. Finally, the use of silence after a question/statement-argument (or argument--question/statement) pair will also be manipulated to examine the impact on outcomes of limiting or extending the opportunity to process presented information. 
CHAPTER II

LITERATURE REVIEW

\section{Literature Overview}

Th1s chapter will review previous empirical studies on effects of questions on learning and persussion. The results of the studies w1ll first be presented, followed by a discussion and oritique of the findings. Note that not all of the studies to be reviewed here will be equally critioal to elther understanding or supporting the planned Investigation. Rather, this review is presented as a comprehensive cross-section of research conducted on the influence of questions on learning and persuasion. The chapter will end with a theoretical integration of the implications of past research for this investigation.

Question Versus Statement Advertising Headlines

Only one study could be found empirically examining question effects on learning in advertising. No studies could be found examining question effects on attitude or belief formation or change in advertising.

Myers and Haug (1967) reasoned that since question headines appeared relatively infrequentiy in print, they had a higher probability of being remembered than the same headline appearing in 
declarative statement form. Question headilnes were obtained from an issue of the Saturday Evening Post and equivalent declarative statement headlines were developed. The two headline forms were malled out to separate consumer panels with additional filler headlines. One week later consumers were sent a second mailing of the headlines and recognition was assessed. Only one of the question headilnes (out of ten) was round to have a significantly higher likelihood of being recognized than its opposing declarative statement version. Myers and Haug suggested that the indisoriminate use of Interrogative headilnes as attention-getting devices does not necessarily lead to better results in terms of retention of the ad by the seneral publion (p. 44). It 1s unknown whether different results would have been obtained utilizing recall as an indicator of learning. Bowever, from an information processing perspective it could be argued that it is not the act of questioning which should be more memorable but rather it is the consequences of questioning which should refleot learning. In other words, it is not the question per se which should be more memorable but ratber it is the textual material that accompanies a question whioh should be affected by the interrogative stimulation of information processing activities. The next five sections will review and oritique studies providing support for this position.

Factual Adjunct Quest1on Effects on Learning

An "adjunct question" is a question presented in conjunction with textual material in which the material provides information relevant 
to answering the question. The paradigm currently popular in educational paychology was first introduced by Washburne (1929) but rediscovered by Rothkopf (1965) with methodological 1mprovements.

In general, the factual adjunct question paradigm involves presenting subjects (always students in the studies to be reviewed) with a textual passage containing questions (versus no questions) Inserted before or after given segments of the passage. Subjects are then tested to see if the questions 1mproved their learning of given aspects of the passage. Note that subjects are either opecifically Instructed to answer any questions they encountered, or warned of an 1mpending exam on the material about to be presented.

As originaliy explained by Rotbkopf (1965), the use of factual prequestions (questions placed before relevant passage segments) should result in question specific attention in processing text, thus facilitating the learning of the material addressed by the questions. However, postquestions (questions placed after relevant passage segments) were thought to engage mmathemagenic behaviors," or behaviors that produce learning (derived from Greek roots MATHEMA, that which is learned, and GIGNESTHAI, to be born). According to the mathemagenic hypothesis, when a subject encounters a postquestion able to be answered, currently Implemented learning strategies should be reinforced in processing subsequent text. However, when a subject encounters a postquestion not able to be answered, learning strategies should be extinguished or changed when processing subsequent text, given that the previous strategles have been found to be ineffective. 
In other words, if someone instructed to perform a task (1.e., answer questions) is unable to do so, it seems reasonable that the person w1l I change the preparatory behavior assoclated with accompliahing the task. Sinoe the current preparatory behavior (1.e., ourrent learning/reading strategy) has proven not to work (1.0., the questions on the reading cannot be answered), new strategies (1.e., new strategies in processing the material) need to be adopted for better learning to occur.

Rotbkopf (1965, 1966) presented subjects with a 20-page passage on marine blology. Factual questions on the passage were utilized, 1.e., questions that asked subjeots to recall specific pieces of Information from the passage (and the same questions were also used on a criterion test as discussed below). Four groups of subjects recelved elther questions before or questions after relevant passage segments with or without correct answers to the questions being provided. 3 Two control groups (not recelving questions) were used: a reading only control group and a control group with specific Instructions to read the material carefuliy. The oriterion test included botb "intentional" and "incidental" material. "Intentional" material was defined as the same adjunct questions presented a second time on the criterion test. "Incidental" material was defined as

${ }^{3}$ Correct answers to questions were provided by having subjects remove a "mask" oovering the answer from the page on whiob the question was asked. Subjscts "not provided correct answers" did not have this opportunity to check on the answer to each question after it was asked. 
criterion test items on information not directly addressed by the adjunct questions. In otber words, "incidental" material included questions developed from textual material other than the information specificaliy addressed by the adjunct questions. Adjunct questions were always presented on pages separate from textual materlal. Subjects were instructed to proceed sequentially through materlal, to attempt to answer any questions they encountered, and not to refer back to previous questions or text. Note that these procedures apparently become standard practice in many subsequent adjunct question experiments.

The findings demonstrated that both prequestion and postquestion Broups (whether or not they recelved answers to those questions) scored significantly higher than both control groups on intentional material but there was no significant difference between pre and postquestion groups on that materlal. It was further seen that only the postquestion group (which did not recelve answers) scored significantly higher than the reading only control group (but not significantly higher than the control group with instructions to read carefuliy) on the learning of incidental material (1.e., material not direotly questioned).

The findings that both pre and postquestions facilitate the learning of directly questioned materlal but that only postquestions facilitate the learning of material not directly questioned has been replicated several times using both the same and different materials (Frase, 1967; Frase, 1968a; Rothkopf and Bisbicos, 1967). Note that in 
each of these studies subjects were instructed to attempt to answer the questions presented. The Rotbkopf and B1sb1c0s (1967) study presents an interesting example of the effects of postquestions on the learning of material not directly questioned. Subjects were presented with a 9,000 word passage on marline b10logy. Subjects exposed to adjunct postquestions that required proper names or measured quantities as answers performed significantly better than other groups on criterion test items different from the adjunct questions but also requiring proper names or measured quantities as answers. Th1s group also performed significantiy better than controls on directiy questloned materlal, 1.e., on the same adjunct questions asked a second time. Adjunct prequestions, however, were only found to facilitate the learning of information direotly questioned.

Support for the mathemagenio hypotbesis 18 inconsistent (see Anderson and B1ddle, 1975). An equaliy plausible explanation for factual postquestion effects is that postquestions fac1litate the cognitive review of previously aoquired information thus increasing the Ilkelihood of later retrleval.

Although first suggested by Frase (1967), explicit support for the cognitive review hypothesis was most clearly provided by MoGaw and Grotelueschen (1972) utilizing a "matched" and "unmatched" criterion test arrangement. This distinotion is best clarified by example. Consider the following text segment:

Then from the surveying ship Bulldog, examining a proposed northern route for a cable from Faroe to Labrador in 1860 , came another report. The 
Bulldog's sounding line, which at one place bad been allowed to lie for some time on the bottom at a depth of 1260 fathoms, came up with 13 starfish olinging to it (p. 670).

An adjunct postquestion derived from this segment asked: "The surveying ship which recovered starfish from a depth of 1260 fathoms in 1860 was exploring a route for a cable from Faroe to ." The "matched" oriterion test question asked: "The surveying $\operatorname{sh1p}$ - wh1ch recovered starfish from a depth of 1260 fathoms in 1860, was exploring a route for a cable from Faroen (p. 670). The "unmatched" criterion test 1tem was extracted from the same page of text and asked for the name of an arctic explorer. Note that although the "matched" criterion test item had substantial elements in common with the adjunct postquestion, it could not be directly answered by information in the postquestion. The "unmatchedn criterion test 1tem, however, had no elements in common with the adjunct postquestions. Subjects were instructed to study the material carefuliy "paying close attention to facts and figures and to names and dates" (p. 582).

The authors found that the use of adjunct postquestions facilitated performance on the matched" oriterion test items, suggesting that a mackward" cognitive review process was engaged. It was a lso seen that the use of adjunct postquestions facilitated the learning of "unmatched" items from passages immediately following the postquestions, suggesting a "forward" process in which general attention is enhanced in the inspection of later materials. This 
suggests that postquestioning resulted in a general beightening of motivation to process information immediately following the postquestions.

Rothkopf and Billington (1974) replicated McGaw and Grotelueschen's "matched" oriterion test findings using similar materials but eliminating "priming," which they defined as learning facilitation due to temporal contiguity of adjunct postquestions and matched criterion items as an alternative explanation. In other words, the "priming" explanation that was rejected examined "whether performance on a test item is better if a question topically related to the test item has recently been asked" (p. 669) and was assessed by performance variation as a function of the location of topically related questions in a 24-page typewritten passage. Subjects wrote the answer to questions asked on a "designated answer space." Rothkopf and Billington summarized their preferred cognitive review explanation of the results as follows:

The data are consistent with the conception that the subject searched his memory while trying to answer an adjunct question during reading. In doing so, the subject reviews and strengthens previously established related memory representations or makes them in other ways more accessible in subsequent tests (p. 609).

Note that the previously mentioned adjunct postquestion effects on Intentional material (the same adjunct postquestions presented a second time on a criterion test) must also involve a cognitive review process almost by definition since subjects are not told the answers 
to the adjunct postquestions when they are enoountered nor are they al lowed to re-examine the relevant textual material. A direct analogy to the intentional adjunct postquestion effect is found in the I1terature on human learning and memory where instructions to attempt recall of information has been found to facllitate subsequent recognition performance of the same information (Hanawalt and Tarr, 1961; Wenger, Thompson and Bartling, 1980).

In a conceptualiy interesting experiment, Boyd (1973) reasoned that if botb prequestions (through selective attention) and postquestions (through cognitive review) facilitate the learning of intentional material then, "the effect of giving a set of prequestions with Identical postquestions should be to increase intentional posttest soores more than a set of pre or postquestions alone" (p. 32). Subjects were instructed to attempt to answer the questions presented. Support for the hypothesis was obtained. Repeating an adjunct question across pre and post positions was found to facilitate intentional learning significantly more than single question conditions. Also note that both single question conditions (1.e., pre and postquestions) performed better than the control group and approximately equal to each other, although no significance test on these comparisons was reported.

An additional stream of research on factual adjunct questions has attempted to more precisely define the locus of question effects on information processing. Britton, et al. (1978) examined the infiuence of adjunct postquestions on the cognitive effort expended in 
processing text. Cognitive effort was measured using the secondary task technique. With this technique subjects are told that their primary task is to comprehend presented text. Their secondary task, bowever, is to respond to a tone by pressing a key whenever it sounds. The tone is activated at intervals while a subject is reading textual material. The response time of a subject in responding to the tone is assumed to be indicative of the degree of cognitive effort expended, or the extent to which an individual 18 cognitively engaged, in processing text (also see, for example, Britton, Westbrook and Holdrodge, 1978).

Britton, et al. presented subjects with the same textual material on marline biology used by Rothkopf (1966). Subjects were either exposed or not exposed to adjunct postquestions and were required to answer the questions presented. As expected, it was found that subjects exposed to text relevant questions took longer in responding to the secondary task probe than subjects not exposed to questions. A second experiment ruled out the possibility that increases in reaction time while processing text were due to interruptions from having to stop to answer questions. Subjects exposed to text irrelevant questions had secondary task reaction times no different than a control group not exposed to questions. The second experiment also showed that reaction times in the text relevant question group Inoreased significantly on pages Immediately following questions when compared to reaction times for second or third pages after questions. This result parallels McGaw and Groteluschen's (1972) "forward" effect 
of questions on learning previously discussed. Finalig, both experiments revealed that the use of text relevant adjunct questions resulted in a significantly higher average reading time per page of text when compared to the group not recelving questions. The authors concluded that the use of adjunct questions results in "an increase in the amount of cognitive capacity used for reading" (p. 271), as Indicated by increases in the secondary task reaction time. However, 1t was unclear whether increases in reading time for the questioned subjects reflected a "cause or a result of changes in processing or learning" (p. 271). In other words, learning Inoreases may have been simply due to an increase in the amount of time spent reading.

Reynolds and Anderson (1982) also ut1lizing the secondary task technique obtained findings that qualified Britton, et al.'s conclusions. These authors used the Rothkopf and Bisbicos (1967) materials, and subjects were informed that a comprebensive short answer test would be given upon completion of reading. It was found that secondary task reaction time, as well as reading time, significantly increased for subjects exposed to adjunct postquestions but only when subsequent text contained information of the same category as the previous adjunct question. In other words, questions were found to primarily have a selective effect on the processing of subsequent text and not to result in a general non-selective beightening of attention. Reynolds, Standiford and Anderson (1979), who also warned of a short answer test on the reading material, found that the use of adjunct postquestions resulted in an increase in 
reading time for question relevant information. 4

The Reynolds and Anderson study examined learning measures in conjunction with the measures of cognitive effort. Similar to Rothkopf and Bisbicos (and other studies previously mentioned), it was found that adjunct postquestions had a facilitating effect on information directly questioned as well as information not directly questioned. Covarying for secondary task reaotion time, the learning effect on information not directly questioned became nonsignificant, although the effect for information directly questioned did not. The authors noted that "the obvious interpretation of this fact is that attention, or a process supported by attention, lies on the causal path between questions and learning" (p. 630). It was concluded that postquestion effects on learning probably stem from two sources: 1) Inoreased selective attention (1.0., cognitive effort) in processing relevant subsequent text; 2) a cognitive review of previously acquired information that can be partially but not wholly explained in terms of selective attention or cognitive effort when processing text.

"Note that neither Reynolds and Anderson (1982) nor Reynolds, Standiford and Anderson (1979) used text irrelevant questions as did Britton, et al. (1978). Britton, et al.'s task mirrelevantn questions were completely unrelated to the presented text, and were compared to "relevant" questions that were related to the text. The other two sets of authors on ly used questions "related" to the text, although those questions differed in how closely they were related to the text. The only point here, however, is that the fundamental conclusion of all three sets of authors (as well as the present investigator) 18 the same: questions can influence the degree of cognitive effort, as well as time, expended in prooessing text. It 18 less clear how closely related questions and subsequent material must be to maximize those effects. 
Britton, et al.'s, Reynolds and Anderson's, and Reynolds, Standiford and Anderson's findings that adjunct questions result in an increase in text reading time are apparently the most consistent findings on this issue in a number of years. This issue has been a controversial one since Rothkopf (1966) reported an "increase" in reading timo associated with the use of adjunct postquestions. In a review of the adjunct question 11terature, Carver (1972) oriticized Rothkopf and other experimenters for either falling to control or measure reading time and not reoognizing the possibility that Increases in learning associat d with questions may simply be due to increases in study time. Such learning facilitation could thus be explained in terms of the total time hypothesis of learning and memory (Copper and Pantle, 1967). Rothkopf (1974) replied that neither Rothkopf (1966), Rothkopf and Bisbicos (1967) nor Rothkopf and Bloom (1970) found "statistically reliable" increases in study time associated with adjunct questions.

Faw and Waller (1976) re-opened the debate by reviewing the literature and computing an "efficiency" score for avallable studies by dividing mean posttest scores by mean study time. Using this index, the authors concluded that evidence of the effects of questions on learning was less compeling than reported in the literature, 1.e., that study time can account for a sizable proportion of the group differences in learning attributable to adjunct questions. However, it should be noted that Rothkopf (1974) pointed out that "who would 
despise a treatment that caused a student to study more efficiently, even if it did take more time?" (p. 4).

Part of the problem with most studies o1ted in this debate by Rothkopf, Carver, and Faw and Haller concerns the questionable rellability of the reading tice measures obtained. Typically, these measures were self-recorded by subjects using a clook provided by the experimenter. In the Britton, et al., Reynolds and Anderson, and Reynolds, Standiford and Anderson studies, however, reading time was automaticaliy recorded by computer with a reported accuracy within m1l118econds. On the other hand, Rothkopf (1974) reported that he conducted an unpublisbed study using an "automation time reoording device in which text inspection time did not increase for the adjunct question group. It is not the intent of this investigation to resolve this controversy except to note that the most recent findings on the 18sue, and findings for which apparently reliable measures were obtained, do consistent ly suggest that questions can influence the time associated with processing information.

Factual Adjunct Question Effects on Learning: Discussion and Critique The literature reviewed so far suggests that the use of questions In connection with textual material fac1litates learning. Overall, the use of factual prequestions has been found to stimulate the learning of information directly questioned. In general, the use of factual postquestions bas been found to stimulate the learning of Information directly questioned (1.e., adjunct questions asked a second time on a criterion test), as well as information not directly 
questioned (1.e., asking questions other than the previously presented adjunct questions on the criterion test). Some support bas also been found for a combined effect of pre and postquestions on the learning of information directly questioned.

Prequestion effects can be explained by selective attention to Information requested. Postquestion effects can be explained by a process of cognitive review of acquired information and by helghtened attention to subsequert relevant material. The use of questions has been found to facilitate the cognitive effort expended in processing material and may be the most parsimonious explanation of effects of questions on learning. The evidence also suggests that questions can Influence the amount of reading time associated with processing information.

This Iiterature seems open to particular criticism in instructing subjects to attempt to answer the adjunct questions presented. Also, procedures that warn of an impending exam on the reading material may stimulate subjects to process information in a manner that might not otherwise occur with normal reading habits. It seems apparent to this author that both the theoretical and practical utility of question effects on learning would be far more compeliling with a demonstrated Influence on learning in the absence of such instructions and procedures. The use of introductions might cause subjects to process information in a manner that might not otberwise occur in the absence of those instructions; differences in the manner in which subjects 
process information might result in corresponding differences in findings (and conclusions).

Finally, Ladas (1973) criticized Rothkopf (1966), Frase (1967, 1968a) and others for the use of multiple t-tests instead of more conservative post hoc procedures in assessing the significance of incidental learning effects using postquestions. He concluded that Whe magnitude of the facilitating effects of questions on incidental material--1f it does exist--1s probably not largen (p. 81). Yet, the degree of consistency of incidental learning findings using factual postquestions does seem to indicate a reliable effect. As summarized by Faw and Walier (1976), ". .the weight of evidence from numerous studies showing enharced incidental learning, even apart from any statistical analysis, leaves little doubt that a small but reliable effect does exist" (p. 308). More recent support by Reynolds and Anderson (1982) also suggests that the effect is reliable. In conclusion, the literature on factual adjunct question effects suggests that attempting to answer a question after it is asked facilitates learning.

Higher-Level Adjunct Question Effects on Learning

The term higher-level questions is one that has been used to refer to a question that requests more than simply the recall of specific factual material. The term has also been used to refer to the qualitative nature of information processing necessary to generate an answer to a question (Andre, 1979). Qualitative differences in the type of information processing engaged by different questions can be 
conceptualized in a manner simliar to Craik and Lockhart's (1972) levels of processing framework for memory research (see Carrier and Fautsch-Patridge, 1981 for a discussion of this relationship).

The notion of higher-level questions can be traced to Bloom, et. al.'s (1956) taxonomy of questions. These authors classified questions into six categories in increasing order of cognitive complexity and independence of assessment: knowledge, comprehension, application, analysis, synthesis and evaluation. The "lowest" order knowledge questions simply require retrieval of factual information, whereas the "highest" order evaluation questions request a respondent to formulate a self-initiated appraisal of material. As noted by Carrier and Fautsoh-Patridge (1981), however, the classification is orlented to the educational practitioner with overlapping categories that do not lend themselves to operational definitions.

Concern with higher-level questions by educational psychologists was stimulated by the bellef that factual adjunct questions served only trivial educational purposes. Emplrioal investigations of h1gher-level questions have focused on the comprehension of concepts and principles. The theoretical premise 18 that questions influence Individual level cognitive activities and questions that require more elaborate or complex processing will facilitate more meaningful comprebension of presented material (Andre, 1979). As discussed by Hatts and Anderson (1971):

There is reason to belleve that questions which force the student to go beyond the literal content of instruction will faollitate learning. The idea 
is that questions that demand more than verbatim recall will promote deeper processing of the instructional materials. Recent studies suggest that procedures which force subjects to comprehend the meaning of sentences fac1litate sentence learning. . . It 18 reasonable to suppose that questions that require subjects to apply the concepts or prinoiples described in a passage can have simllar effects (p. 387 ).

These authors presented subjects with five passages describing different psyohologioal principles, such as displacement. Each passage was fol lowed by one of three types of adjunct postquestions presented in a multiple-nholce format: 1) "name" postquestions-requesting the name of the psychologist assoclated with the prinoiple 1n the preceding passage; 2) "repeated examplen postquestions-requesting correct identification of an example of a principle presented earlier in the text; 3) "application" postquestions-requesting correct identification of the preceding psychological principle with the correct alternative being different from any example described in the text.

There were two 1llustrations (presented in separate paragraphs) of each principle presented in each passage. One treatment group recelved repeated-example postquestions from the first paragraphs; a second group received repeated-example postquestions from the second paragraphs; a third group recelved application postquestions from the first paragraphs; a fourth group recelved application postquestions from the second paragraphs; a fifth group received name postquestions; a sixth reading-only control group read through the passages but 
recelved no adjunct questions. Subjects were informed that they should be prepared to take an exam on material when finished. The oriterion test was comprised of the 25 adjunct postquestions.

Those exposed to application postquestions had an overall performance superior to all other groups on the oriterion test, particularly on the application questions whether or not those items had been previously seen as adjunct postquestions, Also, the application postquestion groups oqualed the performance of the repeated example and name postquestion groups in faoilitating correct recall of repeated example and name items on the oriterion test. The authors concluded that the use of application postquestions encouraged a more thorough processing of materlal when compared to other types of adjunct postquestions.

Mayer (1975) examined the retention of mathematical concepts as a function of adjunct question position (pre versus post) and question type: 1) "definition" questions-requiring concept definition or conversion of a formula into a sentence; 2) "caloulation" questions-requiring values to be computed using formulas provided in the text; 3) "model" questions--requiring the translation of a problem into a conceptual model. Subjects were warned of an impending exam and the oriterion test included all types of questions. It was found that the group exposed to model questions performed better than all other groups on the criterion test, including a control, although the question position was not significant. These results appear consistent with those of Hatts and Anderson (1971) in demonstrating 
the ut1lity of conceptual application, as opposed to factual/verbatim recall, questions in facilitating overall learning performance.

Rickards and DiVesta (1974) Investigated the effects of factual and meaningful learning" postquestions on the learning and recall of intentional (directly questioned) and incidental (unquestioned) material. Subjects were exposed to elght text segments with each segment comprised of two informationaliy distinct paragraphs. Subjects were not allowed to take notes or turn back to a page once it had been read. Each paragraph contained a topio sentence, identifying the paragraph theme, followed by three subordinate facts. Consider the fol lowing segment:

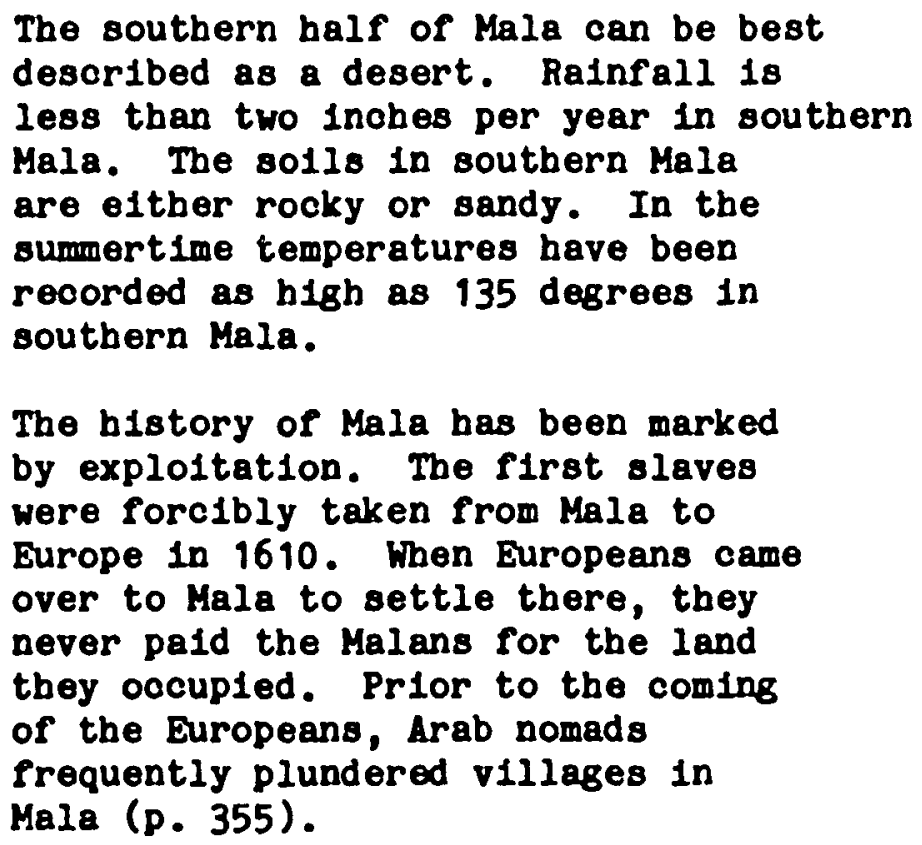

Subjects were exposed to one of three types of postquestions that they were instructed to answer, always directed at the first paragraph of a segment. For the above example, the "rote learning of facts" postquestion asked, "How many inches of rainfall are there per year in 
southern Mala?" The "rote learning of 1dess" postquestion asked: What geographical term best describes southern Mala?" A meaningrul learning" postquestion asked, "Why can it be said that southern Mala is a desert?n (p. 355). As seen, the meaningful learning postquestion required subjects to organize subsumed facts in relation to a textual thome. A "task irrelevant" question, or a question Irrelevant to the passage, was also presented and served as a control. Finally, the frequency of questions was also manlpulated. Subjects recelved elther one question after every two paragraphs of text (frequent condition) or two questions after every four paragraphs of text (infrequent condition). A criterion text examined learning of both questioned and unquestioned material through a free recall procedure.

Results demonstrated that when questions were frequent, meaningful learning questions produced significantly greater total recall than any other question type. When questions were infrequent, however, only rote learning of ideas and facts questions resulted in higher total recall than the control group. When questions appeared frequently, both meaningful learning and rote learning of ideas questions were superior to other question types in facllitating recall of subsumed facts in questioned paragraphs. However, only frequently administered meaningful learning questions were superior to otber question types in facilitating recall of factual information in the unquestioned paragraphs. Similar to Watts and Anderson's (1971) conolusion concerning applioation questions, Rickards and DIVesta argued that meaningful learning questions induced more thorough 
processing" (p. 361) of a passage than other question types. However, the cognitive task requested by these questions requires them to be more frequently rather than less frequently presented to maximize fac1litative erfects.

H1gher-Level Adjunct Question Efrects on Learning: Discussion and Critique

The studies just reviewed indicate that the bigher-level, or conceptual, questions directed at applied or thematic propositions in material are superior to factual type questions in facilitating concept acquisition. Conceptual questions also appear equal to or superior to factual questions in facilitating retention of certain detalls of a message. Conceptual questions seem to evoke more elaborate or extensive processing of presented material, when compared to specific factual questions.

Once again, the studies just reviewed specificaliy instructed subjects to attempt to answer the questions presented. Furthermore, it is unclear whether pre or post conceptual questions will be more effective in facilitating learning. Generalizations concerning question position might also be difficult to make given differences in the nature of the conceptual questions utilized in different experiments. Rickards and Denner (1979) concede that "we are as yet unable to predict which kinds of conceptual questions are likely to function best as prequestions and which as postquestions" (p. 331) and that the answer most likely will depend on what is asked. 
In summary, the literature on higher-level question effects suggests that attempting to answer a conceptual question after it is asked results in learning greater than or equal to the learning which occurs when attempting to answer a factual question. In other words, questions that require a reciplent to do something other than retrieve or acquire a secific plece of factual information may also significantly influence information processing activities affecting learning. This point seems relevant given that questions presented in advertisements are closer in kind to general oonceptual questions than to specific factual questions. For example, advertising questions often request an individual conclusion regarding a product, brand or argument offered in a message. Whether the conceptual types of questions ut1lized in advertisements can facllitate learning in the absence of Instructions to answer the questions or procedures intended to heighten attention to material (e.g., warning of an exam) is an empirioal 18sue.

The Arousal of Curiosity Through Questioning

Two studies were found (one in the fleld of educational psychology and the other in social psychology) demonstrating effects of factual questions on learning apparently without specifically instructing subjects to answer the questions presented or warning of a retention test. These two studies are considered separately here because of the apparent absence of cues directing subject attention to the test material. Both studies postulated a curiosity arousing function of asking questions. 
Bull and Dizney (1973) examined the effects of curlosity-arousing prequestions on long-term retention. These authors defined epistemic curlosity in terms of the degree of conceptual conflict that a question arouses in an individual. Questions were written in accordance with oriteria (see Berlyne, 1962) designed to maximize "the degree of incompatibility of competing response tendencies" (Bull and Dizney, 1973, p. 46). H1gh and low eplstemic curlosity-arousing questions were determined in pro-tests. Judges first rated questions as high or low in ourlosity-arousal utilizing oonceptual conflict criterla. Final disorimination between high and low curlosityarousing questions was determined by asking students, mow much would you l1ke to know the answer to this question?" Fourteen high and low curiosity-arousing questions were finally selected.

Subjects were presented with a passage on educational history. A high epistemic curiosity-arousing question asked, for example: "If teachers are generally viewed as middle class, why was it the Balinese of high caste sent their daughters to be educated?" The equivalent low curfosity-arousing question asked: why did the Balinese send their daughters to be trataed as sohool teachers?" (p. 46). A third group, serving as a control, was instructed to attend to the material and was warned of a retention test. However, note that the two experimental groups were not warned of a retention test. Retention was assessed one week later using a 36-1tem multiple cholce test on questioned and unquestioned material. 
Although the overall treatment effect was not significant $(p>0.05)$, the means were in the expected direction and planned comparisons were performed on a priorl grounds. Only the high epistemlc curlosity- arousing group was found to bave significantly ( $p<0.05)$ higher total passage retention than the group specificaliy instructed to attend to the material. These results seem especially suggestive given the nature of the control group used for comparison purposes, as well as the fact that retention was measured one week after stimulus exposure. Bull and Dizney concluded that the form or nature of a prequestion has an impact on facilitating learning and retention and that curiosity-arousal through the presentation of questions 18 one means by which learning can occur.

Z11 lman and Cantor (1973) examined the effects of rhetorical prequestions versus declarative statements with identical content on recall of (apparently directly questioned) message material. Message distraction was a 180 manipulated through the use of an interfering message which was played slmultaneously with the target message. Subjects exposed to the question condition heard a rhetorical question Immediately followed by the answer to the question: "And how did we learn about the fighting? We saw burned villages from our plane when we first toured the area Inhabited by the Quepo." Subjects exposed to the statement condition heard a content equivalent version of the question and answer in a declarative form: "And we learned about the fighting when we saw burned villages from our plane when we first toured the area inhabited by the Quepo" (p. 1974). The criterion test 
was comprised of questions worded dissimilarly from the previous rhetorical questions.

Rhetorioal questions were found to faollitate greater message recall only under conditions of message distraction. The authors concluded that questions may only facilitate learning in situations where a high level of attention to material 18 reduced. This conclusion is not inconsistent with Andre's (1979) suggestion that questions wil I have maximum impact on learning performance under conditions of low subject motivation to process material.

Z11 Iman and Cantor conducted a replication of their first study to examine whether the findings would be generalizable to an ordinary reception condition without the artificiality of the distraction manipulation. In this second experiment, high levels of attention to material were reduced through the induotion of boredom. This condition was operationalized through first exposing subjects to 20 minutes of uninteresting speeches and then introducing the target speech on a fictitious Philippine tribe. Recall results replicated the previous findings for the message distraction condition.

Zillman and cantor judged their findings to support the speculation that, "the effectiveness of questions 18 based on a curiosity-inducing or attention-eliciting mechanismn (p. 176). Although that conclusion seems reasonable, it must be noted that the curiosity construct cited by ziliman and cantor was not operationalized as it was in Bull and Dizney's study. Nevertheless, the above two studies do provide support for the position that 
prequestions, at least, can stimulate learning even (apparently) without specific instructions to answer the questions or warning of a retention test. In order for that effect to occur, these studies sugsest that a question must arouse reciplent ouriosity, or otherwise stimulate question relevant "thinking," to a greater extent than the group utilized for comparison purposes. What is unolear is whether postquestions without speoific instructions to answer the questions or retention test warnings can also facliltate learning. However, there seems no reason to conclude that the previousiy cited cognitive review explanation of postquestion effects, for example, is only relevant to circumstances with instructions to answer questions.

\section{Question Effects on Attitude and Belief Formation}

The previous studies reviewed were exclusively concerned with the effects of asking and answering questions on learning. Th1s section w1l review Investigations of the effects of asking questions on attitude and belief formation.

Z11 Iman (1972) examined the effects of rhetorfoal postquestions versus content Identical statements on bellef formation under differential conditions of initial attitude towards a target person. A mock jury trial of a juventle charged with second degree murder served as the experimental context. Subjects were provided with preliminary information which manipulatod initial attitude (favorable, unfavorable, neutral) towards the defendant. Subjects were then exposed to a tape recorded summation of the defense attorney with each of ten arguments ending with either a rhetorical question designed to 
el1cit audience agreement (e.g., "But did he ever use his knife as a weapon before?") or a declarative statement (e.g., "But he never used his knife as a weapon before."). Subjects then recommended a prison sentence for the defendant, which served as the critical dependent varlable.

2illman found that subjects exposed to rhetorlcal postquestions recommended a shorter average prison sentence than subjects exposed to declarative statements, although a statistically significant effect emerged only for subjects with an unfavorable initial attitude towards the defendant. Zillman argued that rhetorioal agreement questions are typicaliy paired with strong arguments in soolal discourse. Therefore, the persuasive effect of rhetorioal questions relative to declarative statements can be explained by associative conditioning, where the use of such questions is percelved as marking strong arguments.

Z1llman and Cantor (1974) manipulated the same variables and ut1lized the same materials as 2111 man (1972). However, changes were made in the trial transcripts to make the crime more ambiguous and the arguments less decisive. Also, Z111man and Cantor utilized rhetorical postquestions designed to eliolt audience concession (es., "How could he have protected his sister without threatening his father with some weapon?") versus declarative statements (e.B., "He could not have protected his sister without threatening his father with some weapon."). Subjects recommended prison sentence was again the oritical dependent variable. 
These authors found that under conditions of an initialiy favorable attitude towards the defendant, subjects exposed to rhetorioal questions recommended a significantly shorter prison sentence than subjects exposed to statements. However, under conditions of an initially unfavorable attitude, subjects exposed to questions recommended a significantly longer prison sentence than those exposed to statements.

Zillman and Cantor maintained that the mechanisms underlying the rhetorical elicitation of agreement and concession differ. With rhetorical concession questions, attention is directed towards weak or deficlent counterarguments. The authors contended than an increased awareness of lne arguments involved nfacilitates acceptance in those Individuals who hold attitudes compatible with the proposal, but leads to stronger rejection rather than facilitated acceptance in those who Inftially oppose the proposaln (p. 235). Th1s explanation was presented in oontrast to rhetorical agreement questions where, as noted above, persuasive effeots were attributed to associated conditioning.

In reviewing the zill wan (1972) findings, Petty, Cacloppo and Heesacker (1981) argued that a cognitive response interpretation of the rhetorical question effects may be more accurate than the conditioning bypothesis offered by ziliman. According to the cognitive response view, the use of rhetorlcal quest1ons, either agreement or concession, should enhance thinking about the oontent of a message and result in either enhanced or reduced persuasion 
depending on the strength or weakness of the arguments presented. The authors further bypotbesized that enhanced thinking effects would most likely occur under conditions of low involvement, when individuals are not naturally processing information in a message. Onder conditions of high involvement, however, when a message naturaliy elicits a great deal of thought, the use of rhetorical questions may distract an Individual from thinking resulting in effects opposite those for low involvement. It should be noted, however, that no clear explanation was offered concerning why distraction should be expected with questioning under high involvement conditions.

A four-minute taped communication advocating that undergraduates be required to take a senior comprehensive exam in their major area of study prior to graduation was used as the experimental message. Subjects were asked to evaluate the message. High involvement was manipulated by an introduction informing subjects that the message was concerned with recent academic revisions recommended for their university for the next academic year. Low 1s8ue Involvement was manipulated by informing subjects the message concerned academic revisions at a distant university that would begin in ten years.

The message contained eight major arguments. The strong arguments presented were "logically strong, defensible and compelling" while the weak arguments were "open to skepticism and easy refutation" (p. 435). Each of the major arguments were then summarized with a rhetorical postquestion (e.8., "Wouldn't instituting a comprebensive exam be an aid to those who seek admission to graduate and 
professional schools?n) or a declarative statement (e.8., "Thus, instituting a comprebensive exam would be an ald to those who seek admission to graduate and professional schools."). No argument was made concerning whether the questions were "agreement" or "concession" In terms of Z11lman's usage. The dependent measures assessed attitude towards the comprehensive exam, message top 1c cognitive responses (thoughts: favorable, unfavorable, neutral) and recall of the message arguments.

Support for the hypothesis was reported. Under low involvement conditions, the difference in means (for attitude, favorable and unfavorable thoughts) between the strong and weak rhetorical conditions was larger than the difference in means between the strong and weak statement conditions. Under high involvement conditions a reversal ocourred. The difference in means (for attitude and unfavorable thoughts) between the strong and weak rhetorical conditions s:as found to be smaller than the difference in means between the strong and weak statement conditions. The reasoning behind both sets of contrasts (for high and low involvement) was that greater differentiation between strong and weak messages is indicative of message processing. 5 Z11lman's conditioning hypothesis was rejected since it does not predict differentiation of persuasive effeots as a funotion of argument strength. The conditioning hypothesis would have predicted increased persuasion when using

5personal communication. Richard Petty, May 6, 1985. 
questions for both strong and weak argument messages, but opposite results were found. Analysis of the recall data revealed no meaningful effects of questioning on message learning. It was specificaliy noted that "there was no tendency for the use of rbetorical questions to increase message learning as has been suggested in previous research" (p. 437), such as Z11lman and Cantor's (1973) study.

The authors concluded that rhetorical questions can be most effectively used in facilitating persuasion in low involvement situations when individuals have a low motivation to think about the content of the message. The authors argued that under such conditions the use of rhetorical questions enhances thinking, resulting in an increase in the amount of message topic elaboration that occurs. It was further maintalned that the cognitive response view of rhetorical question effects can account for the 211 lman and Cantor (1974) findings. As previously noted, the circumstances of the crime were made more ambiguous and the arguments less decisive in that study in comparison to the Ziliman (1972) message. Witb a more ambiguous message (1.e., a message that neither strongly supports nor refutes a position), Petty, Cacioppo and Heesacker maintained that a manipulation that enhances thought, such as rbetorical questions, would likely enhance thought in the direction of subjects' initial att1tude towards the defendant:

Thus, when presented with an ambiguous message, favorable subjects would Iikely become more favorable with more thought, and unfavorable subjects 
would likely become less ravorable with more thought (p. 434).

This cognitive response interpretation 18 consistent with what Z1 I I man and Cantor (1974) found. However, it should be noted that Swasy and Munoh (1985) attempted a replication of Petty, Cacioppo and Heesacker using the same materials, medium, manipulations and question/statement position. These authors falled to find any of the three-way interactions reported by Petty, Cacioppo and Heesacker for attitude, positive or negative oognitive response measures.

A signifioant two-way interaction between grammatical form and argument quality was seen where rhetorical questions "increased" attitude for strong arguments but "decreasedn attitude for weak arguments. However, that interpretation was made in the absence of any cell comparisons. A marginaliy significant $(p=0.10)$ similar Interaction was reported for source derogation cognitive responses, where rhetoricals inoreased source derogations "slightly" for strong messages but ndramatically" for weak messages. That interpretation was again made without support of any cell comparisons. I marginally olgniflcant ( $p=0.08)$ three-way interaction was reported for speaker pressuring. Under low involvement, rhetorloals Increased speaker pressuring "slightly" for strong arguments but ncreated a large Increasen for weak arguments. Trends were reversed for high Involvement. Once again, no cell comparisons were reported to support the interpreted findings. Finaliy, a non-significant $(p=0.15)$ threeway interaction was reported on attitude towards the speaker where "the pattern of cell means reflects the three-way interaction for 
pressure already described" (pp. 882-883) and where no cell oomparisons were performed. On the basis of these findings, the autbors concluded that rhetorical effects in low involvement conditions are due to polarization of subject responses to speaker style. That conclusion, however, appears to lack clear support from the data presented. Aside from some obvious concerns with the statistical interpretation of results in the Swasy and Munoh study, the findings are presented here given that the current investigation w11 also examine the effects of questions under "Iow involvementn conditions on ratings of a speaker in an audlotaped medium.

Burnkrant and Boward (1984) examined the effects of introductory questions versus statements on attitude and cognitive response measures. The same variables were manipulated, using the same methods, as in the Petty, Cacioppo and Heesacker study. The same message was also presented, but using print ratber than an audiotaped medium. It was suggested that the motivational effects of questions on Information processing may emerge most clearly when presented before an argument ratber than after an argument. Question Introductions can be used to raise doubt and conflict in a reoipient rogarding an 18sue, which may stimulate the amount of cognitive effort expended when processing a subsequent argument. statement Introductions, however, may actualiy distract an individual from intensive processing of message content by providing the conclusion of an argument to follow:

An introduction that poses questions to be answered in the body of a message 
(e.B., "W1ll comprehensive exams help students get ahead after graduation?") Th1s should motivate the reader to process the message more intensively to answer questions ralsed in the introduction. In oontrast to rhetorioal questions, statements typloally provide information by asserting a conclusion (e.8., "Comprehensive exams will belp students get ahead after graduation.") By stating the oonclusion, statement introductions provide more information than questions.....Providing information would be likely to reduce uncertainty and as a result, it would not be likely to motivate information processing to the same extent likely when questions are provided (p. 1120).

Burnkrant and Boward maintalned that the motivational consequences of prequestions should be reflected in the total number of cognitive responses (thoughts) subjects generate with respeot to a message topic, with total thoughts being indicative of the amount of cognitive elaboration engaged in when processing arguments. Question effects on persuasion similar to Petty, Cacioppo and Heesacker's were anticipated under low Involvement conditions. However, the use of prequestions was not logically expectod to result in distraction from information processing under high involvement conditions given that the questions would be processed prior to message arguments.

Findings were generally consistent with expectations. The use of prequestions resulted in subjects generating a significantly greater total number of message topic cognitive responses when compared to subjects recelving statement introductions. The increase in total thoughts was significantly greater under low involvement conditions but not under high involvement conditions, although the means were in 
the expected direction. These results indlcated that the use of prequestions did not distract subjects from thinking about the message, although a ncelling effect" (1.e., a limit) on total elaboration may have occurred.

It was also seen that prequestions resulted in more favorable thoughts and a more favorable attitude than statements when strong arguments were used, and more unfavorable thoughts and a less favorable att1tude than statements when weak arguments were usod. These findings also appeared indicative of the motivational imact of questions on information processing since thinking about a message has been shown to produce simllar effects (Tesser, 1978; Tesser and Leone, 1977). The functional form of the question/statement $X$ strong/weak arguments interaction did not change over levels of the involvement varlable. Again, no evidence was found supporting the distracting effect of questions under high involvement conditions. However, consistent with Petty, Cacioppo and Heesacker's findings, Z1Ilman's conditioning hypotbesis was rejected since questions increased persuasion relative to statements only when strong arguments were used. Under the conditioning hypothesis, more persuasion would be anticipated with questions than with statements whether the arguments were strong or weak. Evaluations of the writer of the message were found to have no determining effects on the results. It was concluded that questions may have affective consequences on the evaluation of a message topio by stimulating the amount of cognitive effort expended when processing information. 
Question Effects on Attitude and Bel1ef Format1on: Discussion and Critique

The studies just reviewed provide support for the position that questions can be used to influence attitude or belief formation on a position advocated in a message. One synthesized explanation for this phenomenon is that questions may influence individual level processing activities by stimulating the level of cognitive effort devoted to integrating presented material.

Simliar to previous discussions of the learning literature, it is unclear whether a pre or postquestion is superior in influencing information processing. Using the same materials but with questions In different positions both Petty, Cacloppo and Heesacker and Burnkrant and Howard found favorable effects of questions on attitude formation under low involvement conditions. Although Burnkrant and Howard's high involvement findings were different from Petty, Cacioppo and Heesacker's, it should be noted that the latter authors do not really explain how (or why) exposing Individuals to postquestions on a personally relevant message results in distracting them from thinking. Burnkrant and Howard's "celling effect" explanation of prequestioning under high involvement conditions appears more plausible. In any case, the apparent indication is that favorable question effects on attitude formation are more evident in low involvement conditions. Swasy and Munch also reported results consistent with this conclusion, al though their findings lack statistical support.

An unanswered issue is whether combined pre and postquestions can have an additive impact on attitude formation. Theoretically, there 
seems to be no olear reason not to expect such an effect. Prequestions, for example, may stimulate inoreased attention to following material, while postquestions may result in a cognitive review of what was presented. A simllar finding was earlier reviewed for factual adjunct question effects on learning. Whether such an effect can be replioated without the use of instructions to answer the questions is an empirical 1ssue. Concerning attitude formation, it is possible that a celling effect might obscure any additive offects of pre and postquestions on message topic evaluation. Whether or not that limit is exceeded using combined pre and postquestions is an empirical 1ssue.

From an information processing perspective, a difficulty emerges with the explanation for the question-affeot relationship discussed by Petty, Cacloppo and Heesacker. These authors suggested that questions operate to "enhance thinking." Petty, Cac1oppo and Heesacker presented their message and questions using a taped broadoast. What is unclear is how questions could bave enhanced thinking about the meaning or implications of an argument when opportunity was not provided to engage in that thinking with reference to the relevant question presented. In other words, the authors utilized postquestions with no appreciable interval of time belween the presenting of a postquestion on a preceding argument and the 
beginning of a subsequent argument. 6 From an information processing perspective, it oannot be assumed that enhanced thinking concerning an argument given a relevant question is an instantaneous event. Clearly, questions require at least some amount of time to answer and the literature previously reviewed suggests that questions may result In an Inorease in processing time associated with information. Again, as noted in Chapter I, Wright (1974) suggests that warousal to process and opportunity to process" should be considered theoretically separate variables (p. 194). What needs to be examined 1s whether added time to process presented information maximizes the effectiveness of postquestion use.

Note that this $18 s u$ was not a concern with Burnkrant and Boward's study since a print message was utilized and rate of Information transmission was within the recolver's control. Furthermore, opportunity to process would seem to be less of a concern with prequestions, as opposed to postquestions. When a broadcast prequestion is utilized, a recipient has the opportunity to evaluate, analyze, or otherwise "think" about the content of an argument with reference to a question as the information 18 being presented and processed. When a broadcast postquestion is ut1lized, however, that opportunity appears lacking when the content of a further argument

6 Ne1ther Petty, Cacloppo and Heesacker, Z11lman, nor Swasy and Munch raised the issue of the time interval between questions and message text. It is therefore assumed that the pace and spacing of the questions were not treated any differently than other parts of the message. 
immediately follows a question concerning the preceding argument. Even given a limited ability of subjects to simultaneously comprahend the content of a further argument while considering the implications of a question on a previous argument, one would st1ll expect that desired outcomes would be facilitated by maximizing the ability to process questions on one argument without having to attend to additional information. This conclusion seems to logically follow from the notion of Iimited information processing capabilities in Ind1viduals (see Bettman, 1979).

\section{Communioative S1lence}

Although the use of silence as a communicative tool is not a new 1dea, empirical investigations of silence are limited both in number and in scope. Bruneau (1973) notes that "a major misconception preventing intellectual focus on silence is the common basic assumption that silence is completely other than speech, 1ts forelgn opposite, its antagonist" (p. 18). Within a communicative encounter many forms of silence can oocur. Bruneau defines interactive silences as "pausal interruptions" in a communicative exchange that allows a participant to make minferences and judgments about the many possible meanings of a messagen (p. 29). Recognizing this, an advertiser may decide that broadcasting time can be most effectively used by providing recipients with the opportunity to reflect on the arguments presented in a message. Dillon (1982b) notes that: "The Interviewer's use of slience is sald to assist the respondent to express an 1dea, to make inferences and judgments. . . The 
therapist's silence is held to facilitate the patient's communication, to elicit rurtber attitudes and to help the taciturn to verbalizen ( $p$. 141). The advertiser's use of silence in broadcasting may similarly facilitate the meaningful evaluation of a message by a recipient. Th1s may be especialiy true given the dense environment and constant barrage of advertising messages that a recipient is exposed to on a da1ly basis.

As previousiy noted, advertising textbooks suggest that questions can be effeotive tools serving as "attention-getting" devices. Bruneau suggests that silence in itself can serve as an attentiongetter. The use of both techniques in confunction with one another may have complementary benefits. Only one study could be looated examining the effects of silence after questioning on cognitive processes. Rowe (1974) compared the effects of one second versus three- to flve-second Intervals of silence after teacher questioning on a variety of student outcome variables. It was found that increased silence was associated with Increases in the number and length of student responses, as well as increases in speculative and inferential thinking. 7 These results suggest that increases in the amount of time to consider or answer questions before presenting

7 One potential problem is that Rowe's study was conducted in a classroom setting where students likely percelved that they were expected to respond to teacher questions. The present investigation will be conducted in a manner to avold such an expectation. Furthermore, the present investigation will examine the effects of silence after questioning on message learning, which was not measured, and persuasion, which was not an issue of concern in Rowe's study. 
additional material may facilitate desired outoomes. This is consistent with the reasoning of Kenyon and Eckhardt, the developers of the Chrysler ad discussed in Chapter 1. However, the impact of varying amounts of time provided after questioning has not yet been empirically addressed in advertising. Th1s study will examine that 1ssue.

\section{A Cognitive Effort Perspective on Quest1on Effects}

It should be noted that related explanations have been offered for the effects of questions on learning and attitude formation. The education literature suggests that questions may facilitate the cognitive review of previously presented information or set the occasion for further cognitive processing of material, affecting learning. Britton, et al. (1978) and Reynolds and Anderson (1982) seemed to more precisely define this phenomenon by providing evidence that answering questions influences the amount of cognitive effort expended in processing text as measured by the secondary task technique. Reynolds and Anderson (1982) also showed that increases in cognitive effort paralleled increases in learning. Burnkrant and Howard (1984) provided evidence that exposure to questions influenced the amount of cognitive effort expended in processing text, as measured by total cognitive responses, with parallel effects on attitude formation.

Burnkrant and Sawyer (1983) discuss the facilitative effects of processing intensity, or cognitive effort, on botb learning and attitude formation. In terms of recipient evaluation of a message it 
1s suggested that:

Processing intensity should determine the extent to which the reoeiver responds cognitively to the material, evaluating it in terms of what he/she already belleves. It should determine the extent to which arguments and their Implioations are grasped by the receiver and combined with other bellefs on the topio in long-term memory (p. 59).

In other words, variables which influence cognitive processing effort may have affeotive consequences at least partially determined by a more complete integration of the meaning of message arguments within an Individual's cognitive belief syotem. This explanation of the potential affective consequences of increased cognitive processing effort is also consistent with Ausubel's (1963) notion of nintegrative reconciliation" in learning. Ausubel suggested that in order for meaningful learning to occur, newly acquired material must be blended, or integrated, with existing cognitive structures established from previously learned ideas.

It appears, then, that questions may potentialiy influence both learning and affect by having a determining influence on the manner in which Information 18 processed. Questions can be expected to result in an increase in the extent of thinking that ocours with respoct to the target of an interrogative request. Bery ine (1960) indicates that questions are a clear example of motivational or drive-inducing stimulin which initiate cue (target event) related thinking (p. 289 ). He further suggests that uncertainty and conflict are implicit within questions and that if one's answer to a question posed is not known to 
be correct, a type of conceptual confliot, known as doubt oonflict, w1ll arise. Doubt conflict involves a tendency to believe and disbelieve the same thing. On the most fundamental level, Berylne suggests it is the nature of conoeptual conflict which initiates and guides thinking. However, the present investigation will not be concerned with causal dynamics between thinking and doubt, although both constructs will be examined as factors underlying effective question use. Also, this investigation will examine a conceptualization of doube defined as being $*$. . Inclined not to belleve or accept. . to consider unlikely or Improbablen (Webster's Third New International Dictionary). This study will use questions to direct an arousal of doubt in reciplent bel1efs, specificaliy with respect to beliefs in vitamin related leeds, with effects of question use also anticipatad on the extent of thinking concerning the object of questioning (1.e., supplemental vitamins). sssuming that questions are successful at stimulating thinking about vitaming and arousing uncertainty in beliefs concerning whether one's vitamin supply is adequate, the 1ssue of effects on behavior must be addressed. This study w11l not address behavior per se, although behavioral intentions concerning purchasing supplemental vitamins will be examined. In this Investigation, questions are expected to influence (Increase) behavioral intentions for the following reasons: 1) the message arguments advocating supplemental vitaming will be strong and favorable; 2) questions will stimulate thinking about vitamins and arouse uncertainty concerning whether additional vitamins are 
necessary to maintain good health; 3) the product (1.e., supplemental vitamins) has the ability to alleviate that uncertainty. In otber words, since consuming supplemental vitamins would eliminate any doubt over whether one's balance of vitamins 18 adequate, an increased likelihood of purchasing vitamins seems rational.

Finaliy, it should be recognized that it is unolear under which conditions a correspondence between learning and affective change may be found and under which conditions a relative Independence of effects will ocour. In other words, even when a given treatment is expected to influence both learning and affect, it has often been seen that the measures do not behave similarly. The literature examining the relationship between measures of retention (recognition and recall) and attitude formation has provided inconsistent results. The majority of studies have elther found a weak or a statistioaliy nonsignificant relationship between measures of message retention and attitude formation or change (Greenwald, 1968; Oserhouse and Brock, 1970; Keat1ng and Brock, 1974; Petty, Cac1oppo and Heesacker, 1981; Petty and Cac1oppo, 1979; Cac1oppo and Petty, 1979; Petty, Cac1oppo and Schuman, 1983; Hark1ns and Petty, 1981; Anderson and Hubert, 1963; M1llman, 1968; Zimbardo and Ebbesen, 1970; Bov land and We188, 1951; Thist lewaite deHann and Kamentzky, 1955). However, numerous otber studies have produced evidence of a significant relationship between message retention and attitude measures (Haaland and Venkatesan, 1968; Romer, 1979; Reyes, Thompson and Bower, 1980; Eagly, 1974; McGuire, 1957; M1ller and Campbel 1, 1959; Chalken and Eagly, 1976; Eagly and 
Warren, 1976). Additional studies have produced either inconsistent or qualified support for the attitude-learning relationship, further contributing to the controversy (Insko, 1964; Lind and LaTour, 1976; Insko, Turnbull and Yandel1, 1974; Watts and McGuire, 1964; Loken and Hoverstad, 1984; Baumgardner, et al., 1983). Eagly and Chalken (1985) note that "the absence of consistent covariation between retention of message content and persuasion has been interpreted by many investigators as proving that reception is unimportant in attitude change..." (p. 10). Such a conolusion may be premature; indeed, Eagly and Chaiken suggest that the conclusion is probably wrong. Rather, the absence of consistent covariation between message content retention and persuasion may instead indicate that the measures are related under certain conditions but not under other conditions. What those conditions are, however, remains to be determined, inoluding any role that question effects may have. It is not the intent of this investigation to resolve this controversy. The only position taken here is that there are common theoretical grounds for anticipating effects of questions on both learning and attitude formation or change.

\section{Research Implications}

Past research suggests that it may be possible to utilize questions in conjunotion with an advertising message to facilitate learning of that message and favorable evaluation of the product advocated. To maximize the potential for favorable message topic evaluation, the message arguments associated with questioning must be strong and favorable. The theoretical position to be assumed is that 
questions can affect arousal to process through arousing uncertainty and stimulating thinking with a corresponding inorease in the amount of cognitive effort expended when considering the information provided In message. However, arousal to process must be coupled with an opportunity to process information to maximize question effeotiveness in fac1litating desired outcomes.

The prior literature review has identified three variables of primary concern that will be examined here: grammatical form (quastion versus statement), position (pre versus post versus comblned) and communicative sllence, or time delay (yes versus no). Formal hypotheses are presented in Chapter III, but the general form of relationships expected is as follows: Prequestions are expected to be superior to prestatements in producing desired outcomes (e.B., message learning and persuasion), whether or not an interval of silence is provided between different message arguments. This should be true since with prequestions individuals have the opportunity to grasp and Integrate the implications of a question with respect to its relevant argument as the argument is beling presented. However, maximum effects of postquestions on desired outcomes are expected to require an interval of silence between different message arguments (1.e., between a given argument--question pair and the start of the following text). This should be true since the interval of silence should Inorease the opportunity to process postquestions with respect to their following arguments before the presentation of additional information. Combined effects of questions (1.e., use of both a 
prequestion and a postquestion for each message argument) are expected to follow as logical extensions of this framework. The context in which these expectations will be examined is a professionally arranged rad10 show, w1th an inserted supplemental vitamin ad as the target message.

One expected value of this investigation is marked by the prevalence of use of question advertisements in practice (see Chapter I) without empirical support for the belief that questions are indeed more effective than a content equivalent alternative in producing desired outcomes. This study will provide some evidence concerning that belief. Specifically, this study should represent a comprebensive and controlled examination of question effects on botb learning and persuasion in advertising, where such studies are presently lacking. The contribution of this study should include evidence concerning not only whether a certain type of question can be effeotive in facilitating learning and persuasion, but where in an advertising message the question might be most effectively used. Evidence will also be provided concerning whether variation in time to answer given questions affects outcomes. Furthermore, this investigation w1Il allow the testing of theoretical positions on why the use of questions In advertising should be effective. 
CHAPTER III

RESEARCH HYPOTHESES

\section{Overview of Expeotations}

Formal hypotheses are offered for three independent varlables in this investigation: grammatical form (question versus statement); position (pre message versus post message versus combined); and the use of a time delay between message arguments (yes versus no). Each of the following hypotheses involves an expected three-way interaction among these independent variables. Overall, the magnitude of question superiority over statements is expected to depend on position and time delay. Prequestions are expected to be superior to prestatements whether or not a time delay is provided. However, postquestion superiority over poststatements is expected to vary as a function of the time delay provided. Hypothesized effects for combined questions (1.e., questions both before and after each argument) will be seen to follow logically from this general framework.

To fully appreclate the rationale underlying the expected form of the three-way interaction it is 1mportant to note that the time delay variable will be used after each message argument in the supplemental vitamin ad and after the associated question/statement when it appears In the post position. In other words, the time delay variable will 
never be used between a question/statement and its sssociated argument. Time delay 18 only expected to have an impact when used with questions in the post position. Consider the following sequence of events for prequestions: 1) question; 2) argument; 3) time delay. Now, consider the fol lowing sequence of events for postquestions: 1) argument; 2) question; 3) time delay. Finally, consider the same sequence of events for oombined questions: 1) question; 2) argument; 3) question; 4) time delay. Since in the prequestion condition the person has the opportunity to evaluate the implications of a question with respect to 1 ts associated argument as the argument is being presented, the time delay variable is not expected to supplement favorable outcomes. However, in the postquestion condition, rectplents will not have a chance to fulig evaluate the Implications of a question witb respect to its associated argument since the argument is presented before the question. Furthermore, additional arguments or messages will follow eacb question. Therefore, the use of an interval of silence after a question in the post position should contribute to the processing of the request with respect to the $18 s u e s$ implied. As previously noted, research has been conducted demonstrating postquestion effectiveness without explicitiy considering a time delay variable (e.g., Petty, Cacloppo and Heesacker, 1981; Zillman, 1972). Therefore, what will be hypothesized is that postquestion effectiveness should be maximized by providing a time delay. Hypothesized combined question effects will follow from this general framework. The reader might refer to Figures 1 and 2 

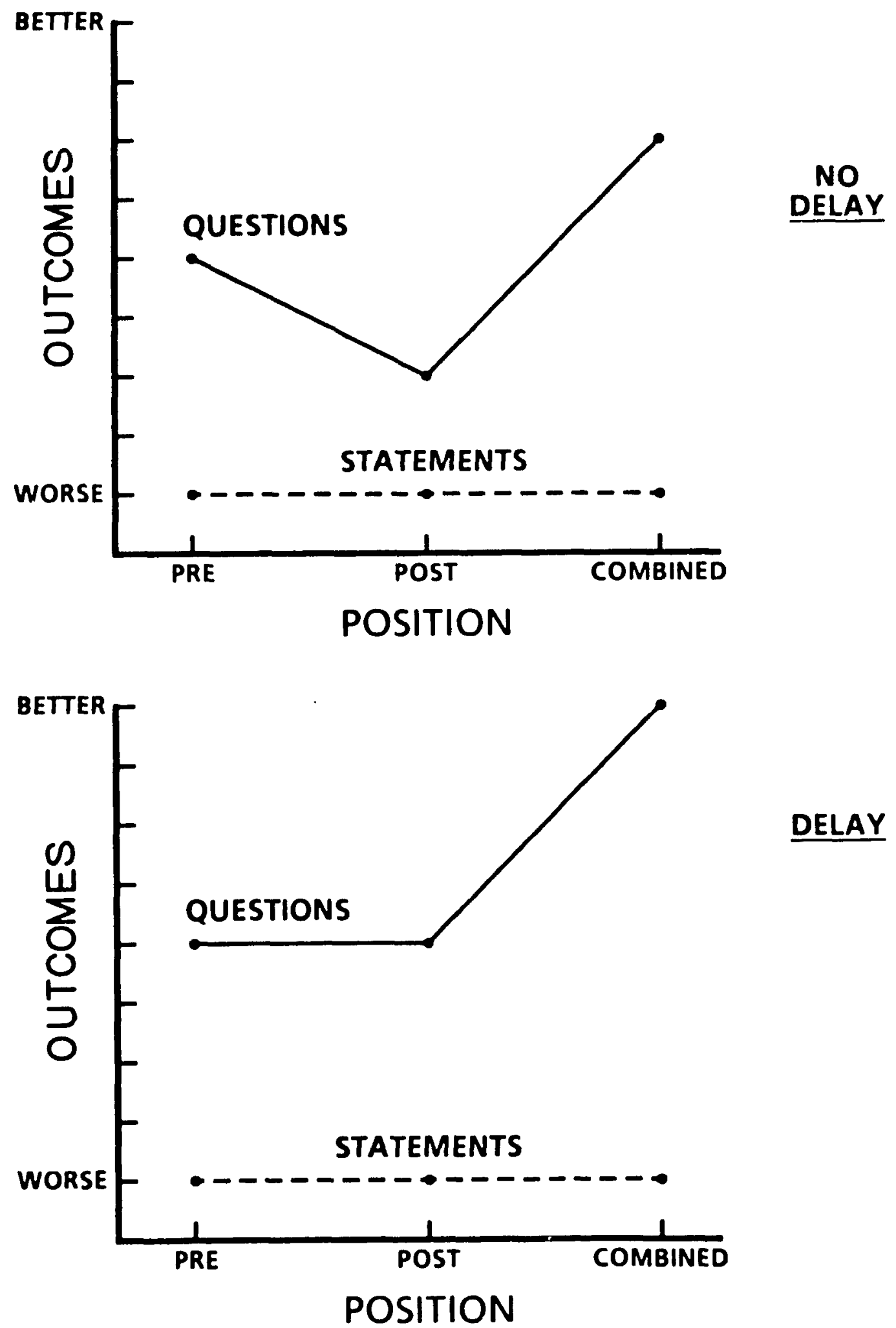

DELAY

Figure 1

Hypothesized Interaction Between Grammatical Form, Position and Time Delay: Overview 


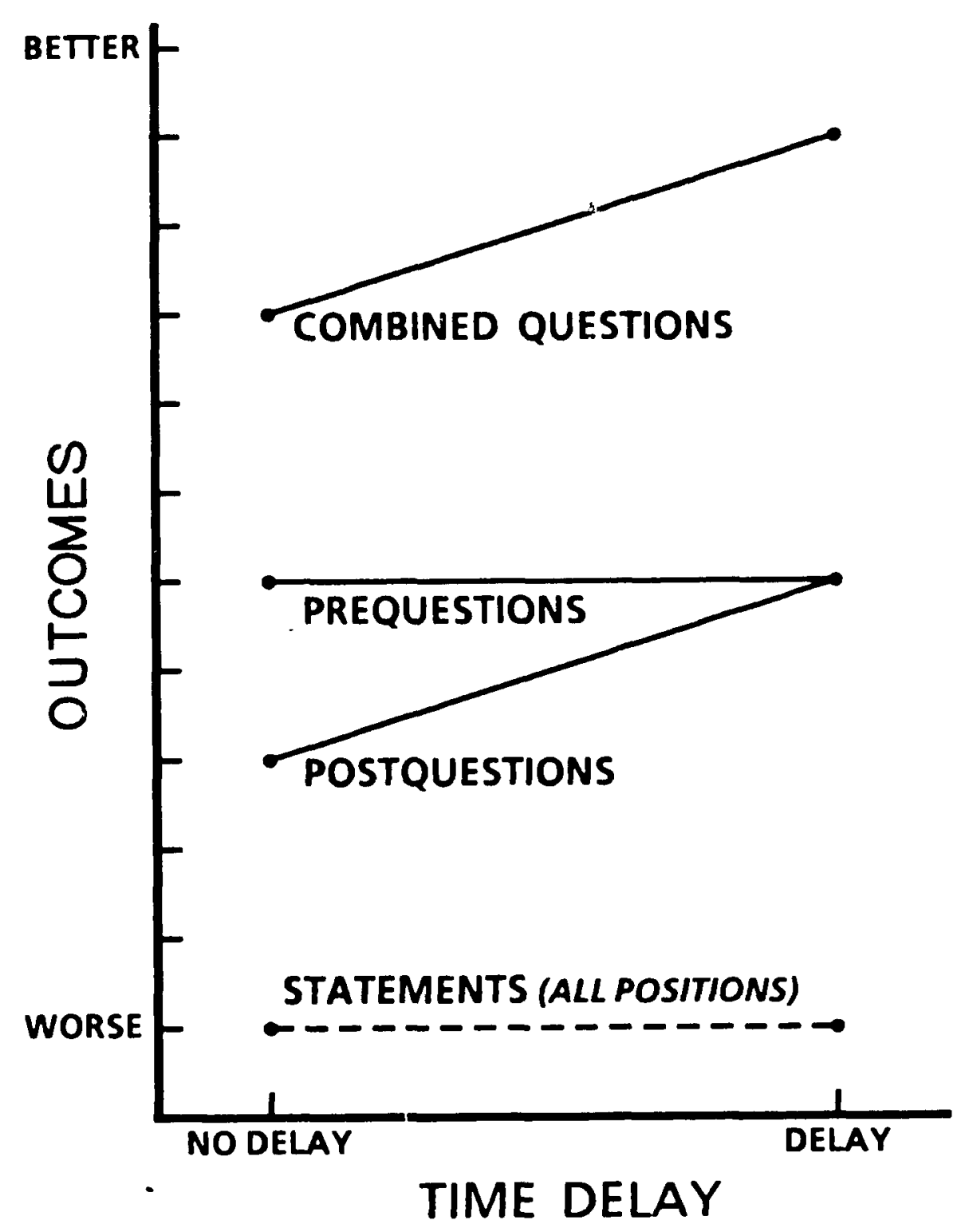

Figure 2

Hypothesized Interaction Between Grammatical Form, Position and Time Delay: Positional Question Effects As A Function of Time Delay 
when considering the bypotheses to be presented. Please note, however, that those figures are presented as descriptive guides to the following bypotheses (1.e., the distances do not reflect known quantities).

It is a 180 important to note that the separate hypotheses to be presented here state expected differences involving specific cell comparisons. The directional effect of each of these cell comparisons can be observed in Figures 1 and 2. Those figures should only be used to make reference to the hypothesized cell comparisons: No other statisticaliy significant cell comparisons are being implied. For the dependent measures, message learning was measured by free recall and corrected recognition scores (to be discussed). Product evaluation was measured by an attitude index, the sum of positive message topic thoughts, the sum of negat1ve message topic thoughts, and by an Item measuring intentions to purchase supplemental vitamins. Beliefs were measured by the sum of reciplent ratings of thelr current state of vitamin adequacy. This belief index w1ll be an operational measure of reciplent "doubt" ooncerning their current state of vitamin adequacy. The extent of message topic thinking was measured by the total number (positive, negative and neutral) of message topic thoughts, and also by an item reflecting the level of recipient thinking about supplemental vitamins resulting from ad exposure. The operationalization of these measures w1Il be discussed later. (See Chapter IV: Dependent Variable Measurements.) 


\section{HYPOTHESES}

Hypothesis I: Prequestions will result in Breater message learning, more favorable product evaluation and beliefs and more extensive message topic thinking than prestatements whether or not a time delay between message arguments is provided.

The use of a time delay after an argument whon prequestions are used is expected not to have an effect on outcomes. When prequestions are used an individual has the opportunity to evaluate and analyze an argument with reference to a question as the argument is being presented. An interval of time provided after the argument 18 presented should not be required to complete any critical aspect of message processing. Therefore, the superiority of prequestions over prestatements 18 hypothesized whether or not a time delay between message arguments 18 provided.

Hypothes1s II: Postquestions will result in greater message learning, more favorable product evaluation and bellefs, and more extensive message topic thinking than poststatements whether or not a time delay between message arguments 18 provided. However, the magnitude of the difference between postquestions and poststatements when a time delay 18 provided will be greater than when a time delay is not provided.

Questions are expected to be superior to statements in the postmessage position when a time delay is provided after the argument-question presentations. This should allow reciplents to evaluate and cognitively review the arguments and their loplications with reference to the questions posed. However, as previously noted, past research has demonstrated that postquestions without a time delay can be more effective than poststatements in influencing attitude and belief 
formation (Z111man, 1972; Z11lman and Cantor, 1974; Petty, Cacioppo and Heesacker, 1981). Therefore, a simflar finding 1s expected here. A critical 1ssue, however, concerns the expected difference between the delay and no delay conditions: the magnitude of the variation between postquestions and poststatements when a time delay is provided is expected to be greater than when a time delay is not provided. In other words, a significant departure from parallelism is expected for question versus statement differences as a function of time delay for the post condition. The maximization of postquestion effectiveness is expected to depend on the use of a time delay after questioning. An inoresse in postquestion effectiveness when a time delay is provided, when compared to when a time delay is not provided, is necessary support for the second hypothesis. This expectation is graphed in Figure 2.

Hypothes1s III: Combined pre and postquestions will result in greater message learning, more favorable product evaluation and beliefs and more extensive message topic thinking than the use of prequestions or postquestions a lone whether or not a time delay between message arguments is provided. However, the magnitude of the difference between combined questions and prequestions, but not postquestions, will be greater when a time delay is provided in comparison to when a time delay is not provided.

Some research has been reviewed (Boyd, 1973) suggesting that combined effects of questions can be obtained. Prequestions, for example, may stimulate increased attention to following material while postquestions may result in cognitive review of what was presented. A simple combined model is hypothesized here where combined effects of questions are expected to be greater than the effects of singuiar pre 
or postquestions. Again, bowever, a oritical issue is the expected difference between the delay and no delay conditions: the magnitude of the difference between combined questions and prequestions, but not postquestions, 18 expected to be greater when a time delay is provided, in comparison to when a time delay is not provided. This should be true since postquestions, but not prequestions, are expected to increase in their effectiveness with the use of a time delay. This expectation is provided in Figure 2. An increase in combined question effeotiveness (relative to prequestions but not postquestions) when a time delay is provided is necessary support for the third hypothesis.

Hypothesis IV: Combined pre and postquestions will result in greater message learning, more favorable product evaluation and bellefs and more extensive message topic thinking than combined pre and poststatements whether or not a time delay between message arguments is provided. However, the magnitude of the variation between combined questions and combined statements when a time delay is provided is expected to be greater than when time delay is not provided.

Using the same reasoning as above, combined effects of questions should result in outcome superiority relative to statements. However, an important issue concerns the difference between the delay and no delay conditions: the magnitude of the variation between combined questions and combined statements when a time delay is provided is expected to be greater than when a time delay is not provided. This should be true since an additive effect of pre and postquestions on outcomes is anticipated, and the use of a time delay after questioning is expected to significantly enhance postquestion effectiveness. An increase in combined question effectiveness when a time delay 18 
provided, when compared to when a time delay is not provided, is necessary support for the fourth hypothesis. Figure 2 presents the expected departure from parallelism anticipated for th1s bypothesis.

Summary of Expectations

In summary, questions are generall $y$ expected to be superior to statements, although the magnitude of anticipated differences is expected to be dependent upon position and time delay. Time delay is not expected to have a significant influence on prequestion effectiveness. However, time delay is expected to introduce significant variation in outcomes associated with postquestions, and therefore combined questions as well. Note that separate components of the bypothesized model are testable. A fallure of the time delay varlable should result in a two-way interaction between grammatical form and position, with combined effects of questions being greater than single position effects. An added fallure of combined effects should result in a main effect of the grammatical form variable with questions being superior to statements. However, it is only the three-way interaction which is being hypothesized. 


\section{CHAPTER IV}

PRETESTS, METHOD AND MEASUREMENTS

\section{PRETESTS}

A supplemental vitamin ad was used as the target message in this study. Three sets of pretests were performed before development of the final advertisement versions used in testing the otudy bypotheses. Argument strength has been determined to be an important factor Influencing outcomes associated with questioning (Petty, Cacloppo and Heesacker, 1981; Burnkrant and Howard, 1984). Therefore, a pretest was performed on the quality of the arguments selected for inclusion in the vitamin ad. A cognitive effort interpretation of question effects on information processing has been offered. A pretest was performed to determine the ability of the questions versus statements selected for study in motivating information processing. Finally, a pretest was performed to determine the appropriate intervals of time delay for use as an independent variable.

\section{Argument Quality Pretest}

Three principle arguments for the supplemental vitamin ad were pretested to determine if they were perceived as relatively strong and equal in strength. This was done in two stages. Initial pretesting 
through surveys and discussion indicated the need to strengthen the first and third arguments relative to the second. 8 The modified arguments were then formally compared. Subjects were tested as a group and informed that their task was to evaluate advertioing copy. The arguments were presented in print. Arguments were rated on three 9-point scales: high quality--low qual1ty; very bellevable--not at al l bellevable; very good--very bad. Rat1ngs were provided by 43 subjects. Rellability analysis revealed that the three items were consistently measuring the same underlying oonstruct for argument one (a lpha=0.91), argument two (alpha=0.81), and argument three (alpha=0.93). Items were therefore summed to yleld an Index of percelved argument strength. The maximum sum total of the three items was 27 and the mean scores were $20.30,20.67$ and 19.79 for arguments one through three respectively. It was judged that the arguments were percelved as relatively strong. Those means were then examined in a repeated measures analysis of varlance. The means were not shown to be significantly different $(F=0.56 ; d f=2.41 ; p=0.58)$. It was concluded that the arguments were percelved as equal in strength. The instrument for the arguments quality pretest is presented in Appendix A.

${ }^{8}$ Initial pretesting on argument quality was conducted Informally and the data was not preserved. 
Question Versus Statement Disorimination Pretest

The second pretest ecamined the differential effects of 1solated questions in comparison to content identioal declarailve statements in motivating information processing. Subjects were informed that their task was to evaluate advertising copy. Forty-seven subjects (tested as a group) were exposed to elther three target ad questions or statements: 1) Is your body's vitamin supply really consistent with your dally needs?/ Your body's vitamin supply should really be consistent with your daily needs.; 2) Are you sure your diet is providing the vitamins and nutrients you expect?/ Be sure your diet is providing the vitamins and nutrients you expect.; 3) Is your body really prepared for 1ts extra vitamin needs?/ Really prepare your body for its extra vitamin needs. The stimuli were presented in print. A question/statement was presented at the top of a page and 1tems to be answered with respect to the question/statement were presented below. Note that the questions were designed to imply that the recipient believes something to be true which may be false. This 1ssue will be discussed further at a later point.

Processing motivation was assessed on four 9-point scales: arouses my curlosity--does not arouse my curlosity; stimulates thought--does not stimulate thought; interesting--uninteresting; the fourth item asked, "How likely would you be to pay attention to an advertising message that followed the above sentence?", and was scaled very likely--very unlikely. These four 1tems were found to reliably measure processing motivation for the first question/statement 
(a)pha=0.93), the second question/statement (alpha=0.94), and the third question/statement (alpha=0.90). The four 1tems were then summed to yleld three indices of processing motivation. The means were then examined in a one-between (question versus statement), onewithin (arguments) repeated measures analysis of variance. It was found that only the between-subjects factor attained statistical significance $(F=4.5 ; d f=1,45 ; p=0.039)$ with questions resulting in a higher motivation to process information than statements (means: questions=70.1; statements=60.6). It was concluded that the questions selected for inclusion in the supplemental vitamin advertisement had a higher likelihood of motivating information processing than the content 1dentical declarative statements. The 1nstrument for the motivational discrimination pretest is presented in Appendix B.

Time Delay Pretest

The final pretest examined the effects of a time delay after questioning on message-related thinking, distraction and acceptance. Tapes of the actual radio show segment developed for final testing were used for this pretest (see Radio Show Programming and The Supp lemental Vitamin Advertisement).

The Intent of the pretest was to determine two appropriate Intervals of time delay for use in hypothesis testing. To accomplish that, the supplemental vitamin ad was recorded by a professional broadcaster who paced the advertisement by experience and judgment. This version of the ad was then used as a reference point in terms of "natural pauses" between arguments. The length of those natural 
pauses" ranged from approximately 0.9 to 1.1 seconds, with an average pause of approximately 1.0 second. Defining a natural pausen (1.e., a "normal" pause) as a 1-second delay, tbe no time delay" condition was defined as half that amount ( 0.5 seconds) and the "time delayn condition as twice that amount (2 seconds). A 4-second delay condition was also developed for testing purposes. It was expected that the longer delays (1.e., 2-second and 4-second) would result in Increased levels of message-related thinking and acceptance (when compared to the 0.5-seoond delay), although it was unclear whether significant results would be obtained for both the 2-second and 4second delay conditions in comparison to the $0.5-8 e c o n d$ delay condition.

Sixty-four subjects were exposed to one of three versions of the postquestion condition: $0.5-8 e c o n d$ delay versus $2-8 e c o n d$ delay versus 4-second delay. In other words, each of the three target questions placed after their relevant arguments in the supplemental vitamin advertisement was followed by elther a 0.5-seoond delay, a 2-second delay or a 4-second delay before subsequent text in the message was presented. Participants were informed that their task was to evaluate an advertisement. Subjects heard approximately 20 seconds of mus1c and 60 seconds of disc jockey discussion before bearing the supplemental vitamin ad. The supplemental vitamin ad was then followed by an advertisement for AT\&T before administration of the dependent measures. In the dependent measures booklet, subjects were Informed that, "The supplemental vitamin ad you fust heard asked three 
different questions. A pause then occurred after each quest1on. For each scale below place an "an in the space that corresponds most closely to how you feel." Message-related thinking was assessed on four 9-point scales. Subjects were asked: 1) If the pauses helped them think about or answer the questions in the ad (derinitely yes-definitely no); 2) If the pauses helped them think about supplemental vitamins (definitely yes--definitely no); 3) In general, how much thinking about each question did they engage in after each question was asked (wuob thinking--no thinking); 4) In general, how much thinking about supplemental vitamins did they engage in after each question was asked (much thinking--no thinking). These items were found to reliably measure the same underlying construct (alpha=0.83). The 1tems were summed to yleld an index of message-related thinking.

Distraction from message processing was assessed on two 9-point scales. Subjects were asked: 1) When the pauses ocourred, were they distracted from thinking about or answering the questlons asked; and 2) When the pauses occurred, did they wonder why the pauses were there. Both items were scaled definitely yes--definitely no.

Message acceptance (1.e., "taking supplemental vitamins 1s. ." was evaluated using four standard attitude items (good--bad; beneficial--harmful; wise--foolish; favorable--unfavorable) measured on 9-point scales. Reliability was assessed (alpha=0.98) and the items were summed to yield an index of attitude towards taking supplemental vitamins. Message acceptance was also measured through a 3-minute thought listing task. Subjects were asked to list the 
thoughts that occurred to them as they listened to the supplemental vitamin ad. Subjects then scored their own responses eltber positive, negative or neutral towards supplemental vitamins.

Oneway (0.5-second versus 2-second versus 4-second) analyses of variance were performed on the message thinking, distraction and acceptance measures. Duncan's multiple range test was used for all post hoc comparisons. A significant effect of time delay was found for the message thinking index $(F=3.57 ; d f=2,61 ; p=0.03)$. Post boc comparisons revealed that the $2-8 e c o n d$ delay condition resulted in significantly more thinking $(p<0.05)$ than the $0.5-8 e c o n d$ delay condition $(X=14.8$ versus 20.4$)$, and marginally greater $(p<0.10)$ thinking than the 4-8econd delay condition $(X=19.2)$.

A significant effect of time delay was also found for the item measuring whether the use of pauses distracted subjects from thinking about or answering the questions $(F(2,61)=5.47 ; p=0.007)$, and for the Item asking whether subjects wondered why the pauses were used $(F(2,61)=13.09 ; p<0.0001)$.

For both 1tems, the 4-second delay condition was judged to be more distracting than both the $2-8 e c o n d(p<0.05)$ and $0.5-8 e c o n d$ $(p<0.05)$ delay conditions. There was no significant difference between the 2-seoond and 0.5-second delay conditions on either of the 1tems.

A significant effect for the time delay was also found for the attitude index $(F=3.36 ; d f=2,61 ; p=0.04)$. Post hoc comparisons revealed that subjects exposed to the 2-second delay bad a 
slgnificantly $(p<0.05)$ more favorable attitude towards supplemental vitamins $(X=32.4)$ than either 0.5 -second delay subjects $(I=26.8)$ or 4 second delay subjects $(X=27.5)$.

Finaliy, a significant effect of time delay was also found for positive message topio thoughts $(F=4.51 ; d f=2,61 ; p=0.01)$. Post hoc comparisons revealed that subjects exposed to the 2-second delay output had a signiflcantly $(p<0.05)$ greater number of positive message topic thoughts $(X=4.52)$ than elther subjects exposed to the $0.5-s e c o n d$ delay $(X=3.0)$ or subjects exposed to the 4 -second delay $(X=2.85)$.

No signifloant effect was seen $(F=1.69 ; d f=2,61 ; p=0.19)$ for negative message topic thoughts, although the means were in a direction consistent with other findings reported above (means: 0.5second $=1.30 ; 2-\operatorname{second}=.71 ; 4-\operatorname{second}=1.20$ ).

It was concluded that the 2-second delay after questioning fac1litated message processing resulting in greater message acceptance when compared to the 0.5-second delay or the 4-second delay conditions. A 4-second delay after questioning may have been percelved as unusual enough to actually interfere with message processing, resulting in lesser degrees of message acceptance when compared to the 2-second delay condition.

The results obtained with the 4-second delay were unexpected and the reasons are unclear. The literature reviewed on communicative silence appears more supportive of a fac1litating effect, rather than an interfering effect, of sllence after questioning. The original intent of the pretest was to determine two conditions of delay for use 
in hypothesis testing. Although the most ravorable results were obtained with a 2-second delay, the 4-second delay deserves further examination. Therefore, the "no time delay" condition is defined as the 0.5-second delay and the "time delay" condition 18 defined as both the 2-second and 4-second delay conditions. Is a baseline model, It is expected that the longer delays (1.e., 2-second and 4-second) will result in increased levels of message-related thinking and acceptance (when compared to the 0.5-second delay), although it is unclear whether significant results will be obtained for both the 2second and 4-second delay conditions in comparison to the 0.5-second delay condition. The instrument for the time delay pretest 13 presented in Appendix C.

METHOD

\section{Design}

The independent varlables in this investigation are grammatical form (question versus statement), position (premessage versus postmessage versus combined), and time delay (0.5-second versus 2second versus 4-second). All variables are between-subjects factors. Thus, a $2 \times 3 \times 3$ between-subjects factorial design was implemented.

\section{Independent Variable Man1pulations}

Grammatical form was manipulated by comparing questions to content Identical declarative statement. Position was manipulated by placing the questions or statements either before message arguments, after message arguments or both before and after message arguments. 
Time delay was manipulated by the use of eltber a $0.5-8 e c o n d, 2-s e c o n d$ or 4-second Interval of silence after each question/statement-argument or argument--question/statement pair.

\section{Study Context}

The context in which this study was executed was a professionaliy arranged radio show. Two advertisements were developed and inserted in the show. The first advertisement, advocating the use of supplemental vitamins, was the target message. The target message was immediately followed by a f1ller ad for AT\&T. A broadcast message was preferred to print for reasons of control over length of exposure to the experimental stimuli. Also, the manipulation of time delay in a print ad context would have necessitated the use of highly artificial experimental arrangements.

\section{Radio Show Programming}

Personnel at the WOSU broadoasting stations in Columbus, Ohio agreed to assist in the development of the radio show (and advertisements) used in this investigation. One individual was used as the radio show d18c jockey and two others were used as volces for the two advertisements inserted in the show. All three assistants were professional broadcasting personnel.

The radio show consisted of four songs, two advertisements, and remarks interspersed by the d18c jockey. The average total broadcast time for the show was approximately 23 minutes, 22 seconds. Table 2 provides a breakdown of the various segments of the radio show by the 
TABLE 2

Radio Program Time Segments

Segment

Introductory Music and Disc Jookey

First Song

Disc Jockey

Second Song

D1so Jookey

Th1rd Song

Disc Jockey

Supplemental Vitamin Ad

AT\&T Ad

D1sc Jockey

Fourth Song

Disc Jockey and Ending Music

Average Total Program Time
Approximate Time ${ }^{b}$

31 sec.

3 min., 13 sec.

$1 \mathrm{~min}, 31 \mathrm{sec}$.

3 min., 15 sec.

$1 \mathrm{~min}, 12 \mathrm{sec}$.

4 min., 32 sec.

1 min.

2 min., 3 sec. (average)

$59 \mathrm{sec}$.

1 min., 7 sec.

2 min., 43 sec.

1 min., 16 sec.

23 min., 22 sec.

\footnotetext{
$b_{\text {Rounded to nearest second. }}$
} 
approximate amount of time involved. Remarks made by the diso jockey were spontaneous (1.e., no prepared text was used). A transcript of the remarks made by the disc jockey is provided in Appendix D.

The musical programming for the show was selected by the disc jockey and approved by this author. The four songs broadcasted (in order) were: 1) Lay Lady Lay (Peter Nero's version); 2) A Taste of Honey (Roger H1lilams' version); 3) Let It Be (Arthur Fiedler's version); 4) It's Yesterday Once More (Peter Nero's version). The muslcal seleotions were all instrumental and perhaps best desoribed as typlcal "elevator music." The cholce of musical selections reflected methodological considerations. One of the problems in conduoting a typical laboratory experiment is that the attention of subjects is often riveted on the target materlal (Eagly and Chaiken, 1984). This was judged to be a partioular concern in a study of a broadcast advertisement since attention to such material is often incidental in nature (Brugman, 1965). Although Brugman discussed Inc1dental broadcast reception in terms of television advertising, the same concerns would seem to apply to broadcast media in general given its low opportunity for "dwelling upon a point of advertising" (Krugman, 1967). Furthermore, Z1IIman and Cantor (1973) found question effects on the learning of message material only in conditions where subjects' attention was not already focused on the material, presumably bocause the stimulating advantage of questions over statements is more evident in such a condition. In other words, these authors suggested that questions might be relatively more effective (1.0., have "more to 
gain") in situations where recipients are "boredn with the broadcast material in which the questions are inserted. Overall, research seems to Indicate that "low involvement" conditions are beneficlal to obtaining favorable question effects. Therefore, the cholce of musical seleotion was made with the intent of minimizing helghtened interest in and attention to the radio show at the time of target message broadcast.

To test whether the musical programming was successful at doing so, undergraduate atudents were randomly assigned to two different conditions. 9 In one condition subjects heard the first three musical arrangements noted above ( 11 minutes, 31 seconds broadcasting t1me) and in another condition subjects heard three songs currently popular with the college age market (11 minutes, 42 seconds broadcasting time) as rated by B1l1board magazine. 10 Participants rated the songs in terms of boredom (very boring--very interesting), attention (beld my attention very well--did not hold my attention well at all) and irritation (very irritating-not at all irritating). Subjects indicated that the songs used in the radio show were significantly more borlng $(F=20.18 ; d f=1,22 ; p<0.0001)$ and less able to hold their attention $(F=15.06 ; d f=1,22 ; p=0.001)$ than the currently popular songs. However, no significant difference was seen in that extent to

\footnotetext{
9 This test was not disoussed previously with other pretests since this test was conducted at conclusion of the formal investigation.

10 That's What Friends Are For (Dionne and Friends); Burning Heart (Survivor); When the Going Gets Tough (Biliy Ocean).
} 
which songs were judged to be irritating $(F<1.0)$. In a second test with an additional sample of 25 undergraduate students, almost Identical results were obtained comparing the radio broadcast songs with three songs popular with the youth markets of the late 1960's (11 minutes, 42 seconds broadcasting time). ${ }^{11}$ The songs used in the radio broadcast were considered more boring $(F=24.27 ; d f=1,23 ; p<0.0001)$, and less able to hold recipients' attention $(F=21.34 ; d f=1,23$; $p(0.0001)$, although no significant difference was observed in the extent to which the two sets of songs were perceived as irritating $(F<1.0)$. Thus 1 appears that the broadcast reception effects were not due to the music being associated with an nolder generation," but rather with the style of the music 1tself. It was concluded that the musical programing in the radio show was most likely successful in minimizing college audience interest in and attention to the broadcast. The instrument for this test is provided in Appendix E.

The Supplemental Vitamin Advert1sement

The supplemental vitamin ad was afred after disc jockey remarks following the third song in the radio show. Approximately 15 minutes, 14 seconds of broadcasting time preceded the target ad. At no time did the disc jockey mention or refer to supplemental vitamins. The supplemental vitamin ad was introduced by the disc jockey stating: "And we'll be back with more right after th1s message."

${ }^{11}$ poems, Prayers and Promises (John Denver); The Sounds of Silence (Simon and Garfunkel; Hard Headed Woman (Cat Stevens). 
Aside from the question/atatement manipulation, the content of

the vitamin ad inoluded a short introduction, three main arguments, and a short conclusion:

Introduction: There are many reasons why people may dec1de to take supplemental vitamins. (Approximate broadcast time = 4.8 seconds.)

Argument I: The American Medical Assoclation reminds us that dally vitamin requirements depend not only on diet, but also on your daliy activities and exposure to stress. Many people experience stress on the job or at school. An Increased level of stress, or even a lack of sleep, can increase the body's need for many nutrients. And people today are more active than ever before. What many don't realize is that being physically active can actually increase the body's need for certain vitamins. (Approximate broadcast time $=28.0$ seconds.)

Argument II: The American Dietet10 Association warns that the way rood 18 prepared is a leading factor in nutritional 108s. For example, many vitamins are heat sensitive. Bolling vegetables in water or cooking meats well done can result in almost complete destruction of many vitamins. Many methods of enhancing the taste and appearance of food also decrease its nutritional value. Remember, it is only the nutritional content of food after meal preparation that counts. (Approximate broadcast time $=27.5$ seconds.)

Argument III: The American Medical Association also reminds us that drugs and disease can aiter our vitamin requirements, resulting in extra vitamin needs. Antibiotics interfere with vitamin absorption, while aspirin causes vitamin loss. Smoking, exposure to smoke, as well as alcobol consumption, can rob the body of many nutrients. Infections, the $r I u$, as well as the common cold: all make vitamin demands on the body. (Approximate broadcast time $=27.2$ seconds.)

Conclusion: Again, there are many reasons why people may decide to take supplemental vitamins. Each person should consider supplemental vitamins as individual choice-for Individual health. (Approximate broadcast time = 10.4 seconds.) 
Individual questions or statements were placed elther before, after, or both before and after each of the three prinolpal arguments: Argument I: Question - Is your body's vitamin supply really consistent with your daily needs?

Statement - Iour body's vitamin supply should realiy be consistent with your daily needs.

Argument II: Question - Are you sure your diet 1s providing the vitamins and nutrients you expect?

Statement - Be sure your diet 18 providing the vitamins and nutrients you expect.

Argument III: Question - Is your body really prepared for 1ts extra vitamin needs?

Statement - Really prepare your body for 1ts extra vitamin needs.

The total length of broadcasting time involved in asking the three questions was approximately 12.3 seconds; the three statements Involved approximately 12.0 seconds of broadcasting time.

The time delay variable ( 0.5 seconds, 2 seconds, 4 seconds) was used after aach of the three main arguments, and after the associated question/statement when it appeared in the post position. In other words, the time delay was never used between a question/statement and its associated argument.

Technical arrangements for the supplemental vitamin ad invol ved recording one master copy of the ad and "splicing in" the different questions/statements at appropriate argument positions and with appropriate time delays. Th1s was done to assure that the same volce Intonations were used across various experimental conditions. Each final tape was then "smoothed" to prevent audience deteotion of the 
splicing. The average length of time for the supplemental vitamin ad across all conditions was 2 minutes, 2.95 seconds, ranging from approximately 1 minute, 51.4 seconds for the pre or post $0.5-8$ econd delay conditions to approximately 2 minutes, 14.5 seconds for the combined 4-second delay conditions.

\section{Sampling Procedure}

Subjects were obtalned from undergraduate marketing classes at the Oh1o State OnIversity and were informed that they would recelve classroom extra credit for their participation. Subjects not allowed to formaliy participate were those previously exposed to pretest materials or earlier question effect studies, those who had this Investigator as a class instructor within six months prior to testing, and those personaliy known by this investigator from any previous class. Subjects were randomly assigned in groups of two to five Individuals to the 18 experimental conditions. The desire was to obtain at least 20 subjects per cell. As a condition attained that level, it was removed from consideration and random assignment continued on the basis of the remaining celis. A sample of 363 subjects was obtalned. Unfortunately, miscounts somewhere along the way resulted in one cell having less than 20 subjects. Two cel is had more than 20 subjects. One case was eliminated because of comments Indicating prior familiarity with the material, resulting in a second cell with less than 20 subjects. To attain cell size equality, two additional cases were randomly eliminated from the colls with a size 
greater than 20 for a final sample of 360 subjects. Final cell alzes for the 18 experimental conditions are presented in Table 3.

\section{Testing Procedure}

All subjects were tested individualiy in specially prepared cublcles designed to allow communication with the experimenter for timing on the cognitive response task. Each subject was informed that his/her task was to "listen to a radio show as you normally would" and to "provide some feedback on the show afterwards." Subject attention was intentionaliy directed to the radio show to minimize "guessing" or suspiolons concerning the purpose of the experiment and to minimize the likelihood of speoific concentration on the target advertisements. Total time of testing (radio show exposure and questions) lasted, on the average, approximately one bour. After testing, subjeots were debriefed, questions answered, asked not to inform others of the experimental tasks, thanked, and dismissed. 12

\section{DEPENDENT VARIABLE MEASUREMENTS}

Hypothesized effects were expected for measures for product evaluation, personal beliefs, message learning, and message relevant thinking. All scaled items in the final study were measured on 9point scales. This section will discuss the principal dependent measures used in the final study, how those measurements were made, and the rationale underlying the use of certain measurements.

\footnotetext{
12 Most questions were directed at what the study was attempting to resolve.
} 
TABLE 3

Cell Sizes for Experimental Conditions $n=360$

Grammat1cal Form

Delay $\frac{\text { Position }}{\text { Pre }}$

Question

Statement

$0.5 \mathrm{sec}$.

20

20

2 sec.

21

20

4 sec.

19

20

\section{Post}

$0.5 \mathrm{sec}$.

20

20

2 sec.

20

20

4 sec.

20

20

\section{Combined}

$0.5 \mathrm{sec}$.

18

20

2 sec.

22

20

$4 \mathrm{sec}$.

20

20 
Measures of Product Evaluation

Product evaluation was measured by positive and negative message topic cognitive responses and 1tems messuring respondent attitude towards taking supplemental vitamins. In a 3-minute thought listing task, subjects were asked to list their "thoughts about supplemental vitamins." Afterwards, respondents were asked to indicate whether each listed thought "was favorable towards supplemental vitamins, unfavorable towards supplemental vitamins, or nelther favorable nor unfavorable towards supplemental vitamins." Greenwald (1968) suggests that respondents are able to provide accurate evaluation of their own thoughts (also see Cacioppo, Harkins and Petty, 1981). The positive message topic thoughts and negative message topic thoughts were then summed to yield two indicators of product evaluation.

Attitude towards taking supplemental vitamins was measured with four scaled items. Each subject indicated my taking supplemental vitamins 1s" good--bad, beneficlal--harmful, wise--foolish, and favorable--unfavorable with the poles of the scales reversed on alternate items to prevent response bias. The four items were found to reliably measure the attitude construct (alpha=0.946) and were summed to yield an attitude index, which served as a second indicator of product evaluation. A rinal measure of product evaluation examined Intentions to purchase supplemental vitamins. Subjects were asked how likely they would be "to purchase supplemental vitaming" (scored very likely--very unl1kely). 
Measures of Bellef Reappra1sal: The Arousal of Doubt

Personal beliers were measured to reflect a construct of mdoubt arousal" concerning an individual's vitamin adequacy. First, note that the questions used in this study were designed to arouse doubt by directiy implying that the recipient believes something to be true which may be false. Consider again the three questions posed in the supplemental vitamin ad: 1) Is your body's vitamin supply realiy consistent with your daily needs?; 2) Are you sure your diet is providing the vitamins and nutrients you expect?; 3) Is your body really prepared for 1ts extra vitamin needs? These questions were developed with the intent of activating reciplent reappraisal of their current state of vitamin adequacy.

Three 1tems were presented to respondents to examine this construct (scaled very likely--very unlikely): 1) How likely or unlikely is it that your body's vitamin supply is consistent with your dally needs?; 2) How likely or unlikely is it that your diet is providing the vitamins and nutrients you expect?; 3) Hou likely or unlikely is it that your body is prepared for its extra vitamin needs? While the reliability of the 3-1tem scale was satisfactory (alpha=0.73), elimination of the third item provided a more consistent scale (alpha=0.80). Items were summed for both the 3 -1tem and $2-1$ tem scales to yield indicators of the arousal of doubt.

Note that the arousal of doubt construct as measured here corresponds to the following definition of doubt: $"$. . to be inclined not to believe or accept. . to consider unlikely or improbablen 
(Webster's Third New International Dictionary). First, the construct is labeled "arousal of doubt," rather than simply melief change," in recognition of the asymmetrical nature of the expected effect. In other words, it is suggested that questioning a belief through a persuasive communication may cause one to oonsider the belief unlikely to be true. The extent to which a decline in the strength of one belief (through questioning) causes an equivalent increase in the strength of an opposing belief (1.e., the bellef that one should take vitamins) is an issue not directly examined here. However, the conceptualization offered is important because a weakening of beliefs in personal vitamin adequacy will be examined as a factor which should determine, for example, attitude towards consuming vitamins and Intentions to purchase vitamins. If such relationships are found, it could be argued that a weakening of bellers in vitamin adequacy brings consumers to be more receptive to information on products able to reverse negative personal consequences associated with their perceived need state. Second, the construct also recoganizes that, in the present context of use, measures of belief change can be viewed as outcome indicators of an underlying process involving the subjective experience of doubt. An appropriate label for the construct, therefore, is "arousal of doubt."

Measures of Message Learning

Message learning was measured by free recall and corrected recognition scores (to be discussed). For free recall measurement, 
each argument was divided into six distinct idea units for scoring purposes as follows:

Argument I: Stress and Activity

1) cites American Medical Profession for argument support

2) daily vitamin requirements depend on factors other than diet

3) da1ly vitamin requirements depend on (e.8., increases with daily) aotivities

4) da1ly vitamin requirements depend on (e.8., increases with) exposure to stress

5) people experience stress on the job and/or school

6) people today are more active than before

7) a lack of sleep can affect the body's need for vitamins

In scoring Argument I, efther point number 2 was counted, or point 3, and/or 4 and/or 7. Point number 2 was not counted topether with elther polnts 3,4 or 7 since those points are specific examples of point number 2.13 Thus, Argument 1 had a total of 6 possible scoring points.

Argument II: Food Preparation

1) cites American Dietetic Association for argument support

2) the way that food is prepared is a leading factor in nutritional loss

3) many vitamins are heat sensitive

4) bolling vegetables in water can destroy vitamins

5) cooking meats well done can destroy vitamins

6) many methods of enhancing the taste or appearance of food decreases nutritional value

7) It is only the nutritional content of food after meal preparation that matters in terms of health

13It was felt that this procedure would reduce redundancy in scoring between argument themes and examples. Memory for the argument examples implies memory for the underlying thene, which was not counted twice. Therefore, a subject recal Iing that "tbe vitamins you should take depend on many things, like being active in sports," was given a score of 1 for the one fundamental idea reflected in points 2 and 3 . 
In scoring Argument II, either point number 3 was counted, or points 4 and/or 5. Point number 3 was not counted togetber with elther point 4 or 5 since those points are specific examples of point number 3. Thus argument II had a total of six possible scoring points. Note that point number 2 was only counted if food preparation was cited as a leading or major factor in nutritional loss.

\section{Argument III: Drugs and Disease}

1) cites American Medical Association for argument support

2) drugs and disease can alter vitamin requirements, or result in extra vitamin need

3) antibiotics interfere with vitamin absorption

4) aspirin causes vitamin loss

5) smoking, or exposure to smoke, can deplete the body of vitamins

6) alcohol consumption can deplete the body of vitamins

7) Infections, the flu and the common cold all make vitamin demands on the body

In scoring Argument III, point number 2 was not counted when used In conjunction with any of the points 3 through 7 , which represent specific examples of point 2. Thus, Argument III had a total of six possible scoring points. Note that mention of either infections, the flu or the common cold was sufficient for scoring of point number 7 .

Note that in scoring all three arguments, the term "vitamin" and "nutrient" were considered as equivalent. Free recall for each case was independently coded by two individuals, both blind to experimental conditions. There was inter-rater agreement in the coding of 87.58 of the cases $(n=315)$. D1sputes were judged and resolved by this investigator. The ratber high level of inter-rater reliability at least partially reflects the rather low level of message recall. 
Scores from the three arguments were summed to yleld an indicator of message learning.

Recognition was measured by interspersing six target items (two from each argument) in a list of 18 distractors. The recognition task followed the recall task. The six target 1tems were as follows:

1) an Increased level of stress can Increase the body's need for many nutrients

2) being physically active can increase the body's need for certain vitamins

3) the way that food is prepared is a leading factor in nutritional value

4) many methods of enhancing the taste and appearance of food also decrease the nutritional value

5) drugs or disease can alter our vitamin requirements

6) smoking and alcohol consumption can rob the body of many nutrients

A corrected recognition score was obtained by subtracting the number of 1tems incorrectly recognized from the number correctly recognized (see Brown, 1976).

Measures of Message Topic Thinking

The extent of message topic thinking was also measured in two ways. The first indicator was the total number (positive, negative and neutral) of message topic cognitive responses discussed by Burnkrant and Howard (1984) as a measure of message-related elaboration. The second indicator was an item which asked respondents to indicate the extent to which the supplemental vitamin ad caused them to think about the product (resulted in my thinking about the product a lot--did not result in my thinking about the product at a11). 


\section{Additional Measures}

A variety of additional measures were further obtained not specifically addressed by hypotheses. These items will be noted during analysis. The instrument used in collecting the dependent measures is provided in Appendix $F$.

Finaliy, note that the extent of product related thinking and the elicitation of doubt are expected to be the factors underlying effective question use. In other words, questions designed to imply to recipients that something they believe to be true (1.e., their body's vitamin supply is adequate) may be false (their body's vitamin supply is not adequate) are expected to result in: 1) an elicitation of doubt with respect to vitamin related needs; and 2) an increase in thinking about the target of the message (supplemental vitamins). Other hypothesized effects observed are expected to follow from these dynamics. 


\section{CHAPTER V}

\section{RESULTS}

\section{Review of Expectations}

Hypotheses I through IV designated specific cell comparisons to be made in the context of an expected three-way interaction between grammatical form, position and time delay. Prequestions and postquestions were expected to be superior to prestatements and poststatements respectively in producing desired outcomes. Combined questions were expected to be superior to combined statements, as well as singular prequestions or postquestions. However, the magnitude of the expected differences was expected to depend on position and time delay. It was anticipated that time delay would have no significant Influence on the effectiveness of prequestions. However, an Increased time delay was expected to Improve the effectiveness of postquestions and combined questions relative to poststatements and combined statements respectively. An increased time delay was also expected to Improve the effectiveness of combined questions relative to prequestions. Again, Figures 1 and 2 provide the form of the bypothesized three-way interaction. In the following tests of these hypotheses, the degrees of freedom are $d f=4,342$. 
Hypotheses Testing

Table 4 provides a summary of ANOVA effects for all bypothesized dependent variables. As seen, the expected three-way interaction was obtained for only two of those dependent variables. For measures of product evaluation, the expected interaction did not emerge for either attitude $(F=1.19 ; p=0.31)$, positive message topic thoughts $(F=0.86$; $p=0.38)$, or negative message topic thoughts $(F=0.77 ; p=0.54)$. The expected interaction was also not seen for measures of personal beliefs (arousal of doubt--3-1tem $(F=0.70 ; p=0.59)$ ); arousal of doubt--2-1tem $(F=0.68 ; p=0.61)$, or for measures of message learning (recall, $F=0.42 ; \quad p=0.79 ;$ corrected recognition, $F=0.27 ; \quad p=0.90$ ). Finaliy, for measures of message topic thinking, the three-way Interaction was not significant for the 1tem measuring the extent of product related thinking $(F=0.48 ; p=0.75)$.

The anticipated three-way interaction was obtained for the total number of thoughts $(F=2.38 ; p=0.05)$. However, cell comparisons revealed (as determined by Duncan's multiple range test) that the locus of the effect was due to a greater total number of thoughts in the combined question condition when compared to the prequestion condition, but only for those exposed to the 0.5-second delay $\left(D_{r}=1.58 ; \quad K=18 ; p<0.05\right)$. A three-way interaction between grammatical form, position and time delay was also seen for the purchase intentions measure $(F=2.55 ; d f=4,432 ; p=0.039)$. However, a I 1 comparisons revealed greater purchase intentions for the postquestion position in contrast to the combined question position but only for 


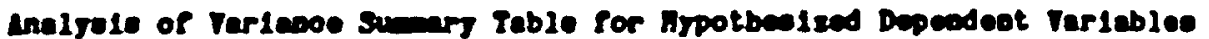

P-llation for Dapeodeat Verinoleo

Iedopeod cont Iarlables

\begin{tabular}{|c|c|c|c|c|c|c|c|c|}
\hline & Prodeot Ire & luat1on & & Perroceal & Dellere & Top 10 & and 1 & Moeace Learalex \\
\hline Alestude & $\begin{array}{l}\text { Positive } \\
\text { Inocerpte }\end{array}$ & mourbe & $\begin{array}{l}\text { Purohese } \\
\text { Iateot 10ase }\end{array}$ & $\begin{array}{l}\text { Doobt } \\
2-1 t e\end{array}$ & $\begin{array}{l}\text { Doubt } \\
3-1 t=2\end{array}$ & $\begin{array}{l}\text { Total } \\
\text { Toovebte }\end{array}$ & $\begin{array}{l}\text { Moleted } \\
\text { melotin }\end{array}$ & Reon11 Roconpition \\
\hline
\end{tabular}

\begin{tabular}{|c|c|c|c|c|c|c|c|c|c|c|c|}
\hline $\begin{array}{l}\text { Gramentionl } \\
\text { Pore }(\infty)\end{array}$ & 1 & 0.56 & 0.01 & 2.21 & 0.20 & 1.22 & 0.09 & 0.04 & 0.28 & 0.02 & 0.09 \\
\hline Posltion (P) & 2 & 0.04 & 0.09 & 1.34 & 1.29 & 0.04 & 0.10 & 1.87 & 0.16 & 0.27 & 2.04 \\
\hline TID Dolay (D) & 2 & 0.09 & 0.15 & 2.09 & 0.44 & 0.92 & 1.13 & 0.26 & 0.63 & 0.77 & 0.05 \\
\hline$\infty \times 1$ & 2 & 1.56 & 3.11900 & 0.90 & 1.88 & $2.92^{\circ}$ & 2.17 & 0.77 & 3.8610 & 1.67 & 1.97 \\
\hline$\infty \times 0$ & 2 & 0.55 & 0.66 & 1.59 & 0.01 & 1.03 & 1.37 & 0.03 & 0.09 & 1.70 & 2.680 \\
\hline$P \geq D$ & 4 & 1.13 & 0.64 & 2.4100 & 1.54 & 1.23 & 0.89 & 0.35 & 0.52 & 1.12 & 0.77 \\
\hline$\infty \times 1 \times 0$ & 4 & 1.19 & 0.86 & $0 . \pi 7$ & 2.5500 & 0.68 & 0.70 & 2.3800 & 0.48 & 0.12 & 0.27 \\
\hline
\end{tabular}

Mos10ual 342

$\cdots<0.05$

$\because 0<0$ 
subjects exposed to the 2-second delay $\left(D_{r}=2.05 ; \mathrm{K}=18 ; \mathrm{p}<0.05\right)$. Also, subjects in the postquestion condition had higher purchase intentions than those in the prequestion condition but only for the 4-second delay $\left(D_{r}=2.05 ; \quad K=17 ; p<0.05\right)$. See below for a discussion of notation. In summary, none of the hypotbeses were supported.

\section{Effects Observed: A Caut1onary Note}

No support was obtained for the original ideas in this study. The following analyses and discussion are presented in an attempt to make sense out of the pattern of data observed. For reasons of completeness of presentation, results for all variables collected, which included far more than the formal dependent variables, will be examined. However, these analyses should be considered a "post-hoc addendum "to the formal study which falled to support the hypothesized results.

Effects Observed: Analytic Approach

Evidence of a significant two-way interaction between grammatical form and position appeared consistently across several dependent varlables. Cell means for all variables demonstrating this Interaction are presented in Table 7. All comparisons were approached with the expectation that questions would be superior to statements in all conditions, but that the magnitude of the differences varled in accounting for the interaction. That expectation seemed reasonable given that none of the original hypotbeses predicted statement superiority over questions in any condition. With 60 subject cells 
across the six conditions (see Table 7), three orthogonal comparisons of interest were made for question vel sus statement contrasts within each position. Independence of comparisons was confirmed through the following rule. With $C_{1}, C_{2}, C_{3}$ referring to comparisons one through three respectively and $x_{1}, x_{2}, x_{3}, x_{4}, x_{5}, x_{6}$ respectively referring to question--pre position, statement--pre position, question--post position, statement--post position, question--combined position, statement--combined position, the following racid testn of orthogonality was made:

$$
\begin{aligned}
& c_{1}=(1) x_{1}+(-1) x_{2}+(0) x_{3}+(0) x_{4}+(0) x_{5}+(0) x_{6} \\
& c_{2}=(0) x_{1}+(0) x_{2}+(1) x_{3}+(-1) x_{4}+(0) x_{5}+(0) x_{6} \\
& c_{3}=(0) x_{1}+(0) x_{2}+(0) x_{3}+(0) x_{4}+(1) x_{5}+(-1) x_{6}
\end{aligned}
$$

where $c_{1}, c_{2}, c_{3}=0$

and the sum of the coeffiolent crossproducts for any two comparisons 1s zero. Duncan's multiple range test was used for all additional comparisons. In the notation for Duncan's procedure $D_{r}$ will refer to the minimum mean difference required for significance at a given level, with the stated probability level indicating that the minimum difference was exceeded, and with $B$ referring to the number of "steps" separating means. Levels of significance less than or equal to 0.05 will be referred to as "statistically significant." Levels of significance less than or equal to 0.10 but greater than 0.05 will be alternatively referred to as marginally significant" or as "approaching significance." Exact levels of significance (1.e, $p=0 . n n$ ) will be provided where possible. In all of the following 
tests, the degrees of freedom for the overall ANOVA are $d f=2,342$ unless otherwise noted.

GYPOTHESIZED MEASURES

Measures of Product Evaluation

The three-way interaction between grammatical form, position and time delay for the purchase intentions measure has already been discussed. A significant two-way interaction was observed between grammatical form and position for the number of positive message topic thoughts $(F=3.41, p=0.03)$. This interaction is presented in Figure 3 . Subjects exposed to postquestions were found to generate more positive thoughts than those exposed to post statements $(F=4.55$; $d f=1,342$; $p<0.05)$. No significant differences were seen between prequestion and prestatement conditions $(F=1.70 ; d f=1,342 ; p>0.10)$, or the combined question and combined statement condition (F<1). Subjects exposed to postquestions also generated a marginally greater number of positive thoughts than those exposed to prequestions $\left(D_{r}=0.69 ; \mathrm{R}=5 ; p<0.10\right.$; $\mathrm{K}=4$ ) and those exposed to combined questions $\left(D_{r}=0.62 ; G=4 ; p<0.10\right)$. However, a similar interaction was not seen for negative message topic thoughts $(F=0.91 ; p=0.40)$.

Negative thoughts did reveal an interaction between position and time delay $(F=2.41 ; d f=4,342 ; p=0.049)$. It was seen that subjects in combined positions exposed to a $0.5-8 e c o n d$ delay generated more negative thoughts than: A) subjects in the pre position 2-second $\left(D_{r}=0.84 ; K=9 ; p<0.05\right)$ or $0.5-$ second $\left(D_{r}=0.79 ; K=5 ; p<0.05\right)$ delay 


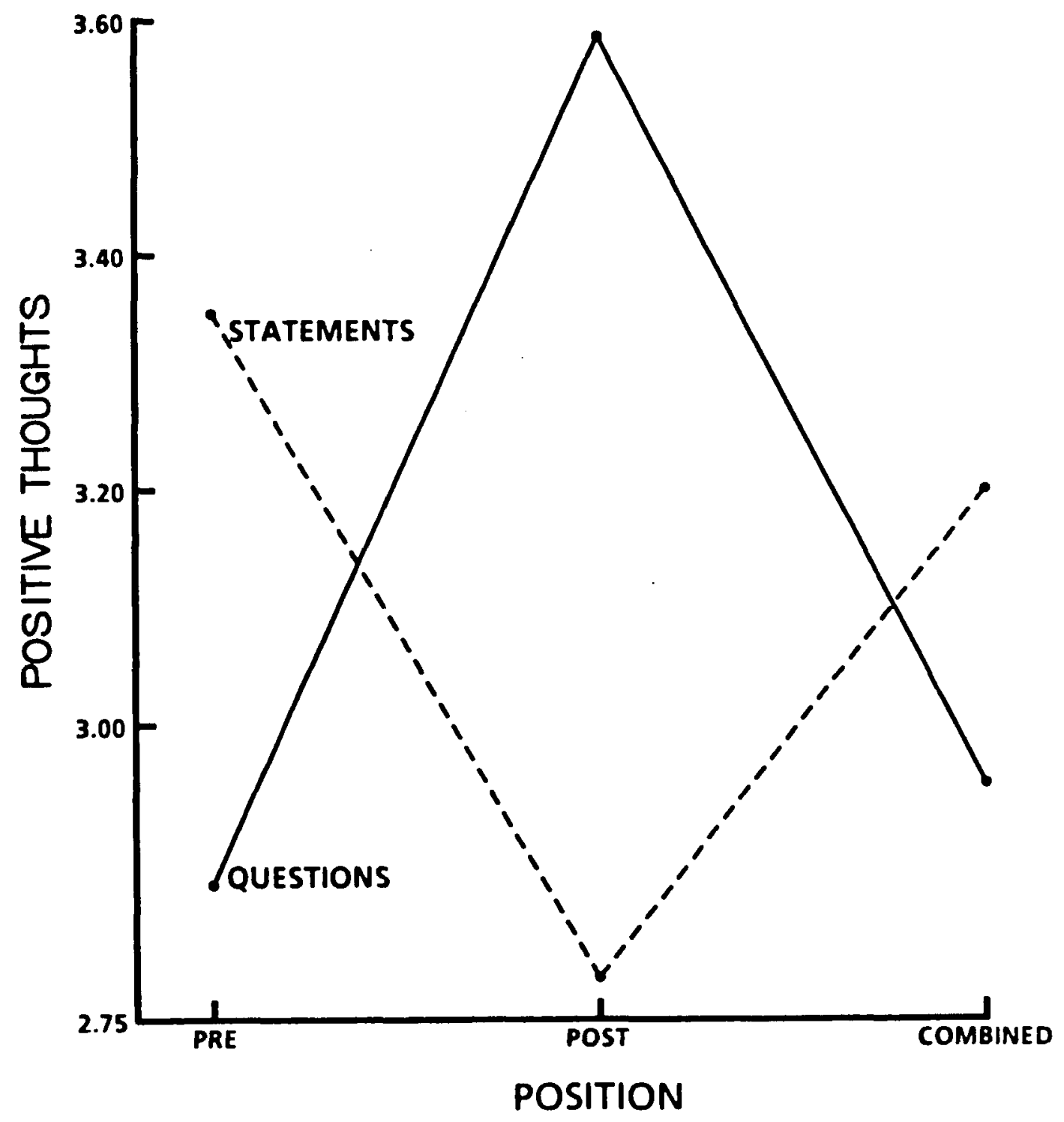

Figure 3

Grammatical Form By Position Interaction For

Production of Positive Message Topic Thoughts 
conditions; B) post position subjects exposed to either a 2-second $\left(D_{r}=0.81 ; K=6 ; p<0.05\right)$ or $4-\operatorname{second}\left(D_{r}=0.82 ; R=7 ; p<0.05\right)$ delay; or $\left.C\right)$ combined position subjects exposed to a 4 -second delay $\left(D_{r}=0.83 ; \quad K=8\right.$ (0.05). Note that no significant treatment effects were seen for the attitude index.

Measures of Belief Reappraisal: The Arousal of Doubt

As earlier discussed, three-1tem and two-1tem indices of bellefs concerning perceptions of vitamin adequacy were developed to reflect "arousal of doubt." No signiflcant results were obtained with the three-1tem Index (1.e., Items concerning all three message arguments). However, for the two-1tem index (1.e, Items concerning the first two arguments), the grammatical form by position interaction closely approached statistical significance $(F=2.92$; $p=0.055)$, where subjects exposed to postquestions conceded that they were less certain concerning their vitamin adequacy than those exposed to poststatements $(F=5.98 ; d f=1,342 ; p<0.02)$. No significant differences were seen between prequestion and prestatement conditions $(F<1)$ or between combined question and combined statement conditions (F<1). This Interaction is presented in Figure 4. Note that all remaining analyses will utilize the two-item arousal of doubt scale. Also note that it 18 possible (given differences in degrees of freedom) for the significance level of an orthogonal comparison to exceed the significance level of the omnibus null hypothesis tested by analysis of variance (see Kennedy, 1978). A separate analysis of the third 1tem, which asked subjects, "How likely or unlikely is it that your 


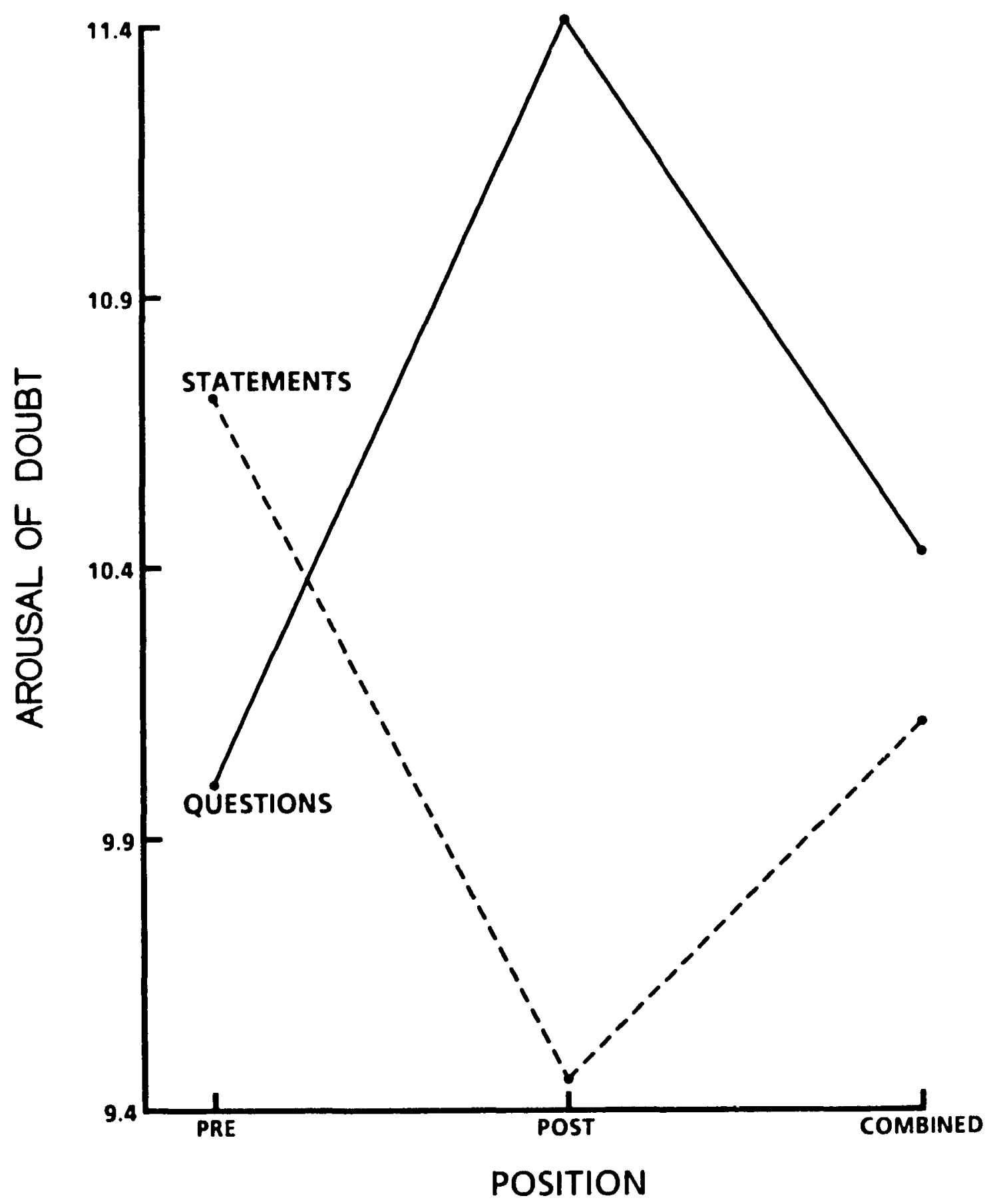

Figure 4

Grammatical Form By Position Interaction For Arousal of Doubt Concerning Vitamin Related Needs 
body's vitamin supply is consistent with your dally needs?" revealed no significant effects on any treatment variable. Finally, no significant differences between treatment groups were found across three additional 1tems designed to measure how knowledgeable, confident, and satisfied respondents felt concerning their understanding of supplemental vitamin benefits.

Measures of Message Top10 Think1ng

The three-way interaction between grammatical form, position and time delay for the total number of message topic cognitive responses has already been discussed. However, a two-way interaction between grammatical form and position was found for the item measuring the extent of thinking about supplemental vitamins $(F=3.86 ; p=0.022)$. No significant differences were seen between the prequestion and prestatement $(F=2.60 ; d f=1,342 ; p>0.10)$, or combined question and combined statement conditions ( $F<1$ ). Subjects exposed to postquestions indicated that the advertisement caused them to think more about supplemental vitamins than those exposed to poststatements ( $F=5.32$; p (0.05). Those exposed to postquestions also indicated greater thinking than those exposed to prequestions $\left(D_{r}=0.88 ; R=5 ; p<0.05\right)$, and marginaliy wore than those exposed to combined questions $\left(D_{r}=0.70\right.$; $K=2 ; p(0.10)$. This interaction 1s presented in Figure 5 . An item which asked subjects to indicate how much effort they expended in listening to the supplemental vitamin ad (very much effort--very little effort) produced no significant results across any treatment group. 


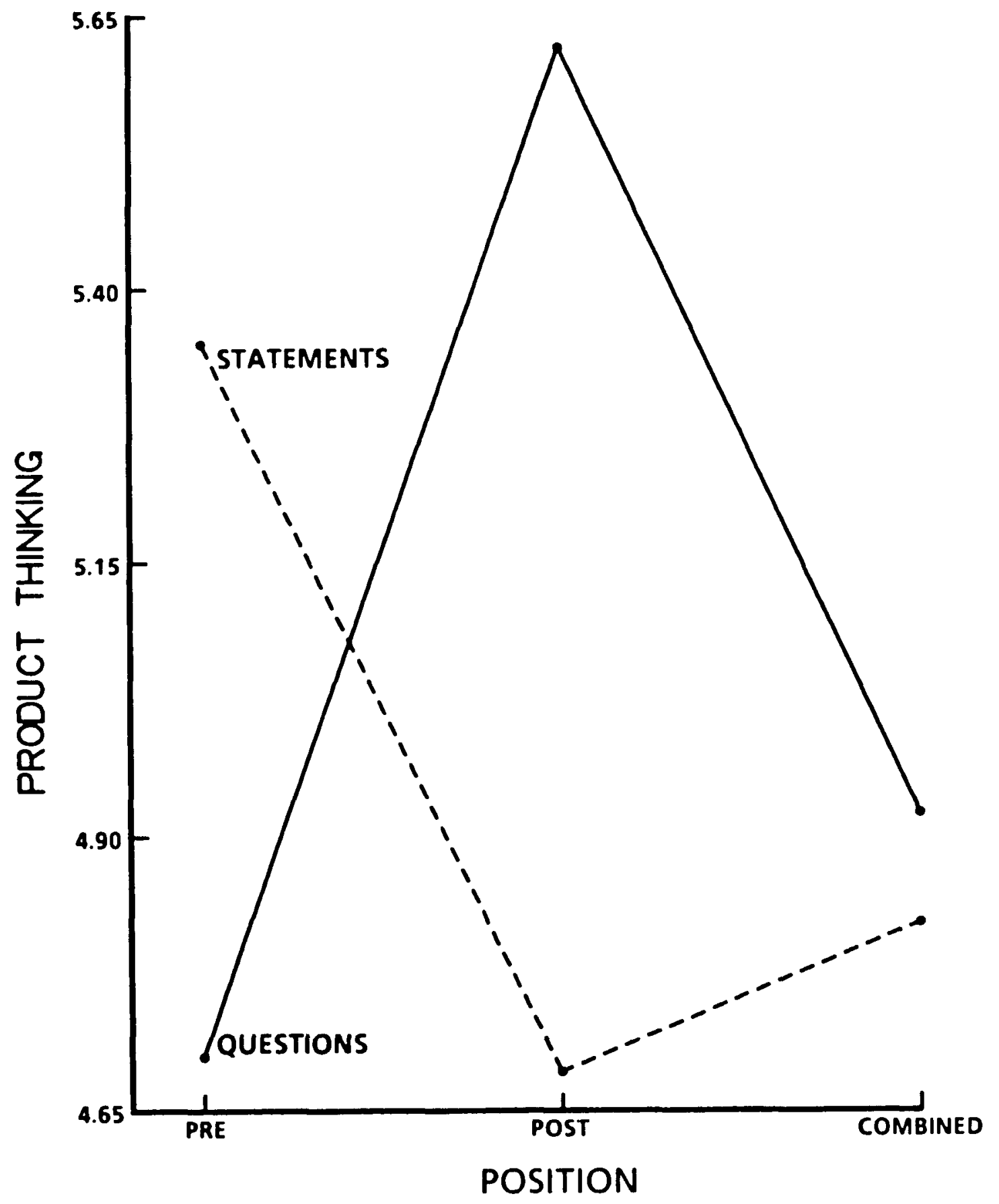

Figure 5

Grammatical Form By Position Interaction For Extent Of Product Related Thinking 
Measures of Message Learning

No signifioant effects were found across any treatment group for recall or corrected recognition measures. Both recall and corrected recognition scores were low. The average recall score across conditions was 3.9 (out of a total possible score of 18); the average corrected recognition soore across conditions was 1.2 (out of a total possible score of 6 ). However, the interaction between grammatical form and time delay approached significance for corrected recognition scores ( $F=2.69 ; p=0.069)$, where 1 was seen that subjects exposed to statements and a 2-second delay had greater recognition than those exposed to question and a $2-$ second delay $\left(D_{r}=0.95 ; K=6 ; p<0.10\right)$.

\section{ADDITIONAL ANALYSES}

Measures of Advert1sement Evaluation

Additional findings of interest were seen on two variables not discussed in terms of original hypotheses development. Subjects rated the supplemental vitamin ad on whether they perceived it as interesting (very interesting--not at al I interesting) and stimulating (very stimulating--not at all stimulating). An analysis of variance summary table for these two varlables is presented in Table 5. A significant two-way interaction between grammatical form and position emerged on ratings of the advertisement's interest ( $F=3.20 ; p=0.042)$. This interaction 18 presented in Figure 6 . Subjects exposed to postquestions rated the advertisement as more interesting than those exposed to poststatements $(F=3.18 ; d f=1,342 ; p<0.05$, one-ta11). 
TABLE 5

Analysis of Variance Summary Table for Ad

StImulation and Interest Measures

\section{F-Ratios for Dependent Variables}

Independent

Varlables

$\underline{d f}$

Ad Interest

Ad Stimulation

Grammatical

Form (QS)

1

0.01

0.00

Position (P)

2

1.63

1.36

Time Delay (D)

2

0.92

1.30

QS $\times P$

2

$3.20=$

$4.35^{* *}$

QS $\times D$

2

1.00

0.07

$P \times D$

4

0.33

0.11

QS $\times P \times D$

4

0.45

0.24

Residual

342

$\because=p<0.05$ 


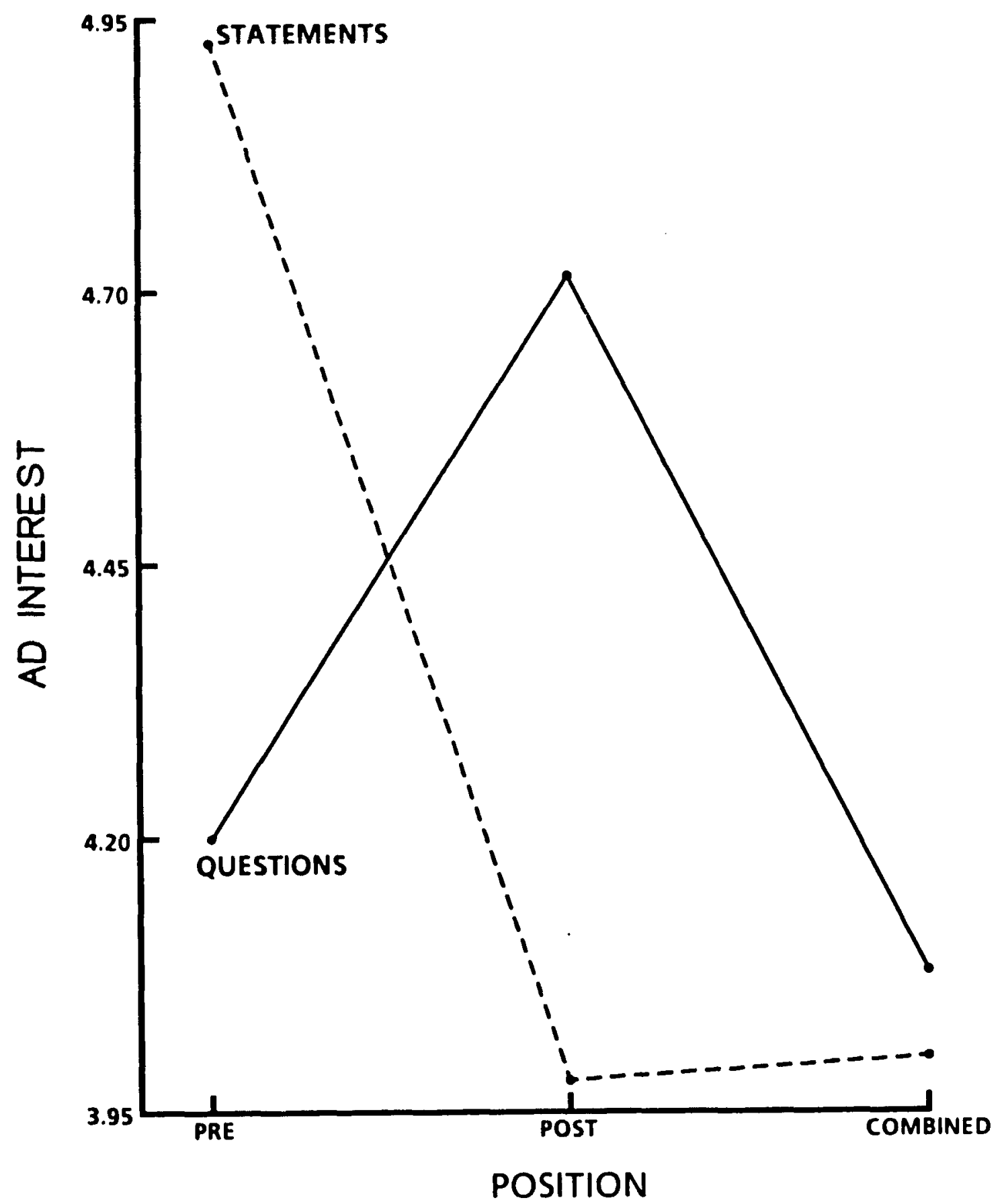

Figure 6

Grammatical Form By Position Interaction For

Ratings of Advertisement Interest 
However, subjects exposed to prequestions rated the ad as less Interesting than those exposed to prestatements $(F=3.18 ; d f=1,342$; $p(0.10) .^{14}$ No signiflcant differences were seen between combined questions and combined statements (F<1). Subjects exposed to prestatements rated the ad as more interesting than those in the poststatement $\left(D_{r}=0.91 ; K=6 ; p<0.05\right)$ or combined statement conditions $\left(D_{r}=0.89 ; \quad K=5 ; \quad p<0.05\right)$. A significant two-way interaction also emerged between grammatical form and position on ratings of the advertisement as stimulating $(F=4.35 ; p=0.014)$. This interaction is - presented in Figure 7. Subjects exposed to prequestions judged the ad to be less stimulating than those exposed to prestatements $(F=4.45$; $d f=1,342 ; p<0.05)$. However, subjects exposed to postquestions judged the ad as being more stimulating than those exposed to poststatements $(F=4.12 ; d f=1,342 ; p<0.05)$. No sign1ficant $d 1 f f e r e n c e s$ were seen between the combined question and statement oonditions ( $F(1)$. In addition, prestatement subjects judged the ad to be more stimulating than either poststatement $\left(D_{r}=0.85 ; K=6 ; p<0.05\right)$ or combined statement subjects $\left(D_{r}=0.84 ; K=5 ; p<0.05\right)$.

It should be noted that no significant effects emerged in ratings of whether the vitamin ad was truthful, ordinary, realistic, bellevable, confusing, or high in quality. The nclosest" any effect came to standard levels of significance was the interaction between grammatical form and position for ratings of ad believability ( $F=2.08$;

$14_{A}$ two-tailed test was necessary for this contrast since the direction of the mean differences was the opposite of expectations. 


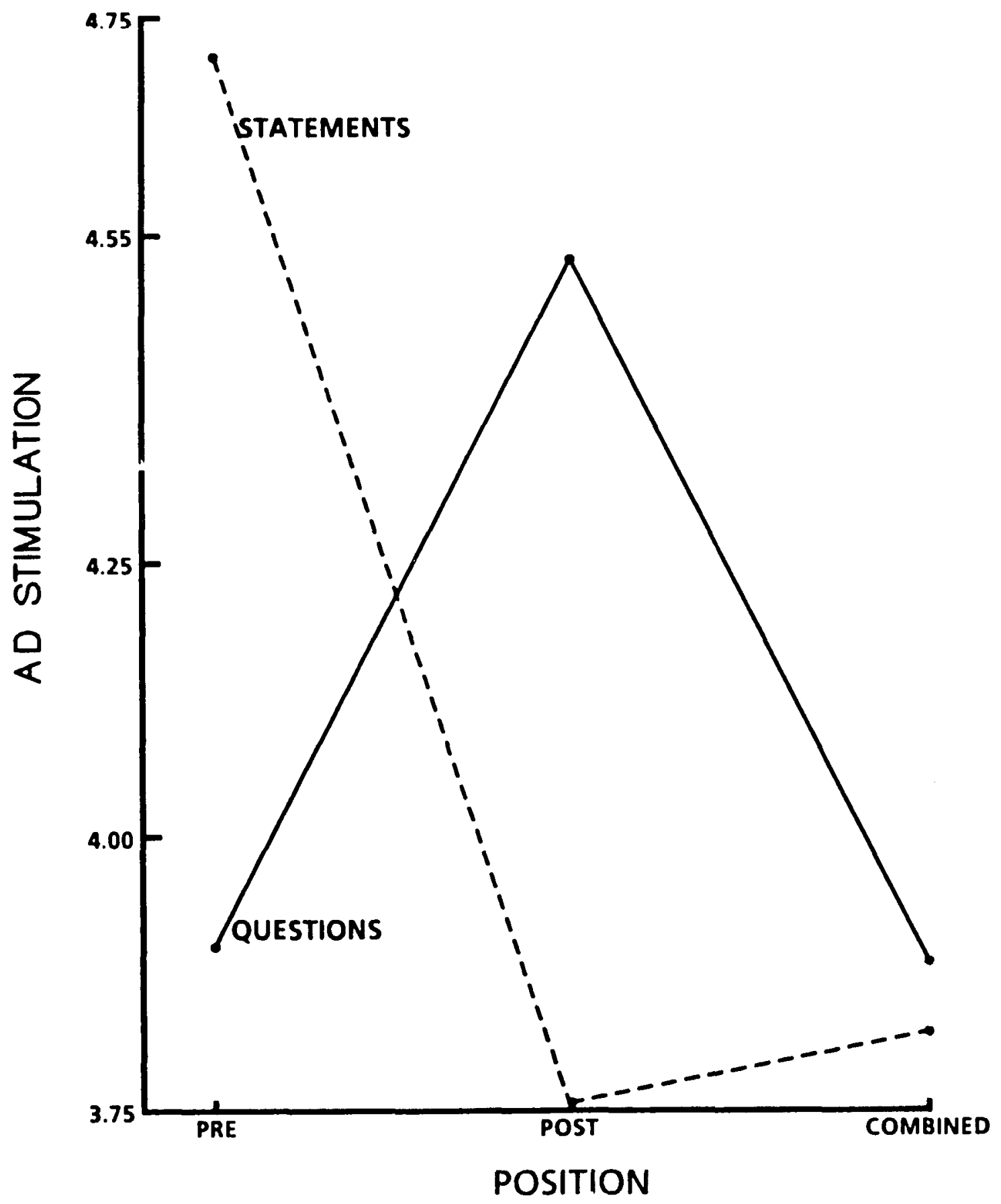

Figure 7

Grammatical Form By Position Interaction For Ratings of Advertisement Stimulation 
$p=0.126$ ), which will be seen to have implications for a later analysis. Finally, no significant treatment group differences were found across four 1tems designed to determine whetber the supplemental vitamin ad threatened decision-making freedom or was perceived as explicitiy attempting to persuade.

\section{Speaker Ratings}

Ten items asked respondents to "rate the individual who served as the speaker for the supplemental vitamin ad." No significant effects were seen on nine out of ten ratings in terms of the speaker being judged as good, blased, sincere, trustworthy, truthful, likeable, knowledgeable, polite, or exerting high pressure. However, a threeway interaction between grammatical form, position and time delay emerged for ratings of speaker confidence $(F=8.51 ; d f=4,342 ; p=0.003)$. It was found that subjects exposed to combined questions with a 4 second delay rated the speaker as having less confidence than those exposed to combined questions with a $2-8$ econd delay $\left(D_{r}=1.43 ; K=18\right.$; $p<0.01$ ), or those exposed to prestatements with a 2 -second delay $\left(D_{r}=1.11 ; \quad K=17 ; p<0.05\right)$.

\section{Perceptlons of Advertisement Length}

Subjects were asked to estimate the length in broadcasting time of the supplemental vitamin ad. These estimates were analyzed in a search for information related to the failure of the hypothesized time delay effects (see discussion in Chapter VI). The average estimate of time across conditions was 1 minute, 19.8 seconds, considerably 
shorter than the actual average time of approximately 2 minutes, 3 seconds. An interaction between position and delay was considered likely since the combined position with a 4-seoond delay was 22.5 seconds longer than either the pre or post positions with a $0.5-8 e c o n d$ delay. In other words, the combined position was approximately 12 seconds longer than either the pre or post positions. And the 4second delay condition was 10.5 seconds longer than the $0.5-8 e c o n d$ condition. However, only a main effect of position was seen $(F=5.20$; $p=0.006$ ). Cell comparisons revealed that while subjects in the combined positions ( $M=87.3$ seconds) gave an estimated ad length longer than post position $\left(M=70.4\right.$ seconds) subjects $\left(D_{r}=10.97 ; K=3 ; p<0.05\right)$, the combined position mean was not longer than the pre position mean $(M=81.65)$. Furthermore, the post position mean was found to be significantly lower than the pre position mean $\left(D_{r}=10.45 ; R=2 ; p<0.05\right)$ when in fact the ad length was precisely the same for those two positions. It is interesting to note that this same effect, albeit a weaker one, was found for estimates of the time length of the AT\&T ad which lmediately followed the supplemental vitamin ad. The average estimated length of the AT\&T ad was 38.2 seconds, again considerably shorter from the actual broadcast time of 59 seconds. The main effect of position closely approached statistical significance $(F=2.78$; $p=0.064)$. Again, the mean estimated ad length for those in the combined positions $(M=40.44)$ was longer than those in the post position $(M=34.56)\left(D_{r}=4.68 ; K=3 ; p<0.10\right)$, but not longer than the average estimate of those in the pre position $(M=39.53)$. The average 
time estimate of those in the post position was also seen to be shorter than those in the pre position $\left(D_{r}=4.43 ; K=2 ; p<0.10\right)$.

\section{Four Factor Design}

With the three factor design, the interaction between grammatical form and position was consistently seen across measures of positive message topic thoughts, arousal of doubt, extent of product related thinking and ratings of the vitamin ad as stimulating and interesting. Given those effects, it seemed curious that similar results were not obtained for the attitude and purchase intention measures. An examination of question wording for those two measures, however, revealed a common feature. Namely, both of those items were worded in a manner to directly imply product usage. Again, the purchase intention item asked respondents, "How likely would you be to purchase supplemental vitamins?n It 18 assumed that if undergraduate university students purchase vitamins, the purchase would be made for personal consumption. The attitude items stated, "My taking supplemental vitamins 1s ..." (emphasis added). Thus, a common feature is that both measures (1.0., the attitude and purchase intention items) directly implied product usage.

A product usage varlable was added to the analysis. It was suspected that a variable reflecting prior experience with supplemental vitamin usage would logically have a substantial impact on outcome measures implicating usage. The product usage variable of choice asked respondents if they had ever nconsistently used supplemental vitamins" for a one-year perlod of time or longer and was 
scored yes $(n=130)$ versus no $(n=230)$. Th1s varlable was preferred over another which asked subjects if they currently used supplemental vitamins (yes versus no) since persons may be currently using vitamins only intermittently. However, the measure reflecting consistent product usage over a given time perlod appeared to more clearly stratify respondents with respect to product usage experience and was therefore expected (and found) to more strongly affect variation in the attitude and purchase intention measures.

With grammatical form, position, time delay, and product usage as between-subjects factors, a $2 \times 3 \times 3 \times 2$ analysis of variance was performed on the attitude and purchase intention measures. An Analysis of Variance Summary table including these measures is presented in Table 6. A strong main effect of product usage was seen for attitude $(F=78.37 ; d f=1,324 ; p<0.0001)$, where subjects having used supplemental vitamins for over a year evaluated taking vitamins more positively than those with less product usage experience. A significant Interaction between grammatical form and position was also found $(F=3.06 ; d f=2,324 ; p=0.048)$. This interaction is presented in Figure 8. Subjects exposed to postquestions were found to have a more favorable attitude towards taking supplemental vitamins than those exposed to poststatements $(F=3.97 ; d f=1,324 ; p<0.05)$. No significant differences were seen between the prequestions and prestatements $(F<1)$ or between the combined question and combined statement conditions $(F<1)$, and no other significant effects emerged. However, a marginaliy significant interaction appeared between position, product 
TABLE 6

\begin{abstract}
Four-Factor Analysis of Varlance Summary Table for Attitude, Purchase Intention and Ad Bellevability Measures
\end{abstract}

\title{
F-Rat1os for Dependent Variables
}

\begin{tabular}{|c|c|c|c|c|}
\hline Variables & $\underline{\text { df }}$ & Attitude & Intentions & Bellevab1l1ty \\
\hline $\begin{array}{c}\text { Grammatical } \\
\text { Form (QS) }\end{array}$ & 1 & 0.26 & 0.03 & 0.59 \\
\hline Position (P) & 2 & 0.06 & 1.95 & 1.79 \\
\hline $\begin{array}{l}\text { Product } \\
\text { Usage (U) }\end{array}$ & 1 & $78.37=6 \times$ & $82.04=14:$ & 0.19 \\
\hline T1me Delay (D) & 2 & 0.07 & 1.22 & 1.27 \\
\hline$Q S \times P$ & 2 & $3.06 *$ & $3.25^{* 11}$ & 2.59 \\
\hline$Q S \times U$ & 1 & 0.40 & 0.72 & 0.22 \\
\hline$Q S \times D$ & 2 & 1.18 & 0.09 & 0.05 \\
\hline$P \times U$ & 2 & 0.09 & 0.21 & 1.30 \\
\hline$P \times D$ & 4 & 0.23 & 0.40 & 1.77 \\
\hline$U \times D$ & 2 & 0.21 & 2.21 & 0.19 \\
\hline$Q S \times P \times U$ & 2 & 0.29 & 0.89 & 0.40 \\
\hline$Q S \times P \times D$ & 4 & 1.34 & 0.84 & 0.95 \\
\hline$Q S \times 0 \times D$ & 2 & 0.17 & 0.13 & 0.48 \\
\hline$P \times O \times D$ & 4 & 2.10 & 0.30 & 1.10 \\
\hline$Q S \times P \times U \times D$ & 4 & 0.87 & 0.35 & 0.82 \\
\hline Residual & 324 & & & \\
\hline
\end{tabular}




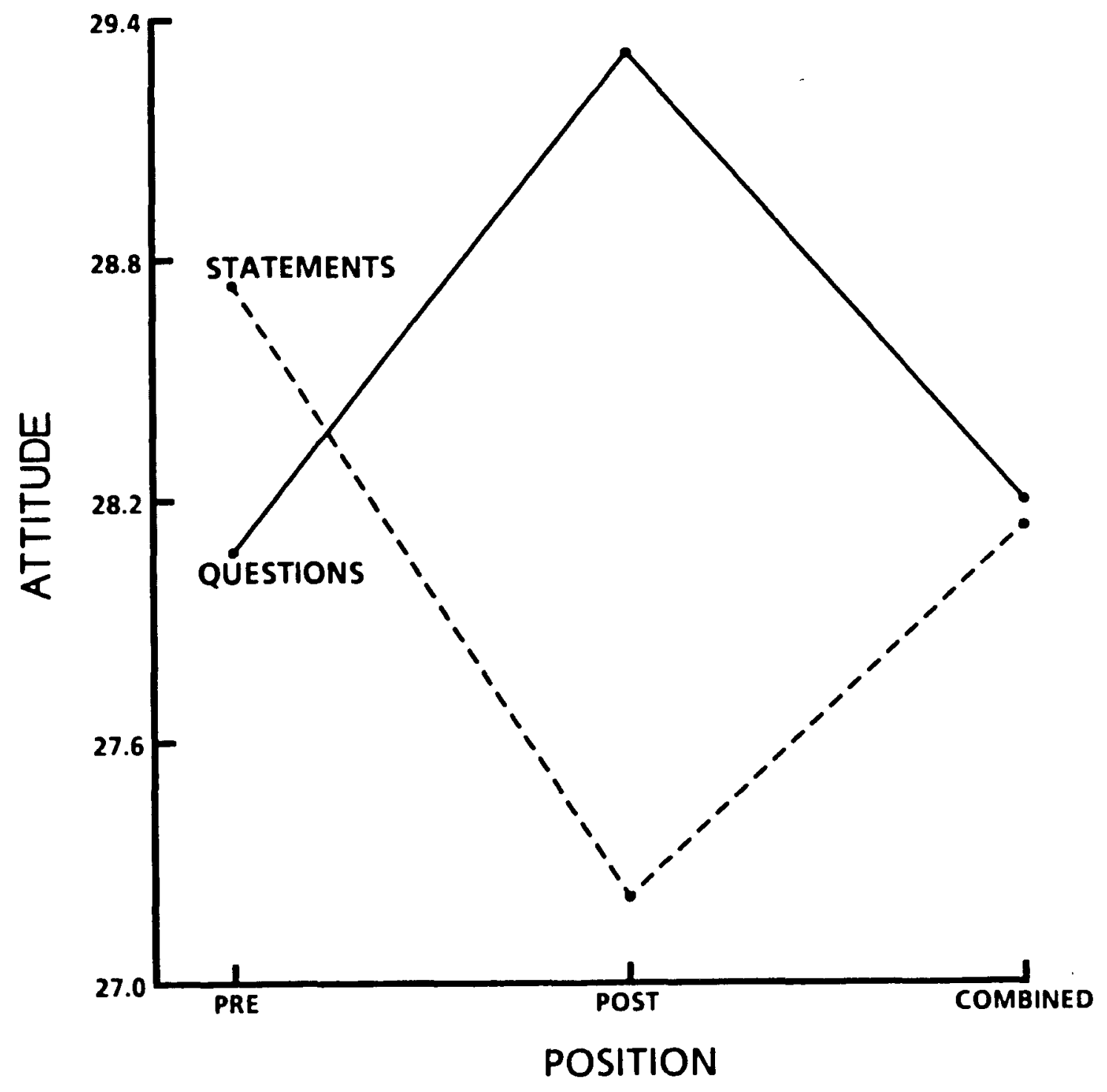

Figure 8

Grammatical Form By Position Interaction For Attitude Towards Taking Supplemental Vitamins 
usage and time delay $(F=2.10 ; d f=4,324 ; p=0.081)$. Consistent across levels of product usage, it was found that subjects exposed to combined questions with a 4-second delay had a more favorable attitude towards taking supplemental vitamins than subjects exposed to combined statements with a 4-second delay $\left(D_{r}=3.79 ; K=18 ; p<0.10\right)$ or those exposed to poststatements with a $0.5-\operatorname{second}$ delay $\left(D_{r}=3.78 ; k=17\right.$; $p<0.10)$. Subjects exposed to postquestions with a 2 -second delay also had more favorable attitudes than the combined statement 4-second delay $\left(D_{r}=3.78 ; K=17 ; p<0.10\right)$ or poststatement 0.5 -second delay subjects $\left(D_{r}=3.75 ; K=16 ; p<0.10\right)$.

A strong main effect of product usage was seen for the purchase intentions measure $(F=82.04 ; d f=1,324 ; p<0.0001)$, with those having higher usage experience being more likely to purchase the product. An interaction between grammatical form and position was also seen $(F=3.25 ; \quad \mathrm{f}=2,324 ; \mathrm{p}=0.040)$. This interaction is presented in Figure 9. Subjects exposed to postquestions indicated a higher likelihood of purchasing supplemental vitamins than those exposed to poststatements $(F=3.58 ; d f=1,324 ; p<0.05$, one-tail). No significant differences were seen between the prequestion and prestatement conditions $(F=1.09$; $d f=1,324 ; p>0.10$ ) or the combined question and combined statement conditions $(F<1)$. Furthermore, purchase intentions were seen to be higher in the postquestion condition in comparison to both the prequestion $\left(D_{r}=0.99 ; R=6 ; p<0.05\right)$ and combined question $\left(D_{r}=0.96\right.$; $K=4$; $p$ (0.05) conditions. No other significant effects emerged for the 


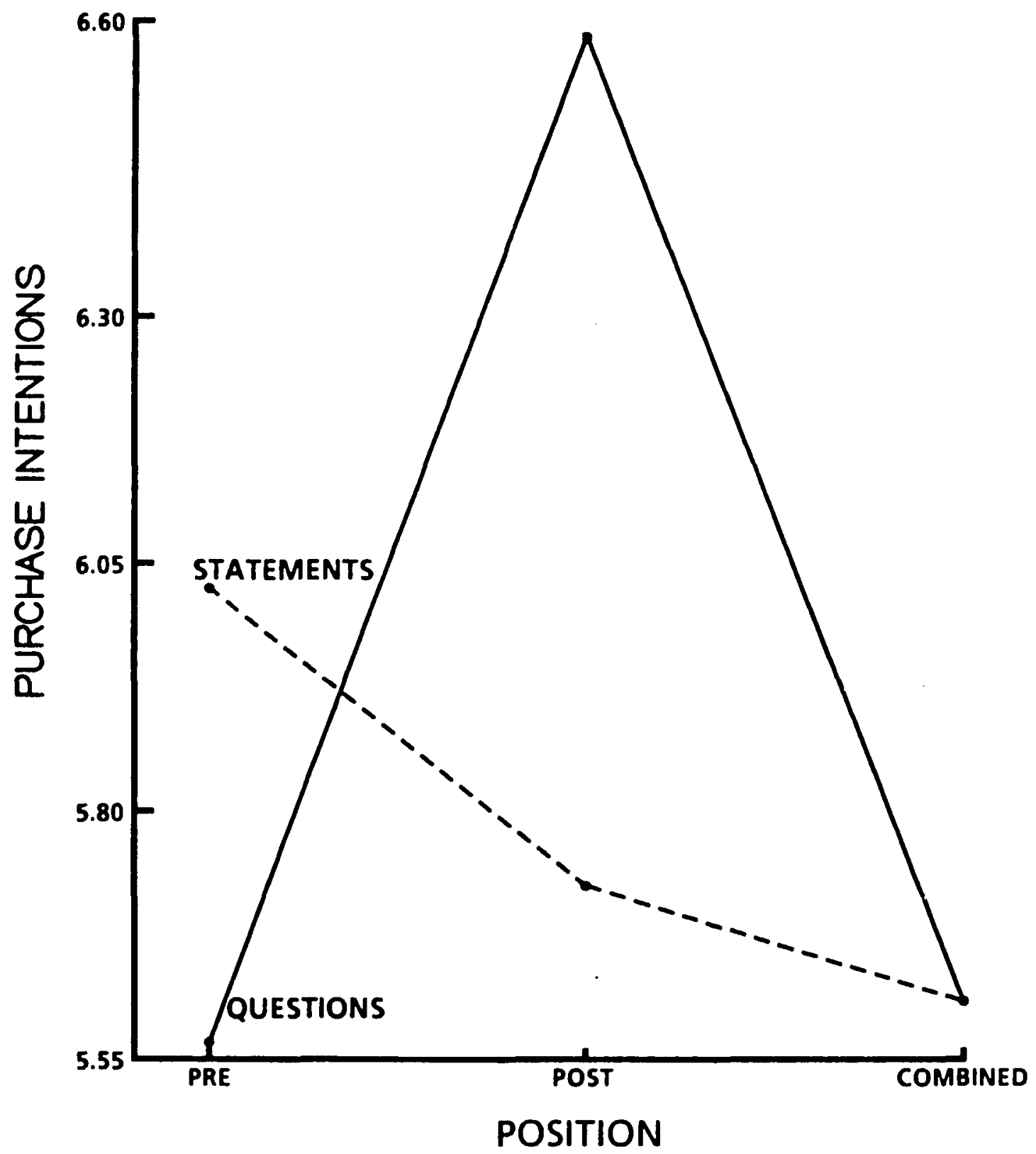

Figure 9

Grammatical Form By Position Interaction for Intentions To Purchase Supplemental Vitamins 
purchase intention 1tem, including the three-way interaction previously discussed ( $F<1$ ).

Finally, it was found that the interaction between grammatical form and position became marginally significant for the item measuring respondent ratings of the bellevability of the supplemental vitamin ad $(F=2.59 ; d f=2,324 ; p=0.077)$. This interaction 18 presented in Figure 10. It was found that subjects exposed to postquestions judged the advertisement to be more believable than those exposed to poststatements $(F=4.30 ; d f=1,324 ; p<0.05)$. No significant differences were seen between the prequestion and prestatement $(F<1)$ conditions or combined question and combined statement $(F<1)$ conditions. No other olgnificant effects were seen for this item, including the main effect for product usage (see Table 6).

The emergence of the significant interaction between grammatical form and position for ad bellevability was not expected. The increase in design efficlency by adding a product usage variable to the design 1s explainable for items directly implying usage (see additional discussion below). However, wording of the ad bellevability item did not directly imply product usage, although it could be argued that perceptions of claim bellevability are a function of past usage experience with a product. St1ll, that is a general argument that could be made for other items presented to respondents (e.g., trustfulness or realism) for whioh the interaction between grammatical form and position did not approach significance with the addition of the usage varlable to the design. In particular, it seemed puzzling 


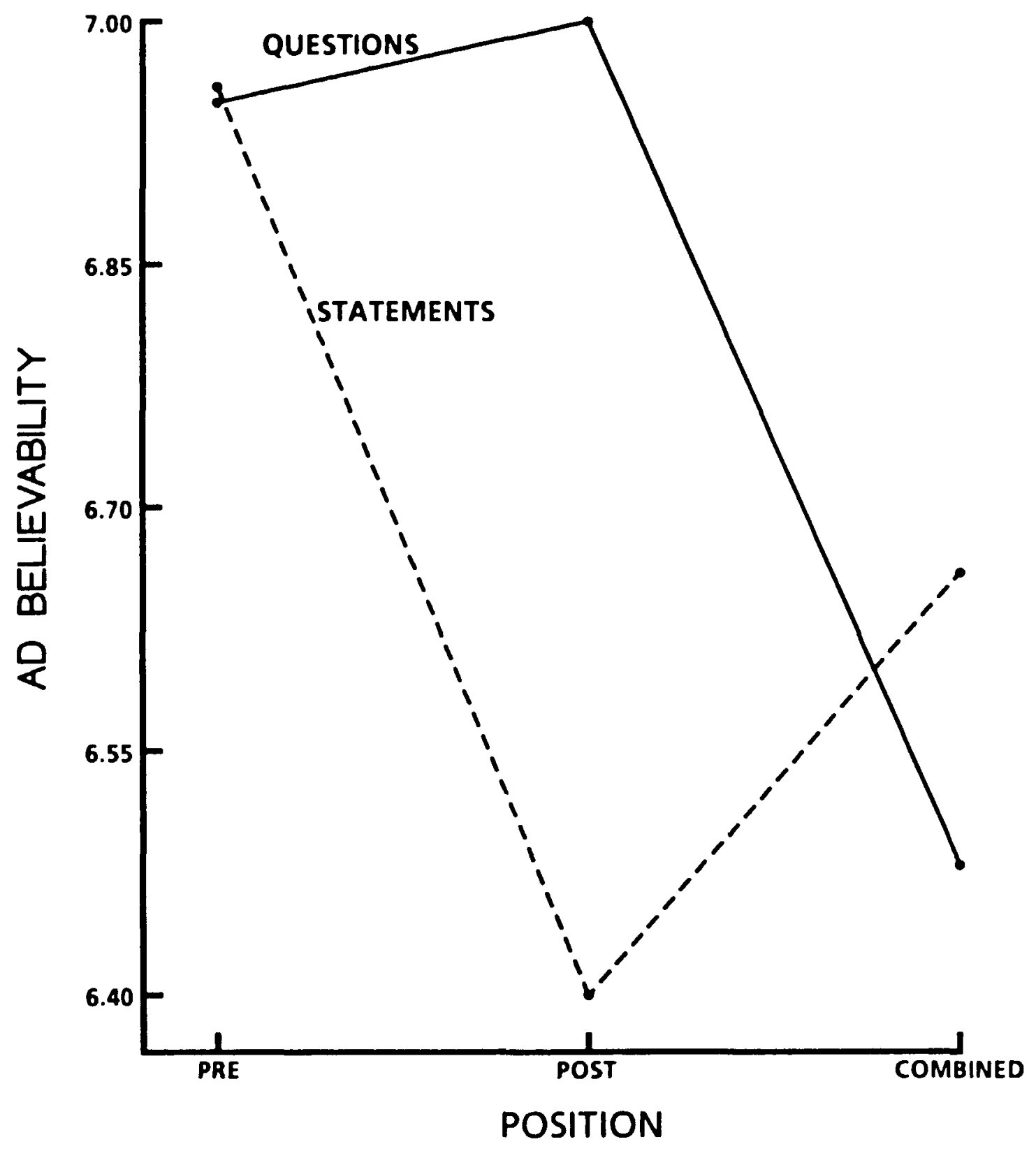

Figure 10

Grammatical Form By Position Interaction For Ratings of Advertisement Believability 
why a significant difference between postquestions and poststatements was found with the addition of a variable to the design which could not be $10 \mathrm{~g} i c a l l y$ linked to the effect in a sense more rational than other 1tems for which the effect was not observed. The ad believability liem was again examined in the context of the three factor design. As previously noted, the interaction between grammatical form and position was not significant $(F=2.08 ; p=0.126)$. However, the greater power of the orthogonal comparison did reveal a significant difference between subjects exposed to postquestions and those exposed to poststatements $(F=4.25 ; d f=1,342 ; p<0.05)$. Again, no significant differences were seen between the prequestion and prestatement $(F<1)$ or combined question and combined statement conditions (F<1). The significant difference observed in the Interaction was not contingent upon addition of the product usage varlable to the design. Table 7 presents cell means for the elght variables revealing a grammatical form by position interaction. Table 8 presents a summary of significant results for the grammatical form by position interaction.

\section{The Effect of Product Usage}

The question to be addressed here is the interpretation of the findings just presented for the attitude and purchase intention measures. As discussed, adding a product usage variable to the design resulted in two effects: 1) a strong and significant main effect for the product usage variable; 2) a significant interaction between grammatical form and position. This directly suggests that the 
TABLE 7

Mean Scores on Outcome Measures Demonstrating a Grammatical Form by Position Interaction

Outcome

Measure

Attitude

Positive Thoughts

Purchase Intentions

Ad Stimulation

Ad Interest

Ad Bellevability

Arousal of Doubt

Product Thinking

Cell S1zes

\section{Condition}

$\begin{array}{cccccc}\text { Pre } & \text { Pre } & \text { Post } & \text { Post } & \text { Combined } & \text { Combined } \\ \text { Question } & \text { Statement } & \text { Question } & \text { Statement } & \text { Question } & \text { Statement }\end{array}$

28.06

28.73

29.31

27.20

28.20

28.13

2.86

3.35

3.58

2.78

2.95

3.20

5.56

6.03

6.58

5.73

5.61

5.61

3.90

4.72

4.53

3.75

3.88

3.83

4.20

4.93

4.72

3.98

4.08

4.00

6.95

6.96

7.00

6.40

6.48

6.66

10.00

10.71

11.41

9.45

10.43

10.11

4.70

5.35

5.62

4.68

4.92

4.83

60

60

60

60

60

60 
TABILE 8

\section{Grementioal Porn I Poeltion Intercotion:}

Sumary of Solcoted coll comarisoos

\section{Depeadeat Meacure}

\section{Coll comparicons"}

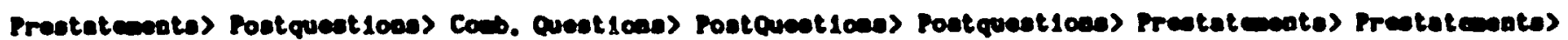

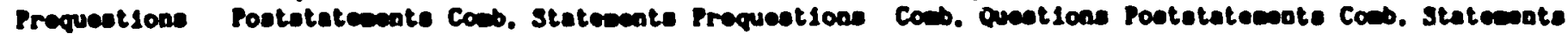

\begin{tabular}{|c|c|c|c|c|c|c|c|}
\hline Atestude & - & 0.05 & - & - & - & - & - \\
\hline $\begin{array}{l}\text { Poolt1re } \\
\text { moucter }\end{array}$ & - & 0.05 & - & 0.10 & 0.10 & - & - \\
\hline $\begin{array}{l}\text { Purohese } \\
\text { Incoat 10ea }\end{array}$ & - & $0.05(1-\tan 1)$ & - & 0.05 & 0.05 & - & - \\
\hline 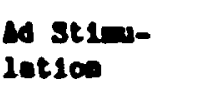 & 0.05 & 0.05 & - & - & - & 0.05 & 0.05 \\
\hline M Interent & 0.10 & 0.05 (1-call $)$ & - & - & - & 0.05 & 0.05 \\
\hline $\begin{array}{l}\text { No sol100- } \\
\text { obl11ty }\end{array}$ & - & 0.05 & - & - & - & - & - \\
\hline $\begin{array}{l}\text { Arowanl } \\
\text { of Doubt }\end{array}$ & - & 0.02 & - & - & - & - & - \\
\hline $\begin{array}{l}\text { Product } \\
\text { Toloning }\end{array}$ & - & 0.05 & - & 0.05 & 0.10 & - & - \\
\hline
\end{tabular}

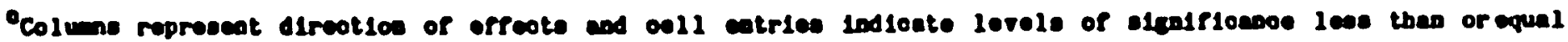
to the entries. 
principal benefit of adding the usage variable to the design was obtained by controlling for the main effect of product usage, thus contributing to greater design efficiency. If that is the case, then executing the three-factor design with product usage as a covariate should provide precisely the same result as the four-factor ANOVA. 15 Th1s was confirmed for both the attitude and purchase intention measures. The regression of attitude on the product usage variable was strong and significant $(F=79.50 ; d f=1,341 ; p<0.0001)$ and the interaction between grammatical form and position became significant $(F=3.02 ; d f=2,341 ; p=0.05)$. An examination of corrected cell means revealed that subjects exposed to postquestions more favorably evaluated taking supplemental vitamins than those exposed to poststatements $(F=5.19 ; d f=1,341 ; p<0.05)$. No otber significant differences were seen. Note that residualizing attitude on the product usage variable in a dummy regression analysis and analyzing the residualized measure (1.e., the raw scores with the influence of product usage partialled out) in the three-factor ANOVA produced the same results. That was expected since regression (covariance) analysis corrects for the main effect of the independent variable (covariate) on the dependent measure.

The same procedures were followed for the purchase intentions measure. The regression of purchase intentions on the product usage covariate produced a strong and significant effect $(F=82.14 ; d f=1,341$;

\footnotetext{
15 Using a dichotomous variable as a covariate follows the same statistical reasoning as dumby regression analysis.
} 
$p<0.0001)$ and the interaction between grammatical form and position became significant $(F=3.27 ; d f=2,341 ; p=0.039)$. An examination of corrected cell means revealed that subjects exposed to postquestions Indicated a higher likel thood of purchasing supplemental vitamins than those exposed to poststatements $(F=4.81 ; d f=1,341 ; p<0.05)$ as well as those exposed to either prequestions $\left(D_{r}=0.97 ; K=5 ; p<0.05\right)$ or combined questions $\left(D_{r}=0.99 ; K=6 ; p<0.05\right)$. No other significant effects were seen. Again, note that analysis of the residualized purchase intention measure obtained through using product usage as a dummy regression varlable produced the same results.

In summary, the interaction between grammatical form and position was found to be significant when variation attributable to the main effect of product usage experience was extracted or controlled. In other words, those items which directly implied product usage required holding a usage variable constant in order for effects to emerge consistent with other outcome variables that did not directly imply product usage. Although there was a consistent directional effect indicating that persons with less experience with vitamins were more strongly influenced by questioning than those with more experience, the effect was not strong enough to introduce an interaction. If this argument is true, then it also suggests that the prevlously discussed effects for the grammatical form by position interaction found witb the three-factor design should remain essentialiy unchanged when examined in the context of the four-factor design. That expectation was confirmed. All significant cell comparisons for the positive 
thoughts, arousal of doubt, product thinking, ad interest, stimulation and believability measures remained significant at exactly the same level when moving from the three- to the four-factor design and no additional comparisons became significant.

\section{Determinants of outcomes}

In the final stage of analysis, the principal outcomes were examined to determine if the effects, as expected, could be accounted for by the arousal of doubt and extent of product thinking. Covariance analysis was used to assess this issue using the arousal of doubt and product thinking measures as covariates.

Results using the three-factor design will be discussed first. Both product thinking $(F=35.34 ; d f=1,340 ; p<0.0001)$ and arousal of doubt $(F=3.86 ; d f=1,340 ; p<0.05)$ were found to be significant determinants of the number of positive thoughts. The grammatical form by position interaction was found to no longer be significant $(F=1.46$; $d f=2,340 ; p=0.233$ ). Only the product thinking measure was seen to be a significant covariate for perceptions of the vitamin ad as interesting $(F=129.81 ; d f=1,340 ; p<0.0001)$. The grammatical form by position interaotion became nonsignificant ( $F=1.09 ; d f=2,340 ; p=0.34)$. Product thinking was also found to be the only significant predictor of ratings of the ad as stimulating ( $F=141.61 ; d f=1,340 ; p<0.0001)$. The grammatical form by position interaction became nonsignificant $(F=1.94 ; d f=2,340 ; p=0.145)$ and corrected cell means revealed no differences, marginal or otherwise, when using orthogonal comparisons. 
With the four-factor design product thinking was found to be the only significant predictor of ad bellevability $(F=84.481$; $f=1,322$; $p=(0.0001)$. The grammatical form by position interaction became nonsignificant $(F=1.43 ; d f=1,322 ; p=0.241)$. The arousal of doubt was found to be a significant predictor of attitude $(F=32.35 ; d f=1,322$; p $<0.0001)$ but witb product tbinking a 180 being a aignificant determinant $(F=25.03 ; d f=1,322 ; p<0.0001)$. The grammatical form by position interaction again became nonsignificant $(F=1.34 ; d f=2,322$; $p=.254)$. Arousal of doubt was again found to be a significant predictor of purchase intentions $(F=13.19 ; d f=1,322 ; p<0.0001)$, and with product thinking also being a significant determinant $(F=13.99$; $d f=1,322 ; p<0.0001)$. The grammatical form by position interaction was seen to be nonsignificant $(F=1.84 ; d f=2,322 ; p=0.16)$ and orthogonal comparisons on corrected cell means revealed no differences, marginal or otherwise.

Note that use of either the product thinking or arousal of doubt measures alone were able to eliminate the significance (marginal or otherwise) of the grammatical form by position interaction for the attitude measure although both were needed to eliminate marginal significance $(p<0.10)$ of the grammatical form by position interaction for the purchase intentions measure. For the positive thoughts measure only the product thinking measure was able to completely eliminate the 1nteraction, which still approached significance $(F=2.76 ; d f=2,341 ; p=0.064)$ when only using arousal of doubt as a covariate. Note that the arousal of doubt had a significant effect 
when used singularly as a covariate $(F=5.08 ; d f=1,341 ; p=0.025)$.

An additional issue that was examined concerned the relationship between product related thinking and the arousal of doubt. It is interesting to note that the arousal of doubt and product thinking measures were found to be independent. Product thinking had a nonsignificant effect on arousal of doubt when used as a covariate $(F=1.56 ; d f=1,341 ; \quad p=0.212)$. The overall correlation $(r=0.065$; $p=0.212)$, as well as correlations within each cell of the grammatical form by position conditions, failed to produce evidence that the relationship between the two measures was greater than zero, although the correlation for the combined question cell ciusely approached significance. Table 9 presents the within cell correlations between product thinking and the arousal of doubt for the grammatical form by position interaction.

TABLE 9

Within Cell Correlations Between Product Thinking and the Arousal of Doubt

Position

$\begin{array}{lccc}\text { Grammatical Form } & \text { Pre } & \underline{\text { Post }} & \text { Combined } \\ \text { Questions } & 0.031 & 0.086 & 0.249 \\ & (0.813) & (0.512) & (0.054) \\ \text { Statements } & -0.122 & 0.072 & 0.026 \\ & (0.352) & (0.582) & (0.838)\end{array}$

$d_{C e l l}$ sizes equal 60 ; two-tailed levels of significance are enclosed in parentheses. 
Finally, a serles of oovarlance analyses was performed to determine if the observed outcomes could be explained by either evaluation of the musical programming used in the radio show, evaluation of disc jockey performance, or ratings of the speaker for the supplemental vitamin ad.

Evaluation of the musical programing and the disc jockey were determined using four scales: very good--very bad, very borling--very interesting, very stimulating--not at all stimulating, beld my attention very well--did not bold my attention well at all. These scales produced a reliable index of both musical evaluation (alpha=0.896) and disc jockey evaluation (alpha=0.913). Analyses of covariance were performed to determine if these evaluations could account for effects observed on outcome measures. That possibility was rejected. The grammatical form by position interaction for all elght principal outoome measures was unaffected by using musical and disc jockey evaluations as covariates. The outcomes observed must be assumed to be independent of respondent evaluations of the radio show. An Index of source evaluation was developed using ratings of the speaker as very sincere--not at all sincere, very trustworthy--not at al I trustwortby, very trutbful--not at all trutbful (alpha=0.785). Using this scale as a covariate was found to have no determining effect on the grammatical form by position interaction for any of the eight outcome measures observed. For reasons of completeness, the remaining seven items providing ratings of the speaker were also separately used in a series of oovariance analyses for the eight 
principal outcome measures. Over these 56 separate tests, it was seen that for perceptions of the ad as interesting the grammatical form by position interaction $(p=0.042)$ was reduced to $p=0.061$ when ratings of speaker knowledge was used as a covarlate, and $p=0.075$ when ratings of speaker confidence was used as a covariate. However, when product thinking was used as a covariate along with the speaker ratings, the effect of the speaker ratings had a nonsignificant effect on outcomes. For perceptions of ad believability, the significance of the critical Interaotion $(p=0.077)$ was reduced to $p=0.099$ when ratings of the speaker as good/bad was used as a covarlate. But again, when used as a covariate along with extent of product thinking, the effect of the speaker rating variable was $n 11$. Finally, the significance of the oritical interaction for ad bellevability was reduced to $p=0.098$ when speaker confidence was used as a covariate. Consistent with the pattern noted above, speaker confidence was not significant as a covariate when used in conjunction with product thinking measure. In summary, in the vast majority of cases speaker ratings had no impact at all on the outcomes reported here. When they did have an impact, the effect was not large in comparison to product thinking as a determinant of the effect. There appears to be no reasonable evidence that source related perceptions can account for the outcomes observed. 
CHAPTER VI

DISCUSSION AND INTEGRATION

\section{Summary of Expectations}

A three-way interaction between grammatical form, position and time delay was anticipated. Prequestions and postquestions were expected to be superior to prestatements and poststatements respectively in producing desired outcomes. Combined questions were expected to be superior to combined statements, as well as singular prequestions or postquestions. However, the magnitude of the expected differences was expected to depend on position and time delay. It was anticipated that time delay would have no significant influence on the effectiveness of prequestions. However, an increased time delay was expected to Improve the effectiveness of postquestions and combined questions relative to poststatements and combined statements respectively. An Increased time delay was also expected to Improve the effectiveness of combined questions relative to prequestions.

\section{Summary of Principal Results}

None of the bypothesized expectations were supported. The finding most consistently observed involved an interaction between grammatical form and position. That interaction was seen for attitude, positive thoughts, purchase intentions, perceptions of the 
advertisement as bellevable, interesting and stimulating, extent of product related thinking, and the arousal of doubt. The general pattern of directional results showed favorable outcomes increasing from the prequestion to postquestion conditions and then decreasing from the postquestion to combined question conditions; favorable outcomes decreased from prestatement to poststatement conditions and then usualiy increased from poststatement to combined statement conditions. As seen in Table 7, however, only three results appear to be consistently supported: 1) a lack of a significant difference in outcomes between prequestions and prestatements, although when a difference is seen it favors prestatements; 2) a significant difference in outcomes between postquestions and poststatements, favoring postquestions; 3) a lack of a significant difference in outcomes between combined questions and combined statements.

The extent of product relevant thinking was found to be a plausible determinant of the other principal results, with the exception of purchase intentions. The arousal of doubt was found to be a significant determinant of positive cognitive responses, attitude and purchase intention measures; however, arousal of doubt was only able to completely explain the attitudinal effects. Evaluations of the musical programming, disc jockey or speaker for the supplemental vitamin ad were found to have no determining effect on the principal results. 
Uninterpretable Effects

Four statistically significant results were obtained which this author was unable to interpret. Three of those findings involved three-way interactions (between grammatical form, position and time delay) for the purchase intention, total cognitive response and ratings of speaker confidence measures. The fourth involved a two-way interaction between position and time delay for negative thoughts. As previously seen, the three-way interaction for purchase intentions was eliminated by introducing a product usage variable to the design (see Chapter V: The Effect of Product Usage). As discussed by Burnkrant and Howard (1984), the total cognitive response measure may behave differently in a broadcast, as opposed to a print medium. It should also be noted that as the number of treatment levels increases, the chance of spurlous findings also increases (Kennedy, 1978). There was no consistency in cell comparison differences across any of the four interactions noted above, nor were the findings understandable in a substantive sense. It is the lack of consistency of the above noted interactions in contrast to the consistency of other interactions observed which leads this investigator to conclude that the former are spurious findings and the latter are not. At the least, the latter are able to be meaningfully interpreted, whereas the former are not.

\section{Failure of the Time Delay Manipulation}

Some literature was reviewed, and a pretest performed (see Chapter IV: Time Delay Pretest), suggesting that a period of silence 
after questioning may affect the processing of the message presented. Specifically, an increased time delay after questioning (for the 2second but not the 4-second delay condition) was found to result in more thinking about the message and a higher likelihood of message acceptance. However, the time delay varlable was found to have no systematic effect on any of the dependent variables, or additional outcome measures, in this investigation. An examination of the procedures used in executing the pretest, as opposed to the formal study, revealed two primary differences of concern. First, subjects in the pretest were instructed that their task was to "evaluate an advertisement," whereas subjects in the final study were told that their task was to "listen to a radio show as you normally would" and provide some feedback afterwards. The critical difference between those instructions appears to be the degree to which subject attention was directed towards the target advertisement. That difference was likely exaggerated by the second major difference between the pretest and final investigation: the presence of cues alerting respondents to the issues of concern to the investigation. In the pretest study, the questionnaire presented to respondents began as follows:

The supplemental vitamin ad you just heard asked three different questions. A pause then occurred after each question. For each scale below place an "X" in the space that corresponds most closely to how you feel.

Five items then asked subjects to indicate how the pauses affected their thinking. It seems likely that, as instructed, subjects evaluated the message with respect to their impressions of the time 
delay to which they were exposed, and not necessarily with respect to the questions or arguments presented. One possibility is that the 2second delay condition was judged as the "least unusual" ad by respondents and judged accordingly, and with that judgment also being reflected in the attitudinal and cognitive response measures. In other words, the ad with the 2-second delay may have corresponded more closely to subject judgments of how long the delay "should have been," when compared to the 0.5-second and 4-second delay versions of the ad. Such differences in judgment may have resulted in the 2 -second delay ad belng evaluated more favorably than the other delay conditions. At the least, instructing subjects to evaluate an ad and then indicating to them what the manipulation of concern actually was is now judged to have been a mistake. Informing subjects of the target manipulation before they answered questions concerning the manipulation may have caused them to respond differently than they would have if not alerted as to what the target manipulation actually was. In final testing, no mention of the time delay occurred and subject attention was not directed at the target ad. Analysis of the estimated length of the vitamin ad indicated that subjects were unable to detect time delay related differences in treatment, although they were able to detect time equivalent differences in text (1.e., post position versus combined position). There is no evidence that subjects were explicitly aware of the time delay differences and results indicate that the differences were not important anyway in affecting outcomes. 
On a positive note, the finding of a lack of variation in outcomes across the three time delay measures can be considered important in 1tself. In developing the 0.5-second delay condition, this investigator was aware that one likely criticism of the expected findings would be that a half-second delay approximated the use of "run-on" sentences. It seems both surprising and noteworthy to find that even with such a delay after questioning subjects still consistently responded favorably to the stimuli. Rejecting the notion that information processing is an instantaneous event appears to leave open at least two plausible explanations. First, subjects may have the ability to continue processing questions concerning the Implications of one argument even while receiving and attending to a further argument. A second explanation, however, is that subjects may not have simultaneousiy processed more than one argument, but instead cognitively delayed processing a second argument until they were finished processing the 1mplications of the first. Either explanation would appear to have implications for the development of question advertisements for broadcasting in practice. For example, the impression of the Kenyon and Eckhardt Co. (developers of the Chrsyler ad discussed in Chapter I) that following a postquestion by a period of silence allows consumers to engage in additional thinking with respect to the ad was not supported in this study. Therefore, broadcasting time might be more effectively used by providing substance rather than silence. 
Questions and Memory

No evidence was found supporting the expectation of increased message learning with the use of questions. An extensive survey of literature has been reviewed in the area of educational psychology reporting question effects on learning. As also noted, however, a major procedural peculiarity was consistently used across those studies: either instructing subjects to answer any questions they encountered or warning them of an impending exam on the material presented. This author's personal conclusion is that such procedural artifacts result in outcomes which are of questionable usefulness for advertising, where no such incentives to process information commonly exist. One further problem for use of the educational paradigm is the practice of comparing a group that receives questions with a standard control group that recelves no equivalent deciarative form of information cue. In other words, questions may serve as cues to pay attention to, or cognitively reviow, certain material; without a statement comparison group it is unclear if any effects are due to the Influence of the information cue or the influence of the grammatical form. Z1llman (1973), however, did obtain effects of questions on learning (when compared to delcarative statements) without the use of incentive instructions. But the questions used were factual questions, immediately followed by the answers. The questions used in this study had no factual answer and were instead developed to facilitate message evaluation with respect to recipient needs. The appropriate conclusion, therefore, seems to be that the type of 
questions used in this study were ineffective at stimulating message learning. In other words, this study found that questions directed at health needs which imply that the reciplent believes something to be true which may be false were ineffective at stimulating message learning. This study can also be added to the previously mentioned long list of past investigations (including Petty, Cacioppo and Heesacker's (1981) rhetorical postquestion study) reporting dissimilar findings concerning treatment effects on learning and persusion.

Question Versus Statement Discrimination Pretest: A Re-examination

As previously discussed, the questions used in this study were compared to statements in a pretest to determine whether those particular questions in themselves had a higher likelihood of motivating information processing. Results indicated that the questions did appear to possess such a differential advantage: Questions were found to have a higher likelihood of motivating Information processing than statements. One implication of that pretest was the expectation that prequestions would be superior to prestatements in facilitating outcomes. The results of this study, however, were not consistent with that expectation.

The inconsistency in results can be explained by the lack of a means to interpret the questions presented in the pretest. It is Important to consider exactly what the pretest stimul1 comprised: a single sentence ending with either a question mark or a period on three separate pages, with four 1tems to be answered with respect to each individual sentence. After re-examining the situation, it was 
concluded that subjects should have had a difficult time judging and evaluating those isolated sentences taken out of context from the message, with no clarifying information either preceding or following the sentences. ${ }^{15}$ The questions/statements were explicity developed with respect to their associated arguments but those arguments were not provided, nor did subjects have an expectation that they would be provided. With a lack of content or context to guide their judgment, subjects may have favored the question sentences on the basis of prior notions of how people naturally respond to questions in general.

To test this 1dea, 42 subjects were randomly assigned to two different conditions. Each condition simply asked subjects to answer the four items previously used on the pretest, with the following modification. In the "question" condition subjects placed an "x" in the space that corresponded most closely to how they felt for the following four items: questions arouse my curiosity--questions do not arouse my curiosity; questions stimulate thought--questions do not stimulate thought; questions result in my paying attention to information that follows--questions do not result in my paying attention to information that follows; questions are interesting-questions are uninteresting. In the "statement" condition the same four items were presented but with the word "statements" substituted for the word "questions." In other words, no "questions" or

${ }^{15}$ Note that in the posttest study even the first prequestion was preceded by an introductory remark clarifying the thrust of the following message. 
"statements" were actualiy presented. Rather, subjects simply responded to the 1tems by themselves. The questionnaire was Introduced to subjects as a survey on communication. The instructions for the "question" condition were as follows:

This is a survey on communication. Perhaps one of the most common occurrences in communication is a "question," defined in the sense of an issue being questioned by someone. Please answer the following four items based on your general experience. Please be honest and thank you for your cooperation and assistance.

The instructions for the "statement" condition were as follows:

This is a survey on communication. Perhaps one of the most common occurrences on communication is a "declarative statement," defined in the sense of an issue being stated by someone. Please answer the following four items based on your general experience. Please be honest and thank you for your cooperation and assistance.

The four 1tems were found to rellably measure the same construct (alpha $=0.710$ ) at a sat1sfactory level. A one-way analysis of variance revealed that questions, in general, were percelved as possessing greater motivational properties than statements $(F=6.39 ; d f=1,41$; $p=0.016)$. In general, pre-existing notions concerning questions, when independent of meaning or context, are dissimilar from pre-existing notions concerning statements. When no evaluative nanchorn is avallable (e1ther context or content) with which to guide judgment, the dissimilarity between the idea of a question and the 1dea of a statement tends to favor the former, at least with respect to the four items used in pretesting. Equivalent results have been observed for 
comparisons using isolated questions versus statements (questions and statements isolated from the content to which they refer, with no expectancy of additional information being provided) and when simply manipulating the "idea" of questions versus statements in general (1.e., use of no specific questions or statements). Therefore, the pretest conclusion that the specific questions selected for study had a higher likelihood of motivating information processing may have been a consequence of the manner in which pretesting was executed (1.e., a lack of substantive content with which to interpret the questions). When the questions were placed back in the context of a larger message, the effect of questions on outcomes was seen to vary dramatically depending on position. Note that this pretest reexamination was conducted in print, as the original pretest was also conducted in print. Also, note that the arguments offered here could not be used to explain favorable outcomes reported by either Burnkrant and Howard (1984) or Petty, Cacioppo and Heesacker (1981) since the effects of questions were seen to be contingent upon the quality of message arguments. The results of this pretest re-examination also could not be used to explain the pattern of findings observed in the present investigation. If questions considered within a meaningful context had the ability to generally facilitate favorable results, one would not expect to find opposing results when examined across either argument quality or position. Rather, the major distinction that needs to be raised is that responses to questions taken out of context from a larger message may be different from responses to questions 
when used within the context of that larger message. The instrument for this pretest re-examination is provided in Appendix G.

Outcomes by Question Position

It is suggested here that there are at least two critical factors determining question effectiveness: 1) how much favorable product information is available to a recipient when response to a question first occurs; 2) when is response to a question likely to occur. The second factor has an important bearing on the first and may be Influenced by the nature of the question itself. What is meant by question response is the cognitive process culminating in, and including, the development of a satisfactory answer to a question. Conscious evaluation of issues posed by questions, as well as any subsequent decisions, follow from the answers that are formulated to those questions. If the answers produced are unclear or unsatisfactory to the respondents, the evaluations which accompany the answering process will be volatile and ambiguous. It is when a satisfactory answer to a question occurs that the evaluative consequences of questioning will be strongest. What is meant by a "satisfactory answer" is an answer that ends a recipient's quest for seeking a conclusion to the question posed. Questions initiate information processing, which ends with the development of a satisfactory answer to the question. It is further suggested that for the questions used in this study, questions designed to suggest to recipients that health beliefs they hold to be true may be false, question response occurred at the point of questioning. No inference 
is being made concerning "how long" it took to formulate responses. However, it seems reasonable to assume that unambiguous answers to the questions presented were easy to produce, since they requested subjects' impressions of their personal health condition.

With the above suggestions in mind, the following events are offered to explain the outcomes observed. In the prequestion position, the information base avallable to recipients to evaluate with respect to the questions posed included their knowledge, prior experience and beliefs. In the postquestion position, the information base avaliable to consider included the message arguments just presented. It is in the postquestion position that the ncognitive work-space" of recipients had been "loaded" with information favorable to the product being advertised.

Prequestions apparently elicited an evaluative reaction from reciplents, but with the response not being favorable to a decision to process subsequent material. In other words, subjects answered the questions on the basis of avaliable information, their current knowledge, experlence and beliefs, found that information and their answers to be adequate or acceptable, and terminated processing. In the postquestion condition subjects also answered the questions on the basis of available information, but with that information base being skewed by the message arguments just received. Since the arguments were strong and favorable to the advertised product, subject responses to the questions were correspondingly influenced. The patterns of data observed in this study are consistent with this interpretation. 
If one responded to a question with more (less) compeling information available it would be expected to produce more (less) thinking concerning the product involved. If one responded to a question designed to elicit a reappraisal of (1.e., cause one to doubt) one's position relative to a product related need with (without) the evidence to support that design, that reappraisal would have a higher likelthood (lesser likelthood) of being successful. As earlier shown, the rest of the effects observed follow from these two determinants. For example, if one responded to a question in an ad when considering (without considering) strong argument support, one would be more inclined (less inclined) to purchase the advertised product.

In general, responses to prequestions, may often be expected to differ from responses to postquestions since the avallable information base utilized in determining evaluation is often not the same. Responding to a question before relevant information is provided versus after relevant information is provided may logically result in different answers; subsequent decisions which follow from those answers may also be quite different. Thus, it is the nature of introductory material in a message which must be considered the most critical, for introductory material has the possibility of terminating subsequent processing and obviating any benefits expected. This was most clearly suggested in this study by the range of findings observed over the pre versus post versus combined question positions. Prequestions lacked, but postquestions provided, outcome superiority over statements. Combined questions, however, also consistently 
lacked any differential advantage over statements. This directly Indicates that the benefits of postquestions were preemptively negated by the presence of prequestions.

It should be noted that the suggestion that prequestions "terminated processing" can be interpreted in more than one way. Information processing can be "terminated" in the sense of subjects no longer even attending (1.e., consclously "listening") to a broadcast, or in the sense that once an evaluative judgment is made (through responses to prequestions) subjects are hesitant to modify that judgment even when later presented with the same questions again. In this case, processing is negated in terms of reciplents not actively appraising the implications of arguments with respect to their personal needs once they have formulated a response on the 1ssues, although they may still be passively listening to information. In the next section, this will be seen to have implications for alternative interpretations of the results. The finding that message learning did not significantly vary by grammatical form and position suggests that subjects were still at least passively listening to the ad even after prequestion reception.

Finaliy, it should be recognized that direct comparisons between different question positions, or different statement positions, did not reveal the same degree of statistical consistency as seen with question versus statement comparisons within positions. The Interpretation of directional effects for question comparisons across positions would involve the same dynamics discussed above. However, 
the presence of directional (although not statistically significant) differences for statements, with prestatements consistently being superior to poststatements, may suggest that prestatements served an organizational function with respect to the following material, thus facilitating favorable outcomes, whereas poststatements may have been percelved as summary conclusions which were elther stronger or different than reciplents' personal conclusions concerning the arguments, thus impeding favorable outcomes. The fact that postquestions left argument conclusions open to reciplent judgment, whereas statement conclusions did not, may have contributed to both questions and statements playing an active but opposite role in determining the magnitude of the differences between them.

\section{Alternative Models}

It has been suggested that the avallability of favorable Information can be used to help explain the pattern of results observed over question positions. The issue to be examined in this section is whether the avallability explanation by itself is a sufficient explanation for the pattern of results observed.

If information avallability is a sufficient explanation for the variability in results observed across question position it seems curious why simflar variabilty was not found in message learning across the same treatment groups. One could argue that if equivalent amounts of message information have been learned, then equivalent amounts of message information are potentially available to subjects for use in making evaluations. 
The problem, however, is the finding of differences in persuasion between postquestions and combined questions where it is clear that equal amounts of favorable product information were available to subjects in those conditions at the time of postquestion presentation. Avallability of message information must be considered equivalent for subjects in those two conditions for two reasons: 1) recognition and recall of the information contained in the message arguments was equal; 2) the recency of processing of message information was the same for both the post and combined positions at the time of postquestion presentation. In other words, the information most recently recelved, and thus avallable, at the time the post position questions were asked (In both the postquestion and combined question conditions) was the message arguments. The avaliability-valence hypothesis (e.g., Tybout, Sternthol and Calder, 1983) suggests that since memory operates on a last-in-first-out basis, information which has been most recently processed should also be the most avallable and should have a disproportionate impact on associated evaluations. Elaborative thinking, stimulated by questions, about the topic of a message with strong and favorable arguments being most available should result in favorable evaluations of the message toptc. While supportive results for this 1dea were obtained with postquestions, they were not obtained with combined questions. The combined question results represent use of a procedure (1.e., questioning in the post position) for stimulating elaborate processing of recently received favorable information that does not enhance persuasion. The 
sufficiency of the availabilty explanation must be rejected.

Theories of impression formation may be useful in the formulation of a modifled view. As discussed by Lingle and Ostrom (1981), initial attitudinal judgments can play a thematic role in the organization of cognitive responses such that subsequent judgments may be independent of target relevant content. In other words, these authors note that subjects may not recall or review specific information content when making a second judgment similar to a first. Rather, people may simply remember the attitudinal theme of their first judgment and generalize that theme in formulating their second judgment (see Haistre et al., 1980 for convergent views). The combined question results of this study (in comparison to the prequestion and postquestion results) are consistent with impression formation theory. 16

${ }^{16}$ All major analyses were re-run eliminating subjects with a recall score of zero $(n=34)$. Given the above line of thought, the elimination of these subjects was not expected to impair the results. That expectation was confirmed. None of the cell comparison differences for all elght varlables demonstrating a grammatical form by position interaction declined in statistical significance when removing subjects with a recall score of zero. On the other hand, the grammatical form by position interaction for the product thinking variable showed a marked improvement $(F(2,325)=4.80 ; p=0.009)$, with postquestion subjects reporting thinking much more about vitamins than poststatements subjects $(F(1,325)=7.17 ; p<0.01)$ All major analyses were again re-run using recall and corrected recognition scores as covariates. None of the significant grammatical form by position interactions were affected by using corrected recognition scores as a covariate and only one was reduced when using recall scores as a covariate (percentions of the ad as interesting: $F(2,341)=2.32$; $p=0.10)$. In exeral, the results of this research indicate that message learning did not play a major role in the differential formation of attitudes and beliefs concerning supplemental vitamins. 
Further Note on Question Response

Initially, the most surprising finding of this study was the lack of superiority of prequestions over prestatements. Favorable prequestion effects were obsnrved by Burnkrant and Howard (1984) and were expected to generalize to the marketing application reported bere.

As suggested above, the issue of when a response to a question first occurs is likely to have a major influence on question effectiveness, since that issue will determine how much favorable information is utilized in making evaluative judgments. It was rurther noted that the nature of the question presented may influence when a response occurs. One of the factors involved bere can be assumed to be whether a reciplent is even capable of generating a reasonable answer to a question posed. In this study, the questions called for impressionistic evaluations of an area in which subjects probably had readily avallable opinions: their personal health. Not all questions, however, request responses on topics of familiarity to recipients. It is, therefore, suggested that when it is not possible to answer a question to recipients' satisfaction without consulting the following material, and persons are motivated and able to do so, the use of prequestions may result in outcome superiority. This distinction seems to define what may have occurred in Burnkrant and Howard's study, but did not occur in the present investigation. It is argued here that for many of the questions presented by Burnkrant and 
Howard, subjects simply did not know the answers with a high level of certainty.

Consider three of the questions presented to subjects in Burnkrant and Howard's "strong argument" condition:

- Will a comprehensive exam requirement be an aid to those who seek admission to graduate and professional schools?

- Will a comprehensive exam requirement lead to improvement in the quality of teaching?

- Will a comprehensive exam requirement belp avold future increases in tuition?

In the absence of the actual argument material, subjects may have been unable to answer most of the prequestions presented definitively, or to their satisfaction. This condition then may have contributed to motivation to evaluate the arguments that followed such that their personal responses to the previous questions presented were formulated either concurrently or after the processing of the message arguments. Thus, in the strong argument condition, the information base available to reciplents was favorable when the responses were able to be formulated, resulting in question superiority relative to statements; in the weak argument condition, the information base avaliable to reciplents was unfavorable when responses were able to be formulated, resulting in statement superiority relative to questions.

One factor critical to the above argument is the suggestion that prequestion subjects in Burnkrant and Howard's study were less able to satisfactorily answer those questions than similar subjects in the present study. To test this 1dea, 40 subjects were randomly assigned to two different conditions. In one condition, subjects were 
administered a booklet with the three vitamin questions used in this Investigation along with three of the questions used in Burnkrant and Howard's study. In the second condition, subjects were administered a book let with the three vitamin questions used in this study along with three different questions used in Burnkrant and Howard's study. ${ }^{17}$

Subjects were introduced to the question booklets by providing essentially the same information provided in both original studies. Respondents were asked to rank order the questions in terms of their desire to know the answer to each question. This manipulation was used orlginally by Berylne (1954) in conceptualizing epistemic curlosity as a function of information seeking behavior. ${ }^{18}$ The sum of the ranks for the vitamin questions in condition one was compared to the sum of the ranks for the comprehensive exam questions in condition two, which similarly compares the sum of the ranks for the vitamin questions in condition two with the sum of the ranks for the comprehensive exam questions in condition one. Oneway analysis of

17 Questions from the "strong arguments" condition were used. One question (out of seven total) was not used in order to provide an equal number of questions across conditions (1.e., three exam questions per condition). The three exam questions in each condition were presented to subjects in conjunction with the three supplemental vitamin questions (see Appendix $H$ ) to al low an equivalent statistical comparison of ranks of the different questions (1.e., three exam and three vitamin questions) across the two conditions.

${ }^{18}$ Note that use of Berylne's manipulation required the use of questions as stimuli and not statements. It would not have been appropriate to ask subjects how much they wanted to know an answer to a certain statement. Requesting subjects to rank statements according to a criterion different than questions would raise the issue of comparability of results. 
variance (Kruskal-Wallis) provided support for the expectations with subjects indicating a significantly greater desire to know the answers to the comprehensive exam questions than the supplemental vitamin questions $\left(X^{2}=5.54 ; p=.019\right)$. These results provide support for the suggestion that respondents either "knewn the answers, or (in a related sense) had a definitive opinion more readily avallable for the supplemental vitamin questions than for the questions used in testing the comprehensive exam 1ssue. ${ }^{19}$ Berylne would suggest that the use of the comprehensive exam prequestions had a higher likelihood of engaging epistemic curiosity, or curlosity based on a quest for knowledge. These findings are consistent with the position that the prequestions in Burnkrant and Howard's study, relative to the present Investigation, may have performed as expected because the respondents were unable to answer the questions to their satisfaction without

${ }^{19}$ It should be noted that all analyses demonstrating a significant grammatical form by position interaction were re-run using an item reflecting knowledgeability about vitamin benefits as a covariate. None of the interactions were affected, although benefit knowledgeability was statistically significant as a covariate for three variables (attitude, positive thoughts and purchase intentions) and marginaliy significant for three variables (arousal of dauht. product thinking and ad stimulation). This cannot be considered, however, a refutation of the above argument since the ability to formulate definitive opinions (1.e., personally mowing" the answers) on many 1ssues may have little to do with how knowledgeable people may be on particular aspects of the issues (e.8., supplemental vitamin benefits). 
consulting the following material.20 Appendix H provides the instruments used in this test.

Given these considerations, it is important to recognize that the results of this study obviously do not suggest that prequestions will be ineffective in advertising. That would be a "naive view" of one searching for a generalized question effect on learning or persuasion. It is this author's opinion that there is "no such thing" as a general question effect on message learning or persuasion. Rather, effects of questions cannot be disassociated from the substance to which they refer, and different forms or types of questions may differ at least In the nature of what is requested and whether the request can be fulfilled without reference to additional information.

In summary, there appears to be at least two critical issues to consider when utilizing questions which request an evaluative response: 1) how much favorable product or issue related information will be avaliable to a reciplent when question response first occurs; 2) when will a reciplent be likely to formulate a response to the question presented.

${ }^{20}$ The difference between this test and the initial pretest that compared isolated questions versus statements should be noted. First, this test provided an interpretative context for the questions (1.e., essentialiy the same introductory information as the original studies). Secondly, the re-examination of the initial question versus statements pretest concluded that perceived characteristics of questions relative to statements results in comparisons between the two forms being different in the absence of an interpretative context, as opposed to being considered within a meaningful context. That conclusion in no way negates the comparative use of vitamin and comprehensive exam questions discussed above. 
Processing Mode

The evidence examined supports product relevant thinking as a plausible determinant of the results observed. For five out of six of the grammatical form by position interactions, controling for product thinking eliminated the effect, while the sixth (purchase intention) was reduced to marginal significance. Petty and Cacioppo (1981) discuss two alternative routes to persuasion. The "central routen to persuasion emphasizes the information that an individual has available concerning an object or 1ssue under consideration: "According to the central view, thinking about issue-relevant information is the most direct determinant of the direction and amount of attitude change producedn (p. 256). Persuasion results from active issue-relevant thinking in the central route. The results of this study are consistent with the view that even in a context of incidental message reception, questions can be used to help facilitate central processing. This seems 1mportant both in theory and in practice given Petty and Cacioppo's assertion that central processing results in more enduring attitude change but, at the same time, developing messages which elicit central processing is often difficult to do. The use of questions in messages may be useful in achieving these objectives.

What is also interesting is that attitudinal effects could be alternatively explained, and positive cognitive response and purchase intention effects partially explained, by the arousal of doubt. This is curious since the arousal of doubt was found to be basically independent of product thinking. Petty and Cacloppo (1981) define the 
"peripheral routen to persuasion as resulting from response to "persuasion cues," which produce attitude change "without any active thinking about the attributes of the issue or object under consideration" (p. 256). Statistically, at least, this seems to define what occurred with the arousal of doubt in this study. This may suggest that certain types of questions can elicit ncued reactions" from individuals in the sense of an automatic response to a "you could be wrong" cue that questions serve when they are supported by powerful references (1.e., American Medical Association; American Dietetic Association). In other words, it is clearly rocognized that more than one explanation could be offered for the finding of a lack of relationship between the measures of product related thinking and the arousal of doubt. The two measures may simply have "tappedn relatively independent aspects of a common phenomenon. For example, the item measuring the extent of product related thinking had a broader potential range of measurement meaning (1.e., there are "several ways" of thinking about supplemental vitamins) than the specific concerns of the items used to measure the arousal of doubt. Th1s issue needs to be explored in more depth.

Finaliy, it should be noted that it is unclear exactly why significant results emerged with the arousal of doubt measure developed on the basis of the first two arguments and questions presented, but not when also including the third. It is possible, and supported by informal subject feedback, that the number of reasons presented in the advertisement (in its entirety) for taking 
supplemental vitamins was overbearing. Thus, subjects may not have actively considered the Implications of the third argument, when presented with the third question, to the same extent as with the first two arguments and questions.

Theoretical Restrictions

It is important that the findings reported here be considered with respect to appropriate restrictions on interpretation and generalizability of the constructs examined. The most significant of these restrictions concerns the nature of different types of questions. The questions used in this investigation were specificaliy designed to suggest to reciplents that beliefs they hold to be true may be false. While this study suggests that the functional effects of questions may be contingent upon their position relative to message arguments, it is also recognized that the form and magnitude of those functional shifts in effects may differ depending on the type of question asked. What is meant by "type of question" is that questions may differ in the nature of the response elicited by an interrogative request, the difficulty in generating a satisfactory response, the person (audience) at whom the question is directed, and the person (audience) or object at which the response is directed. Different types of questions asked may produce corresponding differences in the outcomes that result. In other words, the fundamental intent, or objective, of various questions seen in advertisements often appear dissimilar. For example, a question headline presented in a recent Xerox print advertisement asked, "Whatever happened to Jane?" and was 
followed by a suggestion that Jane, the secretary, had become psychologically and spiritually transformed through use of a Xerox Memory Writer. In this situation, the question clearly could not be answered without referring to the following text and its usage implied a desire to arouse curiosity and organize a theme or topic with respect to a following argument. The point here is that this study has provided a certain pattern of results for a given type of question and the same pattern of results may not hold true for other types of questions.

A second ilmitation is that results obtained in a broadcast media may not generalize to other media (Wright, 1971). The results reported here should be considered specific to the medium that was utilized. Finaliy, the results should be interpreted in terms of Incidental message reception with full respondent freedom to attend or not to attend to a target message.

\section{Future Research}

"Needs" for future research seem to necessarily reflect the biases of individual investigators. The variability noted across positions in this study seems far too rich, and far too important in both a theoretical and applied sense, to ignore in future studies. While it appears that researchers have methodologically accepted that the appropriate comparison condition for questions is content identical declarative statements, it is recommended here that comparisons (of questions vs. statements) across message positions a lso become standard. What would be most helpful is the testing of 
third variables which mediate the relationship between grammatical form and position. For example, a study demonstrating the superiortty of prequestions under one condition but postquestions under a different condition would be most useful. In general, this author perceives an immediate need for a taxonomy of questions for use in marketing research. For example, of the 6,689 question advertisements observed across ten national consumer magazines (noted in Chapter I), it should be intultively obvious that not all of those questions were developed with the same objective or intent, nor could similar results be expected from the use of the various types of questions. Even a rudimentary taxonomy may provide research direotion in when to use prequestions, as opposed to postquestions, and possibly even when to expect additive effects from using, say, two different types of questions in the pre versus post positions. This author is currently engaged in the task of developing such a taxonomy, where question position will be a key variable of interest. For example, use of a provocative prequestion unable to be initlally answered, coupled with a message evaluative postquestion designed to elicit doubt, may possibly result in additive effects.

Finally, this study measured doubt as being inclined not to belleve or accept a given event. However, an alternative measure of doubt (1.e., Berlyne's doubt conflict) could be assessed by having subjects indicate how likely it is that several different levels of a glven belief are true. For example, one alternative method of measuring doubt would have required subjects to "distributen a given 
number of points (e.g., 100 points corresponding to degrees of certainty) across scales on the three 1tems and considering the level of dispersion as an indicator of the level of doubt. At the least, empirical comparisons between these two conceptualizations of doubt might provide useful information.

\section{Summary Conclusion}

Subject to the above limitations this study suggests that postquestions can be more effective than poststatements in facilitating favorable evaluative judgments of an advertised product offering. Furthermore, the functional effects of questions appear to be contingent upon the position of questions with respect to their assoclated arguments such that favorable effects are eliminated when prequestions are introduced. The nature of introductory material in a message appears to be the factor determining subsequent processing. The extent of thinking concerning the product offering was found to be the most plausible determinant of results, although the arousal of doubt concerning product related needs was also seen to be a significant determinant of critical outcome measures. Varying the amount of time provided to answer the questions presented was found to have no effect on outcomes. It is suggested that in developing effective question advertisements particular attention be given to the 1ssue of when a recipient is likely to first answer a question presented and how much favorable product information will be avallable to the person when the answer to the question is resolved. With these 
points in mind, questions have the potential to be a viable means of facilitating information processing in advertising. 
APPENDIX A

ARGUMENT QUALITY PRETEST INSTRUMENT 
For each scale olace an " $X$ " in the space that corresponds most closely to how you feel.

Takino supolemental vitamins is:

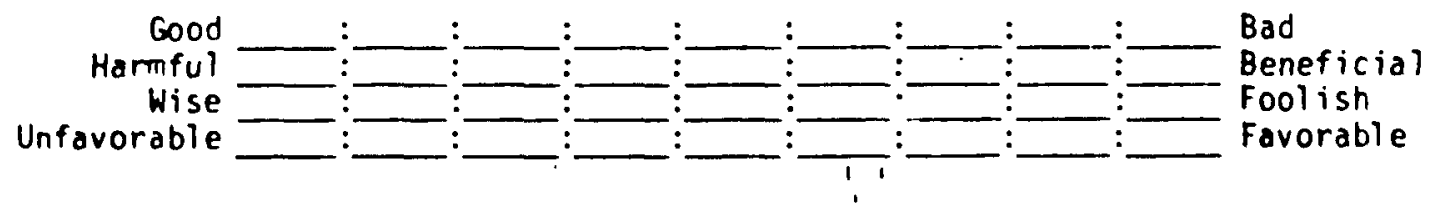

Do you currently take suppiemiental vitamins?

Have you ever tuken supplemental vitamins?
Yes

No

Yes

No 
The American Medical Association reminds us that daily vitamin requirements denend not oniy on diet, but also on your daily activities and exposure to stress. Many people experience stress on the job or at school. An increased level of stress, or even a lack of sleep, can increase the body's need for many nutrients. And people today are more active than ever before. What many don't realize is that being physically active can actualiy increase the body's need for certain vitamins.

Please rate the paragraph you just read by placing an " $X$ " in the appropriate space.

High

Quality<smiles>[3H][13CH3]</smiles><smiles>CC1([V])CCCCC1</smiles><smiles>[3H]</smiles><smiles>C1CCCCC1</smiles><smiles>[C]1CCCC1</smiles>
Low Quality

Not at

Al 1 Bel ievable

.

: :

:

:

:

:

Very

Very

Good : : :

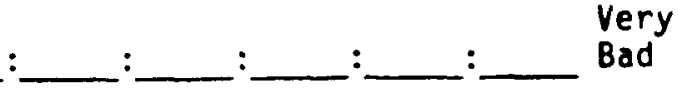


The American Dietetic Association warns that the way food is prepared is a leading factor in nutritional loss. For example, many vitamins are heat sensitive. Boiling vegetables in water, or cooking meats well done, can result in almost complete destruction of many vitamins. Many methods of enhancina the taste and appearance of food also decrease its nutritional value. Remember, it is only the nutritional content of food after meal preparation that counts.

Please rate the paragraph you just read by placing an " $X$ " in the appropriate space.

High

Quality

Not at

Al1

Bel ievable
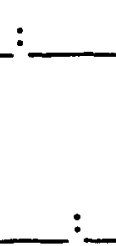

: : :
Low Quality : $-$ : : : :

Very Believable : $:$ : $:$ : $\quad: \quad:$

Very

Good : Bad 
The American Medical Association also reminds us that drugs and disease can alter our vitamin requirements, resulting in extra vitamin needs. Antibiotics interfere with vitamin absorbtion, while aspirin causes vitamin loss. Smoking, exposure to smoke, as well as alcohol consumption can rob the body of many nutrients. Infections, the flu, as well as the common cold, all make vitamin demands on the body.

Please rate the paragraph you just read by placing an " $x$ " in the appropriate space.

High

Quality

$$
\text { : }
$$

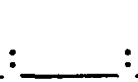

:
Low Q_ Quality

Not at

All

Believable :

:

:

$:$

:

:__ Believable

Very

Good

:

:

: :

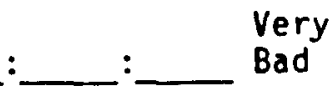




\section{APPENDIX B \\ QUESTION VERSUS STATEMENT DISCRIMINATION}

PRETEST INSTRUMENT 
Advertising Copy Assessment 
For each scale place an " $X$ " in the space that corresponds most closely to how you feel.

Takino supolemental vitamins is:

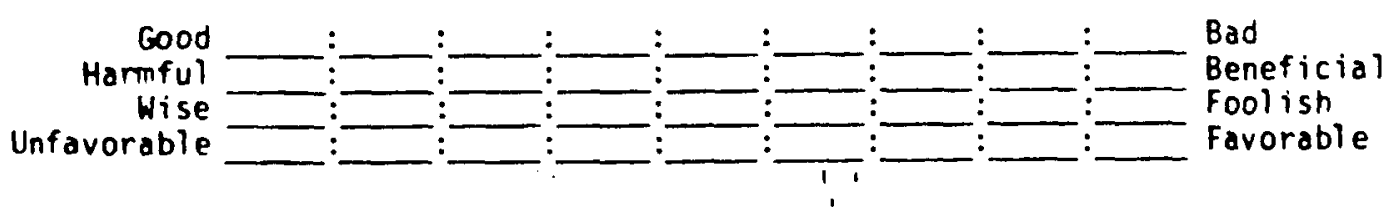

Do you currently take supplemental vitamins? Yes No

Have you ever taken supplemental vitamins?
Yes

No 
Listed below are individual sentences prepared for a supplemental vitamin advertisement.. Plesse read each sentence and rate it by placing an " $x$ " in the appropriate opace.

"Is your body's vitamin supply really consistent with your daily neods?"

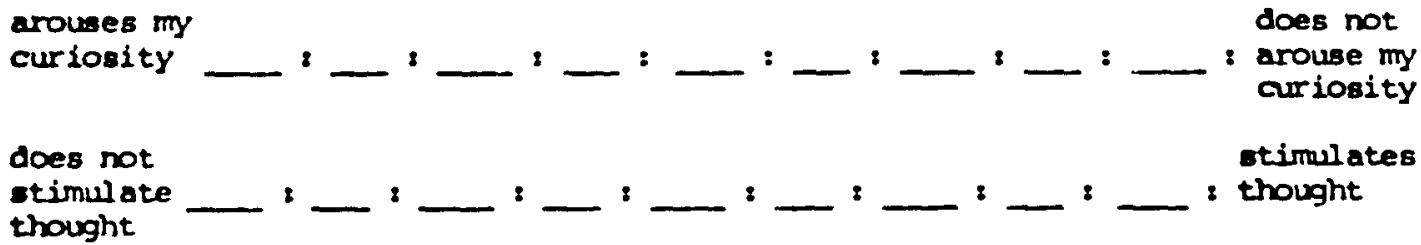

Interesting __ _ _ _ _ _ _ _ _ _ _ _ _ _ uninteresting

How 1 ikely would you be to pay attention to an advertising message that follaved the above sentence?

very

Iikely $\therefore$ : : : $\because$ : : - unlikely 
"Are you sure your diet is providing the vitanins and nutrients you expect?"

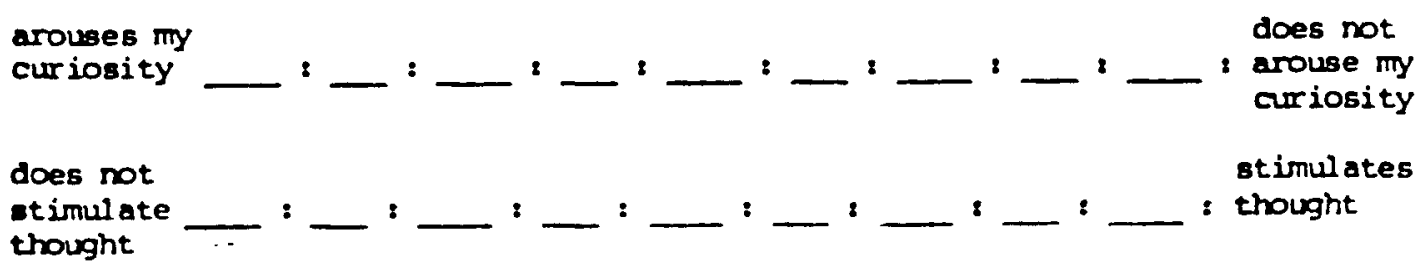

interesting __ : _ _

How likely would you be to pay attention to an advertising message that followed the above sentence?
very
likely
$:$
$:-$
:
$:$
:
very
: unlikely 
"Is your body really prepared for its extra vitamin needs?"

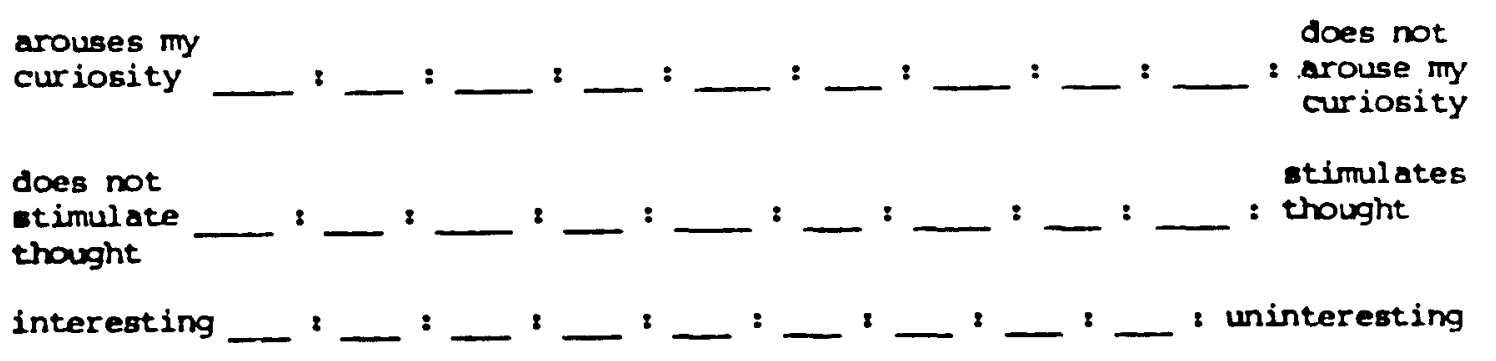

How likely would you be to pay attention to an advertising message that followed the above sentence?

very

likely

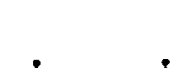

-
$:$

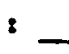

:

:

very : unlikely 


\section{Advertising Copy Assessment}


For each scale olace an " $X$ " in the space that corresponds most closely to how you feel.

Takina supolemental vitamins is:

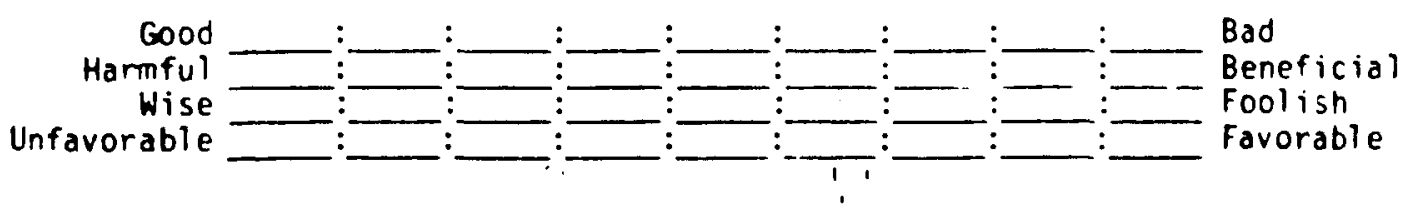

Do you currently take

suppienental vitamins?

Yes

No

Have you ever taken

supplemental vitemins?

Yes

No 
Listed below are individual sentences prepared for a supplemental vitamin advertisement. Please raad each sentence and rate it by placing an " $x$ " in the appropriate apace.

"Your body' s vitamin supply should really be consistent with your daily needs."

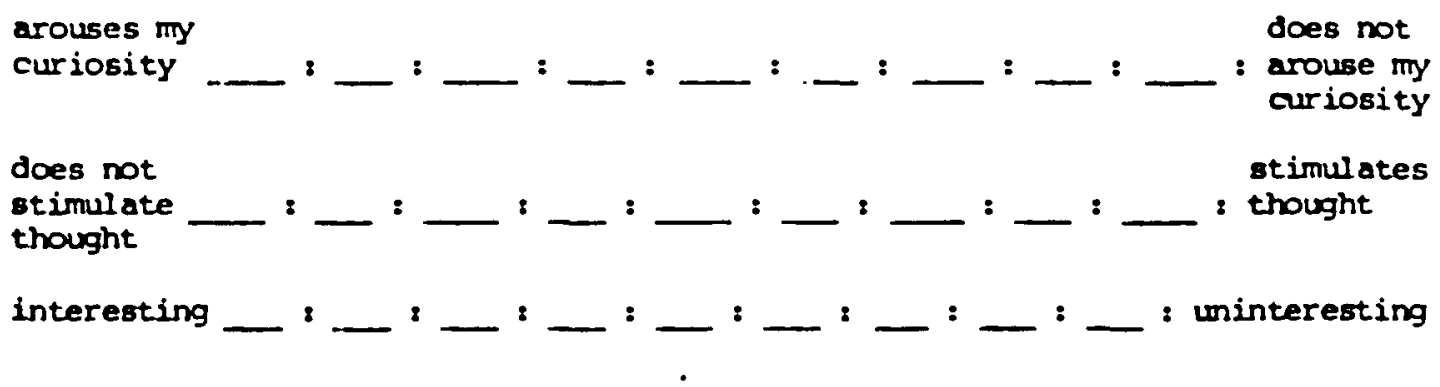

How likely would you be to pay attention to an advertising message that followed the above sentence?

very

likely : : $?$ : : : : : unlikely 
"Be sure your diet is providing the vitamins and nutrients you expect."

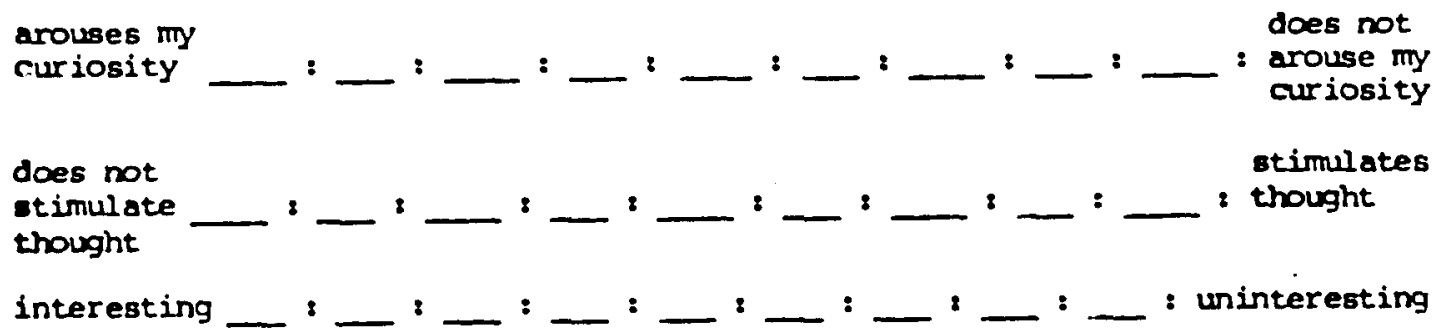

How likely would you be to pay attention to an advertising message that followed the above sentence?

very

likely $:$ . : : : : $+$ : 
"Really prepare your body for its extra vitamin needs."

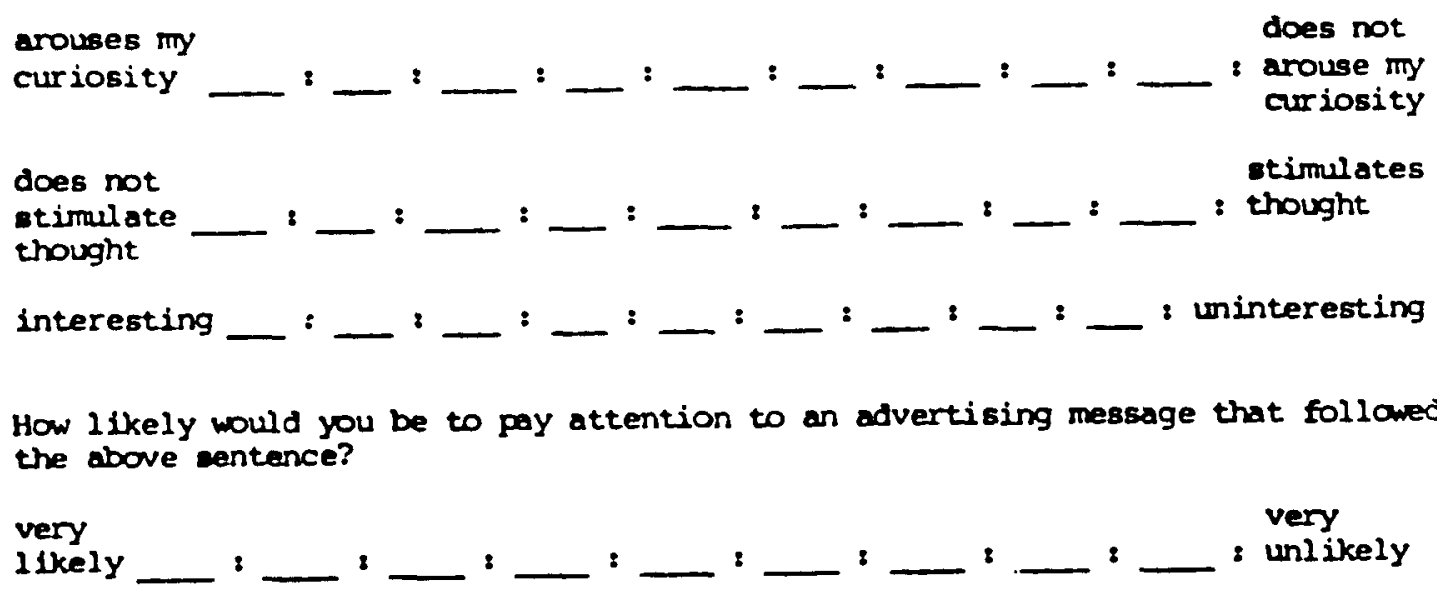


APPENDIX C

TIME DELAY PRETEST INSTRUMENT 
RADIO CUPY ASSESSMENT 
The supplemental vitamin ad you just heard asked three different questions. A pause then occurred after each question. For each scale below place an " $x$ " in the space that corresponds most closely to how you feel.

Did the pause help you think about or answer the questions asked in the ad?

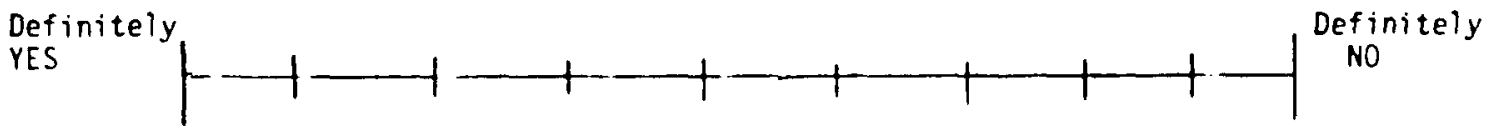

Did the pauses help you think about supplemental vitamins?

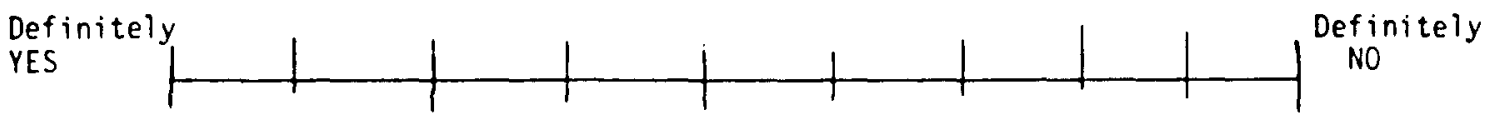

When the pauses occurred did they distract you from thinking about or answering the questions asked?

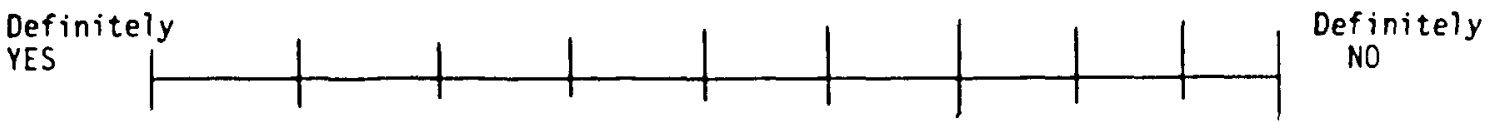

When the pauses occurred did you wonder why the pauses were there?

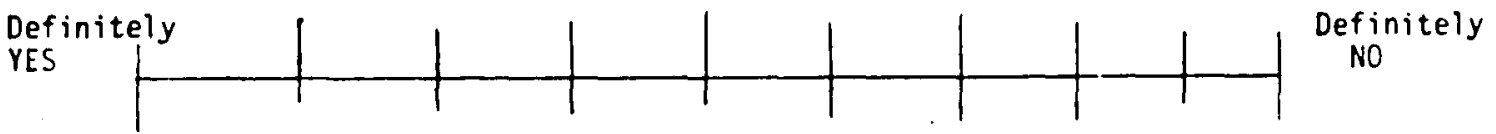

Did you notice the pauses?

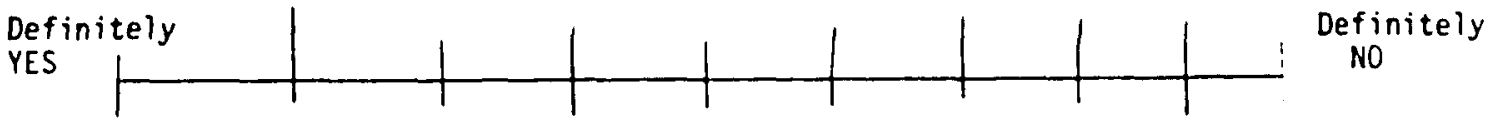

In general, how much thinking about each question did you engage in after each question was asked?

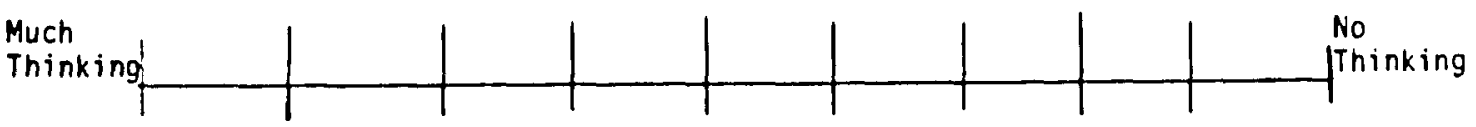

In general, how much thinking about supplemental vitamins did you engage in after each question was asked?

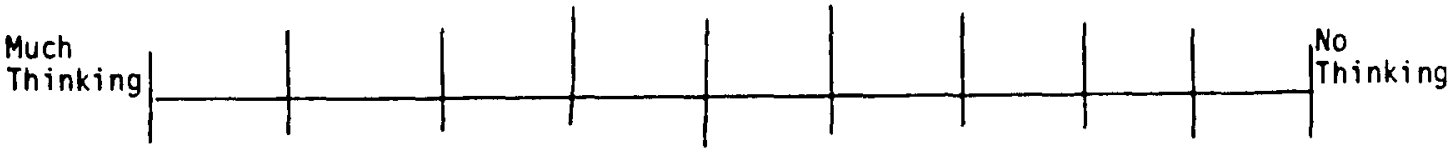


For each scale, place an " $x$ " in the space that corresponds most closely to how you feel.

Taking supplemental vitamins is:

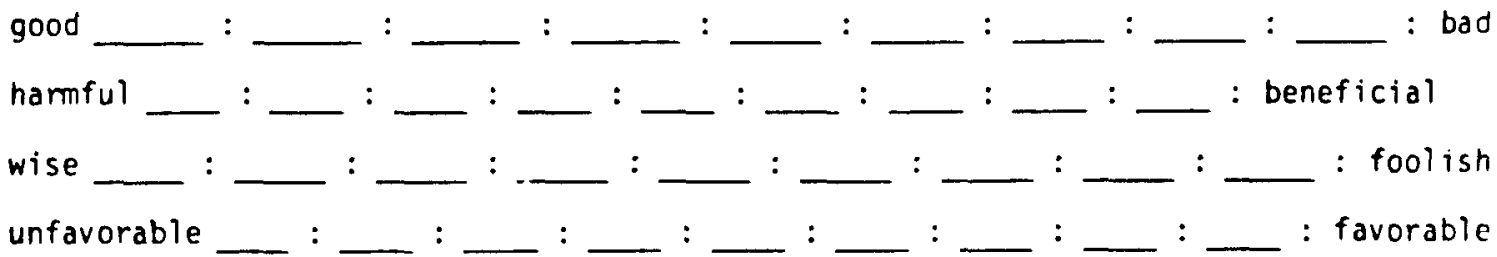

We are now interested in the thoughts that occurred to you when you listened to the supplemental vitamin ad. The next page contains the form we have prepared for you to record your thoughts and ideas. Please only put one idea or thought in each box. Some of these thoughts may have been contained in the ad, others may have related to your own past experiences on the topic. Still others may have related to the procedure employed or the situation in which you heard the ad. We want all of these thoughts if they occurred to you when you heard the ad and any other thoughts that may have occurred to you as well. State your thoughts and ideas as concisely as possible -- a phrase is sufficient. You may ignore spelling and gramer. Don't worry if you can't fill every box. You will have three minutes to write down your thoughts. Please be completely honest and list all your thoughts. Contact the assistant now to tell him you are ready to begin. 


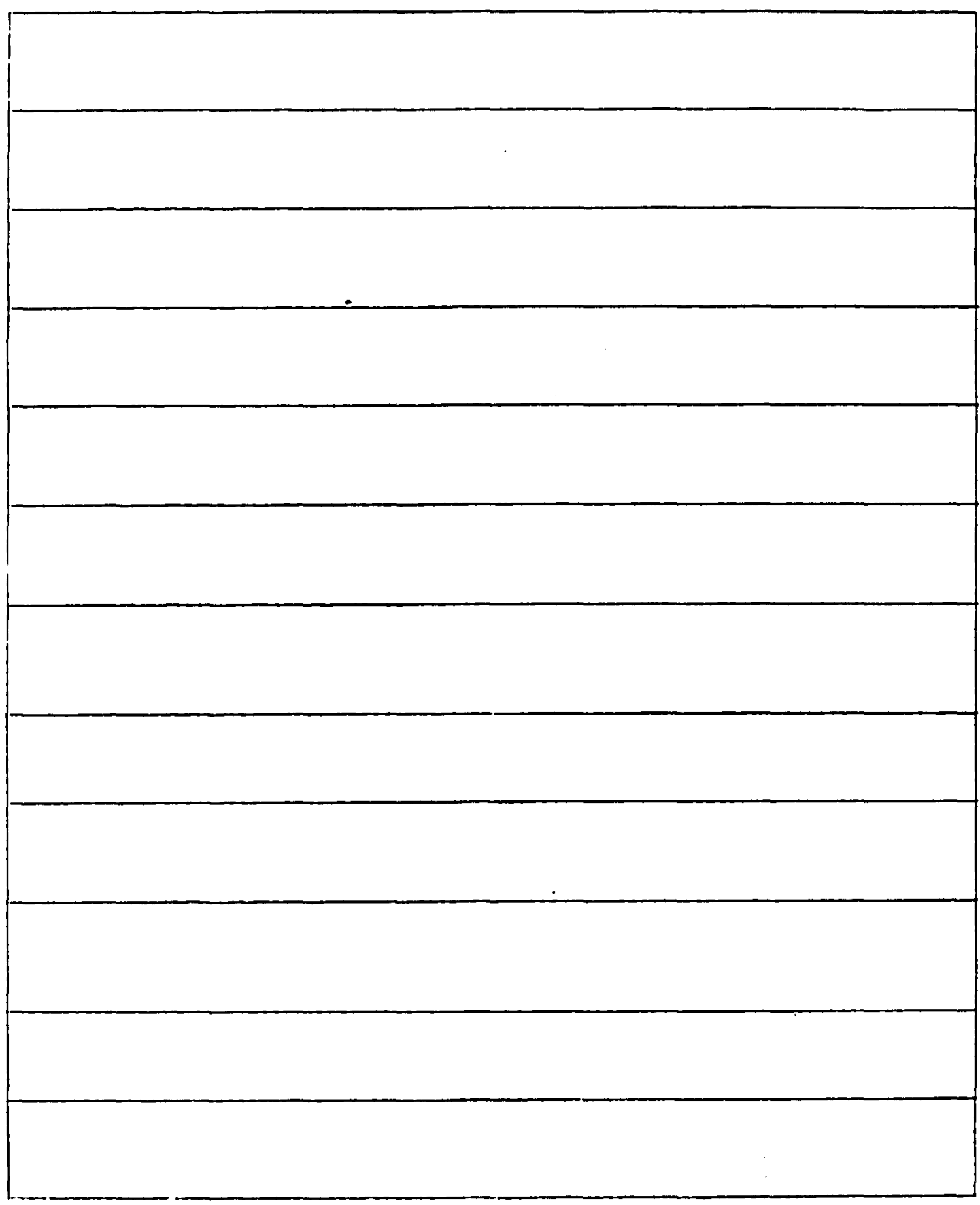

STOP: Hait until instructed to nngceed. 
At this time, we would like you to indicate in the left-hand margin by each thought you recorded whether the thought was (+) favorable towards supplemental vitamins, (-) unfavorable toward supplemental vitamins, or (0) neither favorable nor unfavorable towards supplemental vitamins. Therefore, you are to go back and read each thought you just wrote down. If the thought is favorable towards supplemental vitamins, put a + (plus) in the left-hand margin next to the thought. If the thought is unfavorable towards supplemental vitamins, put a - (minus) in the left margin. If the thought is neutral, place a 0 (zero) in the left margin. Please remember to rate each thought. 
Have you ever taken supplemental vitamins consistently for over a one year period of time?

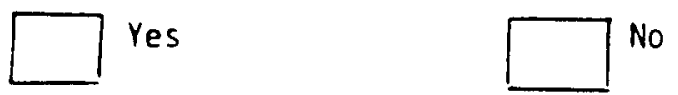

Do you currently take supplemental vitamins?

$\square$ Yes $\square$ No


APPENDIX D

REMARKS MADE BY THE DISC JOCKEY

WHILE ON THE RADIO SHOW 
DISC JOCKEY TEXT

Hello and Welcomel The American Association of Broadcasting Agencies wants to thank you for being with us today. This is Herb Howenstine from WOSU lending a helping hand. We have some nice selections that we think you'll enjoy, so sit back and relax as we bring you the Bob Dilion standard of "Lay Lady Lay." Peter Nero is at the plano on this one.

FIRST SONG

The plano stylings of one Peter Nero from 1973 and the Bob Dylan styling of "Lay Lady Lay"; off the LP "Peter Nero: The World of"; and includes quite a number of good listening tunes, I guess you could say: "Wichita Lineman," "I Love How You Love Me," "For Once in My Life," "Can't Take My Eyes Off of You." Mr. Peter Nero on the piano.

422-8513 is the number to call in case you have a particular favorite you'd like to listen to this afternoon, this evening, or whenever. We'd like you to call in and join us at 422-8513; or basically you could say that's GAB-8513. You're welcome to talk with me, Herb Howenstine; I'll be with you until the close of this segment so whenever you'd Ilke to call in and request a particular song, that's oK by me.

I mentioned the piano stylings of Peter Nero and we're going to go right back to more plano mus1c. Mr. Roger Williams on this one; and a very famous one, made more famous, I guess you could say, by the trumpets so to speak; more so in the stylings of Herb Alpert; or possibly the man from New Orleans way, Mr. Al Hirt. At any rate, "A 
Taste of Honey." Mr. Roger Williams on the piano.

\section{SECOND SONG}

Mr. Autumn Leaves himself, Roger Williams off the nI'll Remember You" album and "A Taste of Honey." A 11ttle bit more familiarly known by the trumpet route, of course, but Mr. Roger H1l11ams nonetheless. Does a very, very fine job indeed here on wOSU; $422-8513$ if you have a particular favorite.

Hope you're having a good week as 1 t goes along and hope you're looking forward to a nice weekend abead. Let's hope that Mr. Weatherman, or Ms. Weatherman as the case may be, cooperates and provides us with some nice weather as we get on into the weekend.

Coming along for you next, we're going to reminisce a little bit with the great maestro of the Boston Pops Orohestra, Arthur Fiedler, who sadly passed away back in 1979 at a very ripe old age of 85 years. But Mr. Fledler and the Boston Pops left us with many, many memories. One of those you might remember: the Fab-Four from Liverpool, England and the Beatles' arrangement of "Let It Be."

\section{THIRD SONG}

Arthur Fiedier conducting the Boston Pops in the Lennon and McCartney version of "Let It Be." Right here on WOSU a.m., I'm Herb Howenstine. You know Michael Steinberg, the Director of Public Relations for the Boston Symphony at the time of Fledler's death once wrote:

When Arthur Fiedler became an institution he did it so thoroughly 
that we forgot how late it happened. Popular he was and a considerable money maker for himself, for record companies, for the Boston Symphony Orchestra, and for the musicians themselves, but he was far into his seventies before he was certified as the grandfather of our country.

and the recording of "Let It $\mathrm{Be}^{n}$ is just a good example of the talent of Arthur Fledler and what the Boston Pops could do under his direction. A very, very fine gentleman indeed. And we'll be back with more right after this message.

\section{VITAMIN AD}

\section{AT\&T AD}

Coming back at you with more good sounds here on WOSU. I'm Herb Howenstine and before my newsman Raymond Chick spilis the beans about the whole thing, I guess I should tell everybody another birthday has come and gone for yours truly, 365 days later, but I w1 1 not tell you exactly what the magic number of that birthday is. If you want to find that out, you'll have to dial $422-8513$ and wish me a happ birthday, or possibly request a particular song that you'd like to hear on WOSU. I'd be happy to get that up for you but you have to do your part as well -- 422-8513.

Going to be closing things out just now. Mr. Peter Nero coming back at you off the album entitled "Say, Has Anybody Seen my Sweet Gypsy Rose?n. Not that particular album cut but another appropriate one, I think, on this birthday for myself; this one made famous, I guess more or less, by the Carpenters, Karen and Richard, a-ways back, 
and this one entitled "It's Yesterday Once More."

\section{FOURTH SONG}

Mr. Peter Nero from 1973 and h1s album entitled "Say, Has Anybody Seen My Sweet Gypsy Rose?n. That particular song entitled, of course, "It's Yesterday Once More."

I want to thank you for being with us today. I hope you enjoyed yourself. Contact your assistant now and let him know the program has ended. Again, thank you for your help. Th1s is Herb Howenstine from WOSU wishing you a very, very pleasant day. 
APPENDIX E

MUSIC INTEREST AND ATTENTION TEST INSTRUMENT 
RADIO PROGRAMMING SURVEY 
INSTRUCTIONS

This is a survey on musical preferences. You are about to hear three songs. We would like you to listen to these songs as you would normally isten to similar molc. Do not turn the page until instructed to do so. 
Please evaluate the music you just heard by placing an " $X$ " In the epace that corresponds rost closely to how you feel.

The rus $1 \mathrm{c}$ was:

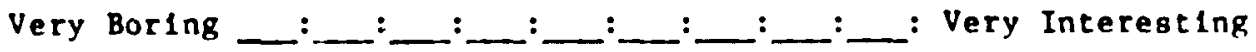

The ous1c:
Held my Attention Very Well
Did Not Hold My
: Atcention Well
At All

The music was:

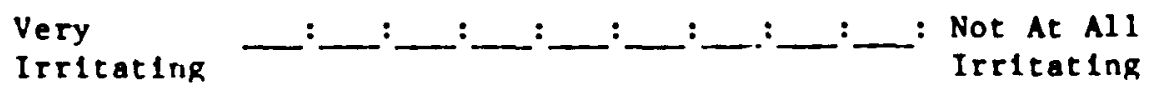


APPENDIX F

INSTRUMENT USED TO COLLECT FORMAL STUDY MEASURES 
RADIO PROGRAMMING SURVEY 
The American Association of Broadcasting Agencies wants to thank you for your participation in this radio programing survey. This survey, being conducted with the cooperation of W.O.S.U., is part of a five year national study deveioped for the purpose of better understanding broadcasting audiences. Different people will be asked questions about different aspects of the radio show segment you just heard. Please answer all of the questions and mark the space for each scale that corresponds most closely to how you feel.

DO THIS

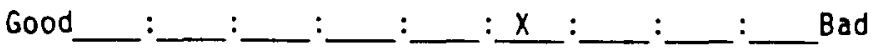

NOT THIS

Good : : : $x$ Bad

Again, thank you for your help. You may turn the page now and begin. 
Please rate the musical selections you heard by placing an " $x$ " in the appropriate space.

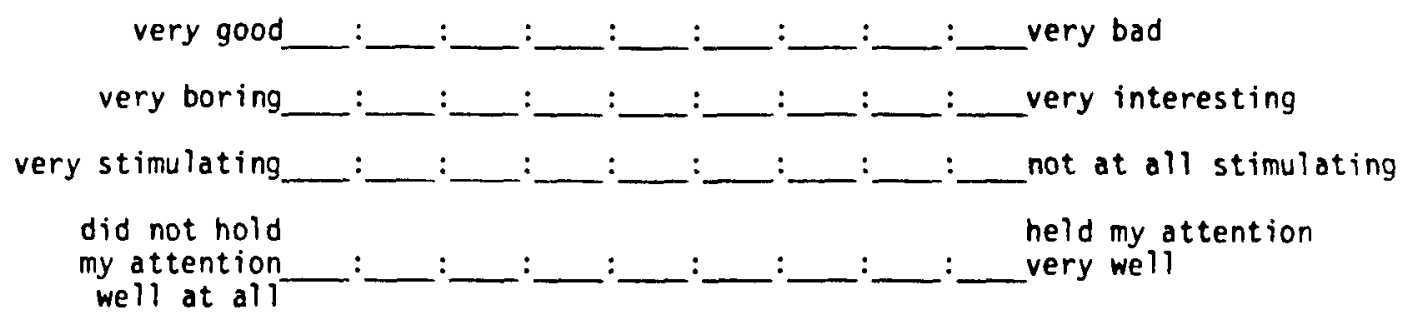

How likely would you be to purchase one of the musical selections you heard?

very likely________________________________ :__ very unlikely

Please rate the individual who served as disc jockey on the radio show by placing an " $x$ " in the appropriate space.

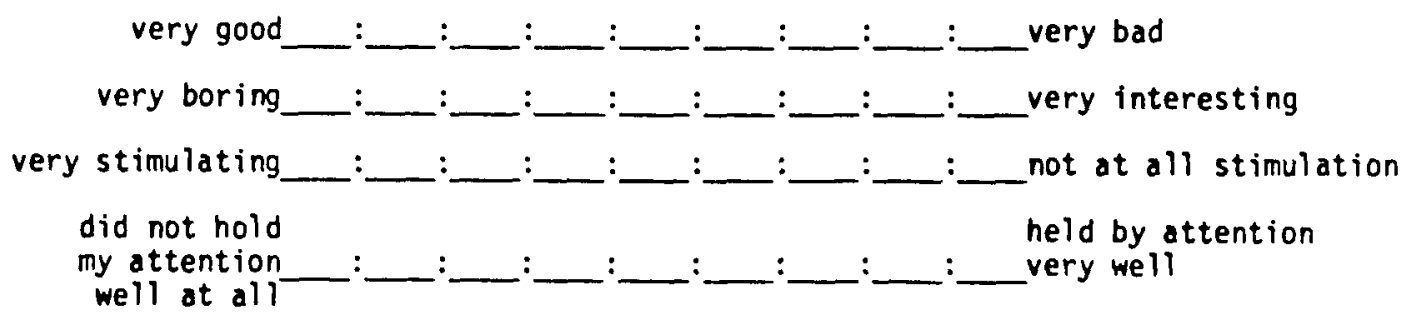

We are now interested in your thoughts about supplemental vitamins. The next page contains the form we have prepared for you to record your thoughts, ideas or questions. Simply write down the first thought that occurs to you about supplemental vitamins in the first box, the second thought in the second box, etc. please only put one idea, thought or question in each box. State your thoughts and ideas as concisely as possibie - a phrase is sufficient. You may ignore spelling and gramar. Don't worry if you can't fill every box. You will have three minutes to write down your thoughts. Please be completely honest and list all your thoughts on supplemental vitamins. Contact the assistant now to tell him you are ready to begin. 
THOUGHTS ABOUT SUPPLEMENTAL VITAMINS

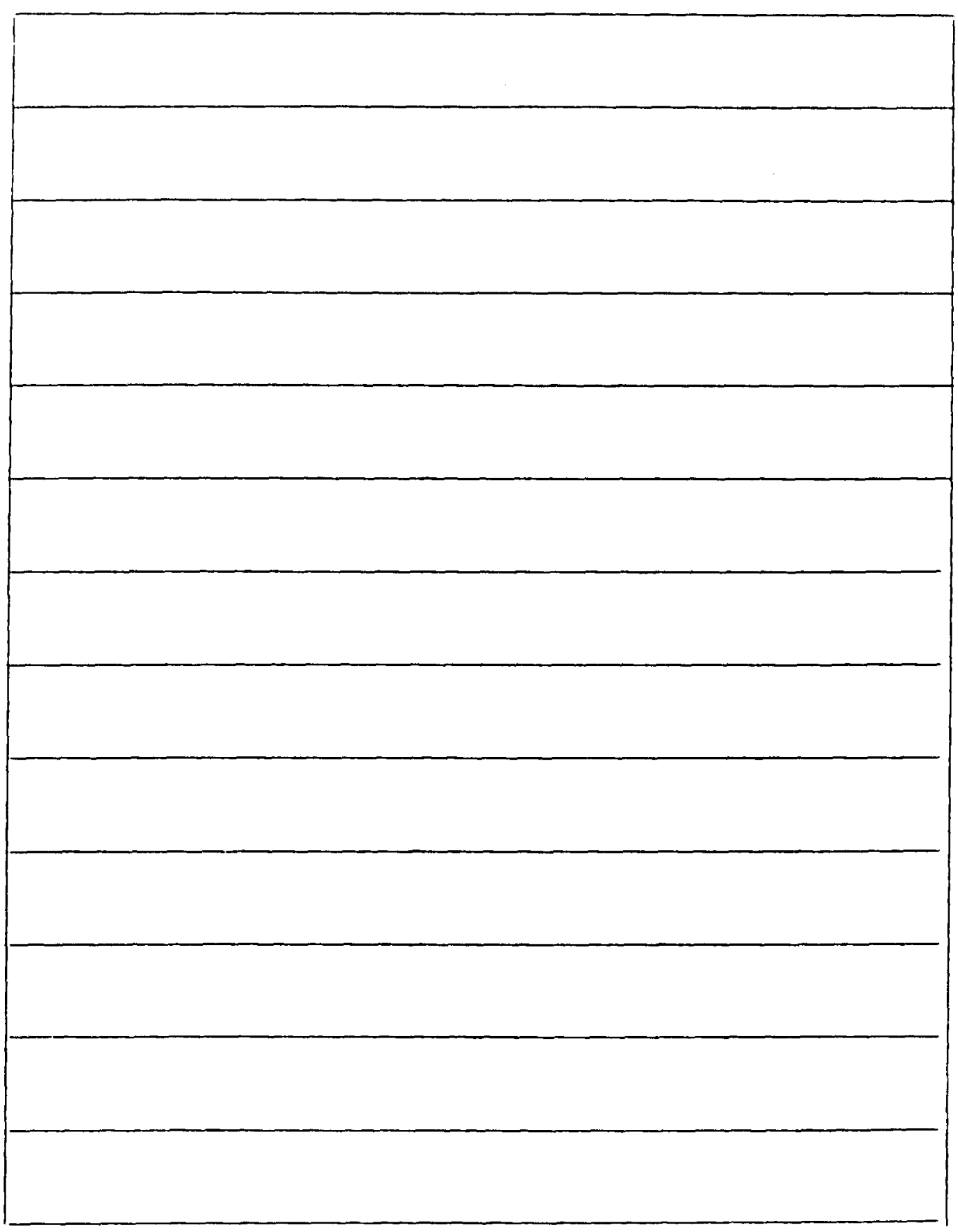

STOP: Wait until instructed to proceed. 
At this time, we would like you to indicate in the left-hand margin by each thought you recorded whether the thought was $(+)$ favorable towards supplemental vitamins, (-) unfavorable toward supplemental vitamins, or $(0)$ neither favorable nor unfavorable towards supplemental vitamins. Therefore, you are to go back and read each thought you just wrote down. If the thought is favorable towards supplemental vitamins, put a + (plus) in the left-hand margin next to the thought. If the thought is unfavorable towards supplemental vitamins, put a - (minus) in the left margin. If the thought is neutral, place a 0 (zero) in the left margin. Please remember to rate each thought. 
For each scale, place an " $x$ " in the space that corresponds most closely to how you feel.

My taking supplemental vitamins is:

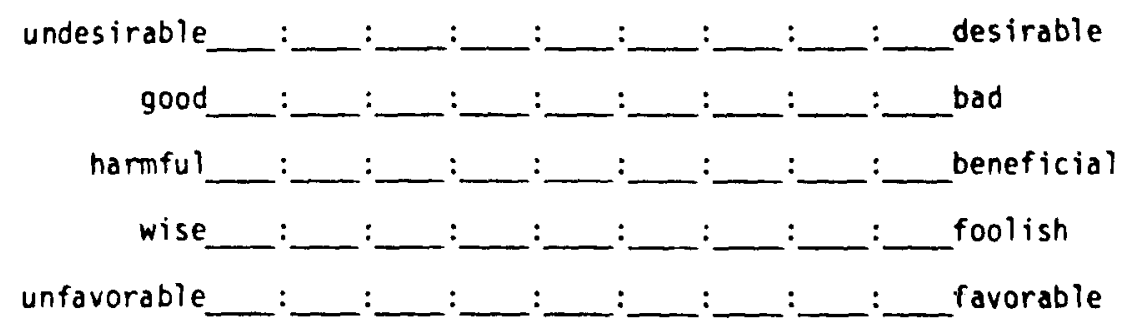

How likely would you be to purchase supplemental vitamins?

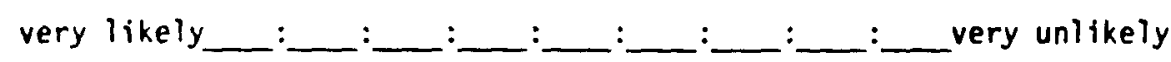

How likely would you be to consider purchasing supplemental vitamins?

very likely__________________________________ :__ery unlikely

How much effort did you expend in listening to the supplemental vitamin ad?

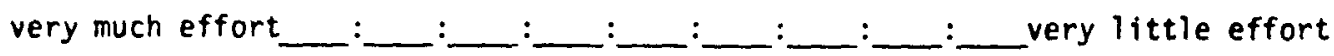

In the next 3 questions we are interested in your personal beliefs about supplemental vitamins.

How likely or unlikely is it that your body's vitamin supply is consistent with your daily needs.

very likely______________________________ery unlikely

How likely or unlikeiy is it that your diet is providing the vitamins and nutrients you expect.

very likely_______________________________ery unlikely

How likely or unlikely is it that your body is prepared for its extra vitamin needs.

very likely_______________________________ :__ery unlikely 
Please rate the supplemental vitamin ad you heard by placing an " $x$ " in the appropriate space.

The supplemental vitamin ad was:

not at all truthful $:$

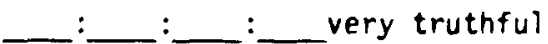

The supplemental vitamin ad was:

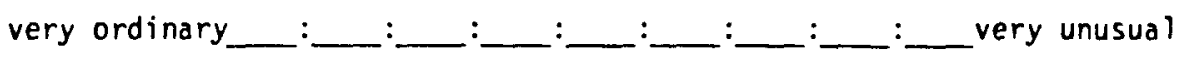

The supplemental vitamin ad was:

very interesting : :

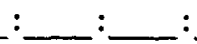
: very boring

The supplemental vitamin ad was:

$$
\begin{gathered}
\text { not at all } \\
\text { stimulating }
\end{gathered}
$$

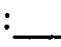
: :__ very stimulating

The supplemental vitamin ad was:

very believable $-$ : : : : not at all believable

The supplemental vitamin ad was:

very realistic $:$ : : not at all realistic

The supplemental vitamin ad was:

very low quality $: \_$________ : :___very high quality

The supplemental vitamin ad:

resulted in my

thinking about the product o lot 
The supplemental vitamin ad:

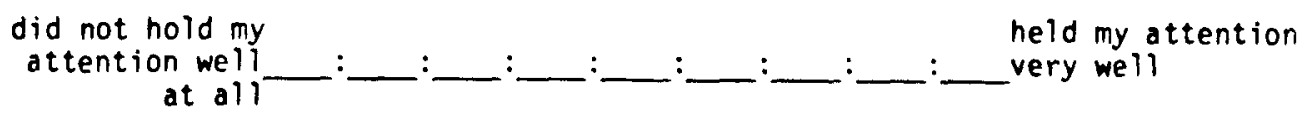

The supplemental vitamin od was:

very confusing :

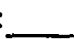
: $: \quad: \quad: \quad: \quad:$ : not at all confusing

Please indicate the extent to which you agree or disagree with the following statements about the supplemental vitamin ad:

The supplemental vitamin ad threatened my freedom to decide for myself. strongly agree

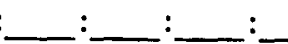
$: \quad:$ : Strongly disagree

The supplemental vitamin ad informed me without trying to persuade me.

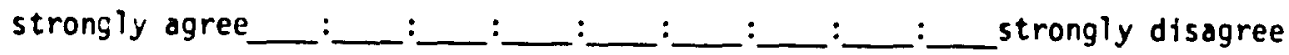

The supplemental vitamin ad led me to judge supplemental vitamins for myself. strongly agree : $:$ strongly disagree

The supplemental vitamin ad showed very little respect for my ability to think for myself. strongly agree : strongly disagree

For each scale, place an " $x$ " in the space that corresponds most closely to how you feel. How knowledgeable are you concerning supplemental vitamin benefits?

\begin{tabular}{|c|}
\hline very \\
\hline
\end{tabular}

How confident are you concerning your understanding of supplemental vitamin benefits? very confident : not at all confident

How satisfied are you concerning your understanding of supplemental vitamin benefits? very satisfied : : not at all satisfied 
In the following questions, please rate the individual who served as the speaker for the supplemental vitamin ad by placing an " $x$ " in the appropriate box:

The individual who served as speaker for the supplemental vitamin ad was:

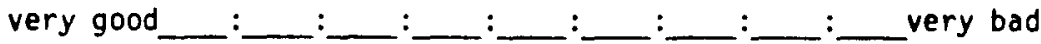
The individual who served as speaker for the supplemental vitamin ad was: very biased

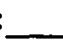

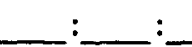
$: \quad: \quad:$ very unbiased

The individual who served as speaker for the supplemental vitamin ad: exerted very
high pressure

The individual who served as speaker for the supplemental vitamin ad was: very sincere not at all sincere

The Individual who served as speaker for the supplemental vitamin ad was: very trustworthy _ not at all trustworthy

The individual who served as speaker for the supplemental vitamin ad was: not at all truthful : $[\quad: \quad: \quad$ :______ery truthful

The individual who served as speaker for the supplemental vitamin ad was: very likeable :_____________ : :______ not at all likeable

The individual who served as speaker for the supplemental vitamin ad was: very knowledgeable __________________________________________ not at all knowledgeable

The individual who served as speaker for the supplemental vitamin ad was:

$$
\text { not at all polite }
$$
: $\left[\_\right.$: very polite

The individual who served as speaker for the supplemental vitamin ad was: very confident : : : : - $:$ : : not at all confident 
Have you every consistently taken supplemental vitamins for a one year period of time or longer?

$$
\square \text { yes } \square \text { no }
$$

Do you currently take supplemental vitamins?

$$
\square \text { yes } \square \text { no }
$$

Please estimate the length (in broadcasting time) of the supplemental vitamin ad that you just heard: seconds

Please estimate the length (in broadcasting time) of the AT\&T ad that you just heard: seconds

How "realistic" was the radio show that you heard? very realistic : : $:$ $:$ not at all realistic

How "realistic" was the AT\&T ad that you heard? very realistic : not at all realistic 
On the ines provided below and on the following page. try to recall as closely as possible the content of the supplemental vitumin ed you heard. list the exact content of thet jou heard. If posstble. If jou are unable to recall the exact content. then paraphrase that you remember. If you cannot paraphrase, simply put down as many points. Facts. Or ideas as you can remember being discussed in the advertisement. In one form or another. please list everything that you can renember about the content of the supplementel vitanin advertisement: 


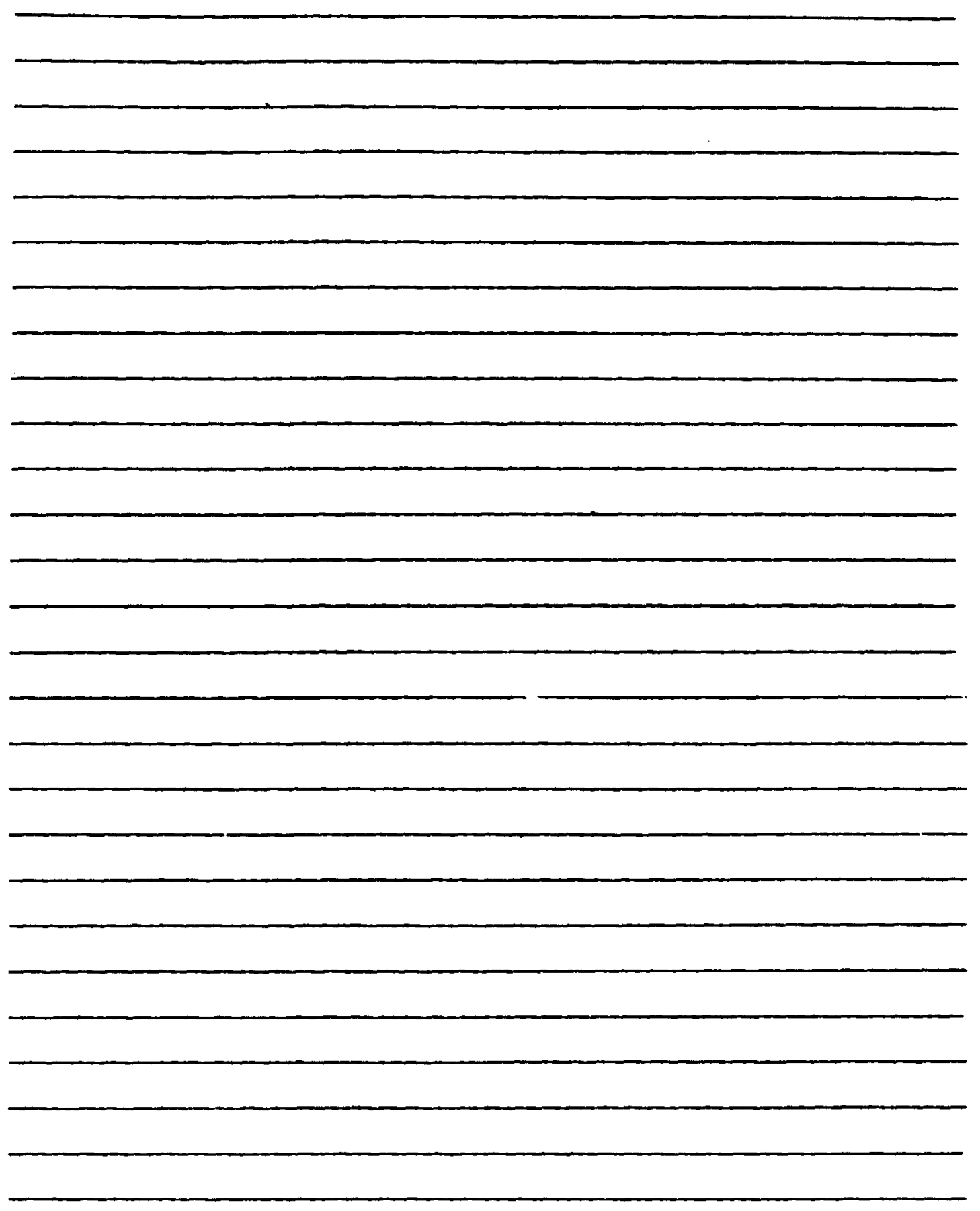


In this section we would like to assess your recognition of reasons that people may decide to take supplemental vitamins. according to the supplemental vitamin ad. place an " $x$ " on the line by each reason you remember being cited in the ad.

I Supplemental vitamins may help in maintaining skin care.

Certain vitamins can be important in maintaining mental health.

An increased level of stress can increase the body's need for many nutrients.

Vitamins are a cost effective method of health care.

Supplemental vitamins may help provide quick energy.

Supplemental vitamins may reduce the need for sleep.

Being physically active can increase the body's need for certain vitamins.

Additional vitamins and nutrients help reduce problems from excess carbohydrate intake.

The way that food is prepared is a leading foctor in nutritional loss.

Supplemental vitamins help you resist illness.

Supplemental vitamins help compensate for poor eating habits.

The intake of toxic substances may cause bodily damage.

Vitamins heip shorten periods of 111 ness.

Many methods of enhancing the taste and appearance of food also decrease its nutritional value.

Additional vitamins and nutrients may enhance tastes for certain foods.

Vitamins help in the body's mending process from cuts and bruises. 
$\square$ Vitamins help ward off diseases.

$\square$ Drugs and disease can alter our vitamin requirements.

$\square$ Vitamins help in maintaining eye care.

$\square$ Vitamins and nutrients may help in mental concentration.

$\square$ Smoking and alcohol consumption can rob the body of many nutrients.

Supplemental vitamins can be especially important for students.

$\square$ Supplemental vitamins can be especially important for working people.

$\square$ Supplemental vitamins can be especially important for older people. 
THANK YOU FOR YOUF PARTICIPATION. YOU ARE FINISHED AFTER YOU ANSWER THE QUESTIONS BELOW.

Please state in your own words what you believe this research was trying to test.

Was there anything about the radio show, the advertisements, the measures, or any other part of this research that you found odd, confusing, or suspicious? Did you feel misled or deceived in any way? If so, it will be very helpful to us for you to describe these problems in detail.

Was there anything that might have biased your answers on the questionnaire in some way? In other words, was there something about this research study that caused you to be negative or positive or different in some way in how you answered some of the questions? If so, please describe below. 


\section{APPENDIX G \\ QUESTION VERSUS STATEMENT DISCRIMINATION \\ PRETEST RE-EXAMINATION INSTRUMENT}




\section{INSTRUCTIONS}

This is a survey on communication. Perhaps one of the most common occurrences in communication is a "question", defined in the sense of an issue being questioned by someone. Please answer the following four items based on your general experience. Please be honest and thank you for your cooperation and assistance. 
FOR EACH SCALE, place an " $X$ " In the space that corresponds most closely to how you feel.

Questions Arouse

my Curiosity

e : : : : :

Questions Do Not Arouse My Curiosity

\begin{abstract}
Questions Do Not Stimulate Thought
\end{abstract}

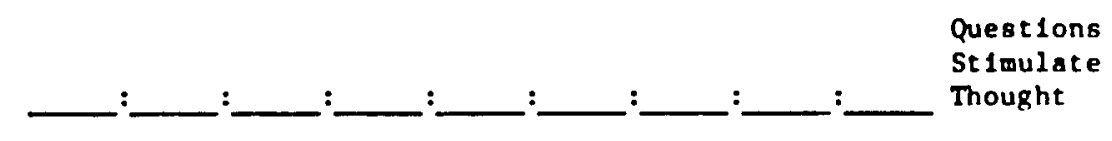

Questions Result In my Paying

Attention to Inf ormation that Follows

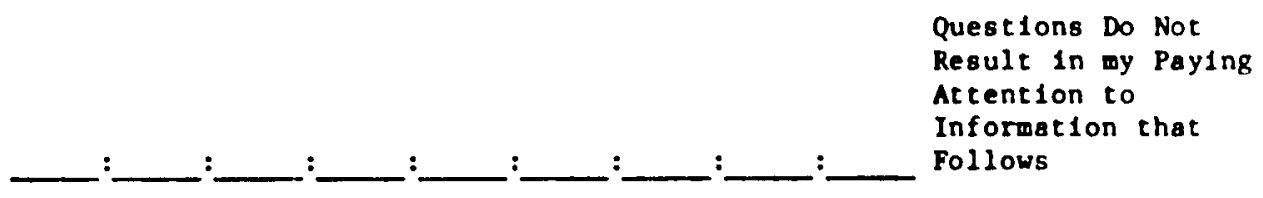

Questlons are Uninteresting
Ouestions are Interesting 


\section{INSTRUCTIONS}

This is a survey on communication. Perhaps one of the most common occurrences in communication is a "declarative statement", defined in the sense of an issue being stated by someone. Please answer the following four items based on your general experience. Please be honest and thank you for your cooperation and assistance. 
FOR EACH SCALE, place an " $X^{\prime \prime}$ In the space that corresponds nost closely to how you feel.

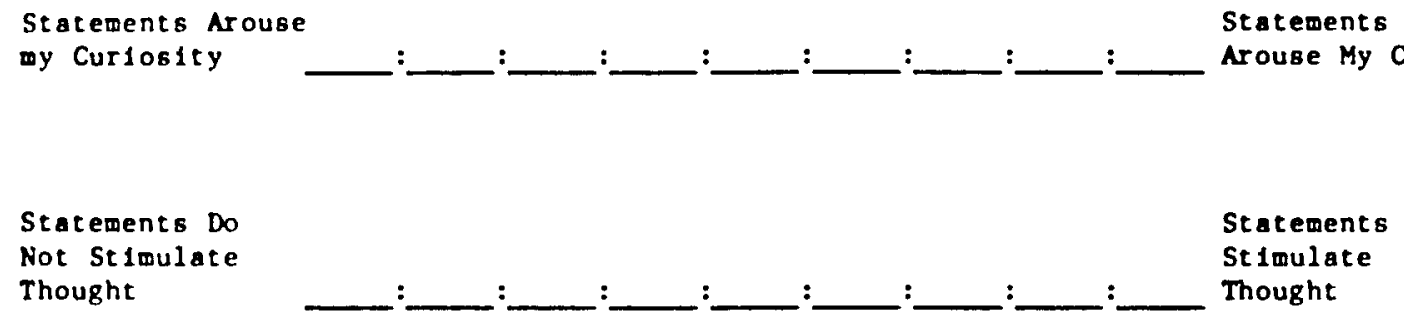

Statements Result in my Paying

Actention to

Inf ormation that

Follows

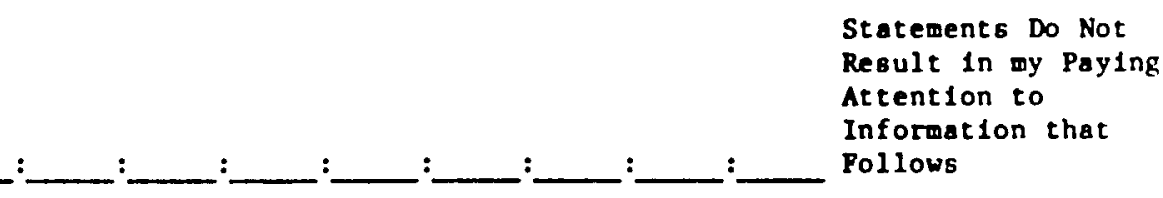

Statements are Uninteresting

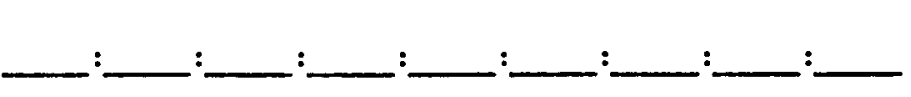

Statements are Interesting 
APPENDIX H

QUESTION COMPARISON INSTRUMENT

214 
QUESTION SURVEY 
THIS IS A SURVEY ON THE USE OF ZUESTIONS. THE FOLLONING PACE WILL PRESE:TT YOU WITA SIX 2UESTIONS. THREE OF THE LUESTIOliS ARE RELATED TO FEASOlis, DEFEADED IN A REAEIT EDITORIAI, FOR REZUIRING SENIORS AT TNE UNIVERSITY OF MISSOURI TO PASS A PROPOSED COMPREREISIVE EXAM IN THEIR DECLARED MAJOR PRIOR TO GRAJJATION, BESIININS IN 1997. THE REMAININS THREE QUESTIONS ARE RELATED TO REASONS WHY PEOPIE MAY DECIEE TO TAKE SUPPLEMENTAL VITAMINS AND HAVE REJENTLY BEEN USED IN AN ADVERTISEAENT ADVOCATING THE USE OF SUPPIENENTAL VITANINS.

PLEASE RANK ORDER (FROM "I" TO "6") THE SIX QUESTIONS ON THE FOLLOWINS PAGE IUi TERMS OF YOUR DESIRE TO KNON THE ANSWER TO EACH QUESTION. NEXT TO THE ZUESTION TO WHICH YOU WOULD MOST LIKE TO KNOW THE ANSAER MARI A "1" IN THE SPACE PROVIDED. NEXT TO THE RUESTIOIN TO WHICH YOU WOUL SECOND MOST LIKE TO KNON THE ANSWER MHRK A "2". CONTINUE IN YOUR RAIKIHO UNTIL YOU EET TO TAE RUESTION TO WHIAH YOU WOULD IEAST LIKE TO KNON TIE ANSWER AND MARK a "6" IN THE SPANE PROVIIED. PLEASE DO NOT GIVE TWO OR MORE QUESTIOiis THE SAVE RANK. REMEMBER, a "I" MEANS YOU HaNT TO KNOW THE ANSAER TO THAT QUESTION THE MOST, A "6" MEANS YOU WNIT TO KNOW THE ANSWER TO THAT QUESTIOH THE IEAST.

YOU MAY TURN THE PATE NON AND BEGIN. THANK YOU FOR YOUR COOPERATION NID ASSISTAIIE. 
- JIIL A COMPREIENSIVE EXAM REQJIREMEITT INCREASE THE PRESTIJE OF THE ALUMII AND ACADEMIC IISTIUTIOLS?"

"IS YOJR BODY'S VITAMIN SUPPLY REALLY COIISISTENT WITA YOUR DAILY IEEDS?"

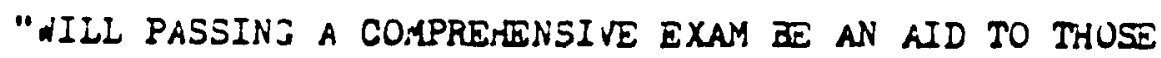
WHO SEEK ADMISSION TO GRADUATE NJD PROFESSIONAL SCHOOLS?"

"ARE YOU SURE YOUR DIET IS PROVIDING THE VITANIIIS ANID NUTRIENTS YOU EXPECT?"

"dILL A COMPRE.WENSIVE EXAM FEZUIREMENT INCREASE THE AMOUNT STUDENTS IEART AND CET OUT OF UNDERGRADUATE COURSE MATERIAL?"

"IS YOUR BODY REALLY PREPARED FOR ITS EXTRA VITANIN NEEDS?" 
3UESTION SURVEY 
THIS IS A SURVEY ON THE USE OF RUESTIONS. THE FOLLONING PAEE WILL PRESENT YOU WITH SIX ZUESTIONS. THREE OF TRE ZUESTIONS ARE RELAIED TO REASONS, DEFEIDED IN A RETEITT EDITORIAL, FOR REZUIRING SENIORS AT THE UNIVERSITY OF MISSOURI TO PASS A PROPOSED COMPRENENSIVE EXA1 IN THEIR DECLARED MAJOR PRIOR TO GRADUATION, BESIININS IN 1997. THE REMKININJ THREE QUESTIONS ARE RELATED TO REASONS WHY FEOPIE MAY DECIDE TO TAKE SUPPLEMENTAL VITAMINS AND HAVE RETENTLY BEEII USED IN AN ADVERTISEMENT ADVOCATING THE USE OF SUPPIEMENTAL VITAMINS.

PLEASE RANK ORDER (FROM "I" TO "6") THE SIX QUESTIONS ON THE FOLLOWING PAEE IIi TERMS OF YOUR DESIRE TO KNON THE ANSWER TO EACH QUESTION. NEXT TO TNE 2UESTION TO WHICA YOU WOUD MOST LIKE TO KNOW THE ANSWER MARK $A$ "I" IN THE SPACE PROVIDED. NEXT TO THE QUESTION TO WHICH YOU WOULD SECOND MOST LIKE TO KNOW THE ANSWER MARK A "2". CONTINUE IN YOUR RANKING UNTIL YOU CET TO THE RUESTION TO WHIOH YOU WOULD LEAST LIKE TO KNON THE ANSAER AND MARK A "6" IN THE SPAGE PROVIDED. PLEASE DO NOT GIVE TWO OR

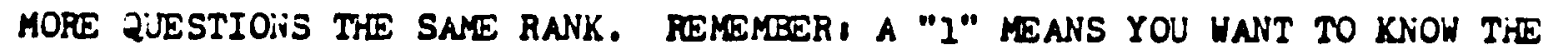
ANSWER TO THAT QUESTION THE MOST, A "6" MEANS YOU WANT TO KNOW THE ANSWER TO THAT QUESTION THE LEAST.

YOU MAY TURN THE PATE NON AND BEGIN. THANK YOU FOR YOUR COOPERATION AHD ASSISTANTE. 
"WILL A COHPREHENSIVE EXAM 3ENEFIT STJIENTS WHO ARE GOING INTO THE JO3 MARKET?"

"IS YOUR BODY"S VITAMIN SUPPLY REALLY CONSISTENT WITH YOUR DAILY INEDSS?"

"AILL A COMPREIENSIVE EXAM REXUIREMENT IEAD TO AN IMPROVEMENT IN THE RUALITY OF TEACHING?"

"ARE YOU SURE YOUR DIET IS PROVIDING THE VITAMINS AND NUTRIENTS YOU EXPECT?"

" WILL a COMPREHENSIVE EXAM REZUIREMENT hELP AVOID FUTURE INCREASES IN TUITION?"

"IS YOUR BODY REALLY PREPARED FOR ITS EXTRA VITAMIN NEEDS?" 
LIST OF REFERENCES

Anderson, R. C. and Biddle, W. B. (1975). On asking people questions about what they are reading. In G. H. Bower (ed.), The Psychology of Learning and Motivation Advances in Research and Theory, Vol. 9, New York: Academic Press.

Anderson, N. H. and Hubert S. (1963). Effects of concomitant verbal recall on order effects in personality impression formation. Journal of Verbal Learning and Verbal Behavior, 2, 379-391.

Andre, T. (1979). Does answering higher-level questions while reading facilitate productive learning? Review of Educational Research, $2,280-318$.

Ausube 1, D. P. (1963). The Psychology of Meaningful Verbal Learning. New York: Greene and Stratton.

Barton, R. (1950). Advertising Handbook. New York: Prentice Hall.

Baumgardner, M. H., Leippe, M. R., Ronis, D. L. and Greenwald, A. G. (1983). In search of reliable persuasion effects II: associative interference and persistence of persuasion in a message dense environment. Journal of Personality and Social Psychology, 45, 524-537.

Berylne, D. E. (1954). An experimental study of human curiosity. British Journal of Psychology, 45, 256-265.

Berylne, D. E. (1962). Uncertainty and epistemic curiosity. British Journal of Psychology, 53, 27-34.

Berylne, D. E. (1960). Conflict, Arousal and Curiosity. New York: McGraw Hill.

Bloom, B. A., Englehart, M. . Furst, E. J., Hill, W. H. and Krathwohl, E. (1965). Taxonomy of Educational objectives: Cognitive Domain. New York: David MoKay.

Bolen, W. H. (1984). Advertising. New York: John Wiley. 
Bovee, C. L. and Arens, H. F. (1982). Contemporary Advert1sing. Homewood, IL: Richard D. Irwin.

Boyd, W. M. (1973). Repeating questions in prose learning. Journal of Educat lonal Psychology, 64, 31-38.

Brewster, A. J., Palmer, H. H. and Ingram, R. G. (1974). Introduction to Advertising. New York: McGraw Hill.

Britton, B. R., Piha, A., Davis J. and Wehausen, E. (1978). Reading and cognitive capacity use: adjunct question effects. Memory and Cognition, 6, 266-273.

Britton, B. K., Westbrook, R. D., and Holdredge, T. S. (1978). Reading and cognitive capacity usage: effects of text difficulty. Journal of Experimental Psychology: Human Learning and Memory, 4, 582-591.

Brown, J. (1976). Recall and Recognit1on. New York: John Wiley,

Bruneau, T. J. (1973). Communicative silences: forms and functions. Journal of Communication, 23, 17-46.

Bull, S. G. and Dizney, H. F. (1973). Eplstemic-curlousity-arousing prequestions: their effect on long-term retention. Journal of Educational Psychology, 65, 45-59.

Burnkrant, R. E. and Howard, D. J. (1984). Effects of the use of introductory rhetorical questions versus statements on information processing. Journal of Personality and Social Psychology, 47, 1218-1230.

Burnkrant, R. E. and Sawyer, A. G. (1983). Effects of involvement und message content on information-processing intensity. In $R$. J. Harris (ed.) Information Processing Research in Advertising. Hillsdale, NJ: Lawrence Erlbaum.

Burton, P. W. and Breer, G. B. (1962). Advertising Copy Writing, 2nd ed. Englewood Cliffs, NJ: Prentice Hall.

Burton, P. W., Kreer, G. B. and Gray, J. (1949). Advertising Copy Writing. New York: Prentice Hall.

Cac1oppo, J. T., Harkins, S. G. and Petty, R. E. (1981). The Nature of Attitudes and Cognitive Responses and Their Relationships to Behavior. In R. E. Petty, T. M. Ostrom and T. C. Brock (eds.) Cognitive Responses in Persuasion. Hillsdale, NJ: Lawrence Erlbaum. 
Cacioppo, J. T. and Petty, R. E. (1979). Effects of message repetition and position on cognitive responses, recall and persuasion. Journal of Personal1ty and Social Psychology, 37, 97-109.

Carrier, C. A. and Fautsch-Patridge, T. (1981). Levels of questions: a framework for the exploration of processing activities. Contemporary Educational Psychology, 6, 365-381.

Carver, R. P. (1972). A critical review of mathemagenic behaviors and the effect of questions upon the retention of prose materials. Journal of Reading Behavior, 4, 93-119.

Chalken, S. and Eagly, A. H. (1983). Communication modality as a determinant of persuasion: the role of communicator salience. Jourinal of Personality and Soc1al Psychology, 45, 241-256.

Chaiken, S. and Eagly, A. H. (1976). Communication modality as a determinant of message persuasiveness and message comprehensibility. Journal of Personality and Social Psychology, $34,605-614$.

Cooper, E. H. and Pantle, A. S. (1967). The total time hypothesis in verbal learning. Psychological Bulletin, 68, 221-234.

Dav1s, D. W. (1955). Basic Text in Advertising. Pleasantville, New York: Printer's Ink Bocks.

Dillon, J. T. (1982a). The multidisciplinary study of questioning. Journal of Educational Psychology 74, 147-165.

Dilion, J. T. (1982a). The effects of questions in education and other enterprises. Journal of Curriculum Studies, 14, 127-152.

Dunn, S. W. and Barban, A. M. (1974). Advertising: Its Role in Modern Marketing. H1llsdale, NJ: Dryden Press.

Eagly, A.H. (1974). Comprehensibility of persuasive arguments as a determinant of opinion change. Journal of Personality and Social Psychology, 29, 758-773.

Eagly, A. H. and Chaiken, S. (1985). Cognitive theories of persuasion. Advances in Exper1mental Soc1al Psychology 19, 5082.

Eagly, A. H. and Warren, R. (1976). Intelligence, comprehension and opinion change. Journal of Personality 44, 226-242.

Faison, E. W. J. (1980). Advertising: A Behavioral Approach for Managers. New York: John Wiley. 
Faw, H. W. and Waller, T. G. (1976). Mathemagenic behaviours and efficiency in learning from prose materials: review, oritique and recommendations. Review of Educational Resear:h, 46, 691720.

Frase, L. T. $(1968 \mathrm{a})$. Some data concerning the mathemagenic hypothesis. American Educational Research Journal, 5, 181-189.

Frase, L. T. (1968b). Questions as alds to reading: some research and theory. Amertcan Educational Research Journal, 5, 319-332.

Frase, L. T. (1967). Learning from prose material: Length of passage, knowledge of results, and position of questions. Journal of Educational Psychology, 58, 266-272.

Gibs on, C. and Berkman, H. W. (1980). Advert1slag: Concepts and Strategies. New York: Random House.

Greenwald, A. G. ( $(968)$. Cognitive Learning, cognitive responses to persuasion and attitude change. In A. G. Greenwald, T. C. Brock and T. M. Ostrom (eds.), Psychological Foundations of Attitudes. New York: Academic Press.

Haaland, G. A. and Venkatesan, M. (1968). Resistance to persuasive communications: an examination of the distraction hypothesis. Journal of Personality and Social Psychology, 9, 167-170.

Henawalt, N. G. and Tarr, A. G. (1961). The effect of recall upon recognition. Journal of Experimental Psychology, 62, 361-367.

Harkins, S. G. and Petty, R. E. (1981). Effects of source magnification of cognitive effort on attitudes: an information processing view. Journal of Personality and Social Psychology, 40, 401-413.

Hastie, R., Ostrom, T. M., Ebbeson, E. B., Wyer, R. S., Hamilton, D. L. and Carlson, D. E. (eds.). (1980). Person Perception: The Cognitive Basis of Social Perception. Hillsdale, NJ: Lawrence Erlbaum.

Hovland, C. I. and Weiss, W. (1951). The Influence of source credibility on communication effectiveness. Public Opinion Quarterly, 635-650.

Insko, C. A. (1964). Primacy versus recency in persuasion as a function of timing of arguments and measures. Journal of Abnormal and Social Psychology, 69, 381-391. 
Insko, C. A., Lind, E. A. and LaTour, S. (1976). Persuasion, recal 1 and thoughts. Representative Research 1n Soc1al Psychology, 7 , 66-68.

Insko, C. A., Turnbull, W. and Yande11, B. (1974). Fac1litative and inhibiting effects of distraction on attitude change. Soclometry, 37, 508-528.

Keating, J. P. and Brock, T. C. (1974). Acceptance of persuasion and the inhibition of counterargumentation under various distraction tasks. Journal of Experimental Social Psychology, 10, 301-309.

Kennedy, J. J. (1978). Analysis of Experiments in Psychology and Education. Washington: University Press of America.

Kleppner, 0. (1979). Advertising Procedure. Englewood Cilffs, NJ: Prentice Hall.

Rrugman, H. (1965). The impact of television advertising: learning without involvement. Public Opinion Quarterly, 29, 349-356.

Rrugman, H. (1967). The measurement of advertising involvement. Public Opinion Quarterly, 30, 583-596.

Ladas, B. (1973). The matbemagenic effects of factual review questions on the learning of incidental information: a critical review. Review of Educational Research, 43, 71-81.

Lingle, J. H. and Ostrom, T. M. (1981). Principles of Memory and Cognition in Attitude Formation. In R. E. Petty, T. M. Ostrom and T. C. Brock, (eds.), Cognitive Responses in Persuasion. Hillsdale, NJ: Lawrence Er Ibaum.

Loken, B. and Hoverstad, R. (1985). Relationship between Information recall and subsequent attitudes: some exploratory findings. Journal of Consumer Research, 12, 155-168.

MandeI1, M. I. (1974). Advertising. Englewood Cliffs, NJ: Prentice Hall.

Mayer, E. R. (1975). Different problem-solving competencies established in learning computer programming with and without meaningful models. Journal of Educational Psychology, 67, 725730 .

McGaw, B. and Grotelueschen, A. (1972). Direction of the effect of questions in prose materials. Journal of Educational Psychology, $63,580-588$. 
McGuire, W. J. (1957). Order of presentation as a ractor in . "conditioning" persuasiveness. In C. I. Hov land (ed.), The Order of Presentation in Persuasiveness. New Haven, CT: Yale Un1versity Press.

Milier, N. and Campbell, D. T. (1959). Recency and primacy in persuasion as a function of the timing of speeches and measurements. Journal of Abnormal and Social Psychology, 1-9, 59.

Miliman, S. (1968). Anxiety, comprehension and susceptibility to social influence. Journal of Personality and Social Psychology, $9,251-256$.

Myers, H. J. and Haug, A. F. (1967). Declarative versus interrogative advertisement head Iines. Journal of Advertising Research, 7, 4144.

Petty, R. E. and Cacloppo, J. T. (1979). Issue Involvement can increase or decrease persuasion by enhancing message relevant cognitive responses. Journal of Personality and Social Psychology, 37, 1915-1926.

Petty, R. E. and Cac1oppo, J. T. (1981). Att1tudes and Persuasion Classic: and Contemporary Approaches. Dubuque, IA: W1 l11am C. Brown.

Petty, R. E., Cacioppo, J. T. and Heesacker, M. (1981). Effects of rbetorical questions on persuasion: a cognitive response analys1s. Journal of Personality and Soclal Psychology, 90, 432440.

Petty, R. E., Cacioppo, J. T. and Schuman, D. (1983). Central and peripheral routes to advertising effectiveness: the moderating role of involvement. Journal of Consumer Research, 10, 135-146.

Reyes, R. M., Thompson, W. C. and Bower, G. H. (1980). Judgmental biases resulting from differing availabilities of arguments. Journal of Personality of Soclal Psychology, 39, 2-12.

Reynolds, R. E. and Anderson, R. C. (1982). Influence of questions on the allocation of attention during reading. Journal of Educat lonal Psychology, 74, 623-632.

Reynolds, R. E., Standiford, S. N. and Anderson, R. C. (1979). Distribution of reading time when questions are asked about a restricted category of text information. Journal of Educational Psychology, 71, 183-190.

Rickards, J. P. and Denner, P. R. (1978). Inserted questions as aids to reading text. Instructional Science, $7,313-346$. 
Rickards, J. P. and DiVesta, D. F. (1974). Type and frequency of questions in processing textual material. Journal of Educational Psychology, 66, 354-362.

Romer, D. (1979). Distraction, counterarguing and the internalization of attitude change. European Journal of Social Psychology, 9, 117 .

Rothkopf, E. Z. (1974). Barbarism and mathemagenic activities: comments on criticisms by Carver. Journal of Reading Behavior, $6,3-8$.

Rothkopf, E. Z. (1966). Learning from written instructive materials: an exploration of the control of inspective behavior by test-like events. American Educat1onal Research Journal, 3, 241-249.

Rothkopf, E. Z. (1965). Some theoretical and experimental approaches to problems in written instruction. In J. D. Brumboltz (ed.), Learning and the Educational Process. Chicago: Rand McNally.

Rothkopf, E. Z. and BIIIIngton, J. J. (1974). Indirect review and priming through questions. Journal of Educational Psychology, 66 , 669-679.

Rothkopf, E. 2. and Bisbicos, E. (1967). Selective facilitative effects of interspersed questions on learning from written material. Journal of Educational Psychology, 58, 56-61.

Rothkopf, E. Z. and Bloom, R. D. (1970). Effects of interpersonal interaction on the instructional value of adjunct questions in learning from written material. Journal of Educational Psychology, 61, 417-422.

Rowe, M. B. (1974). Wait-time and rewards as instructional variables, their influence on language, $\log 1 \mathrm{c}$ and fate control: part one-wait-time. Journal of Research in Science Teaching, 11, 81-94.

Runyon, R. (1979). Advert1sing. Columbus: Charles Merrill.

Sandage, C. H., Fryburger, V. and Rotzoll, R. (1979). Advert1sing Theory and Practice. Homewood, IL: Richard D. Irwin.

Starch, D. (1914). Advert1s1ng: Its Principles, Practice and Technique. Chicago: Scott, Foresman.

Tesser, A. (1978). Self-generated attitude change. Advances In Experimental Soc1al Psychology, 11, 289-338. 
Tesser, A. and Leone, C. (1977). Cognit1ve schemas and thought as determinants of attitude change. Journal of Experimental Social Psychology, 13, 340-356.

Th1st lewalte, D. L., deHann, H. and Kamentzky, J. (1955). The effects of "directive" and "non-directive" communication procedures on att1tude. Journal of Abnormal and Soc1al Paychology, 51, 107113.

Hashburne, J. N. (1929). The use of questions in social science material. Journal of Educational Paychology, 20, 321-359.

Watts, G. H. and Anderson, R. C. (1971). Effects of three types of inserted questions on learning from prose. Journal of Educat lonal Psychology, 62, 387-394.

Watts, W. A. and McGuire, W. J. (1964). Persistence of Induced opinion change and retention of the indicing message content. Journal of Abnormal of Social Psychology, 68, 233-241.

Webster, F. E. (1981). Top management's concerns about marketing 188 ues for the $1980^{\prime} \mathrm{s}$. Journal of Marketing, 45, 9-16.

Wenger, S. B., Thompson, C. P. and Bartling C. A. (1980). Recall fac1litates subsequent recognition. Journal of Experimental Psychology: Human Learning and Memory, 6, 135-144.

Wright, P. L. (1974). Analyzing media effects on advertising responses. Publ10 Opinion Quarterly, 38, 192-205.

21llman, D. (1972). Rhetorical elicitation of agreement in persuasion. Jouraal of Personal1ty and Social Psychology, 21, 159-165.

Z11lman, D. and Cantor, J. R. (1974). Theoretical elicitation of concession in persuasion. Journal of Soc1al Psychology, 94, 223236.

Z11lman, D. and Cantor, J. R. (1973). Induotion of curiosity via rhetorical questions and its effect on the learning of ractual materials. British Journal of Educational Psychology, 43, 172180 .

Zimbardo, P. G. and Ebbesen, E. B. (1970). Experimental modification of the relationship between effort, attitude and behavior. Journal of Personality and Social Psychology, 16, 207-213. 